\title{
COMMUNICATION OF TECHNICAL INFORMATION
}

\section{TO LAY AUDIENCES}

\author{
John E. Bowes \\ Keith R. Stamm \\ Kenneth M. Jackson \\ Jeff Moore \\ Communication Research Center \\ School of Communications DS-40 \\ University of Washington \\ Seattle, Washington 98195
}

May, 1978

This report was prepared by the University of Washington under subcontract $89 Y$ 22337V with Union Carbide Corporation, Nuclear Division, under contract number W-7405-ENG-26 with the Department of Energy. The subcontract was administered by the Office of Waste Isolation. 


\section{DISCLAIMER}

This report was prepared as an account of work sponsored by an agency of the United States Government. Neither the United States Government nor any agency Thereof, nor any of their employees, makes any warranty, express or implied, or assumes any legal liability or responsibility for the accuracy, completeness, or usefulness of any information, apparatus, product, or process disclosed, or represents that its use would not infringe privately owned rights. Reference herein to any specific commercial product, process, or service by trade name, trademark, manufacturer, or otherwise does not necessarily constitute or imply its endorsement, recommendation, or favoring by the United States Government or any agency thereof. The views and opinions of authors expressed herein do not necessarily state or reflect those of the United States Government or any agency thereof. 


\section{DISCLAIMER}

Portions of this document may be illegible in electronic image products. Images are produced from the best available original document. 


\section{COMMUNICATION OF TECHNICAL INFORMATION}

TO LAY AUDIENCES

\author{
John E. Bowes \\ Ke ith R. Stamm \\ Kenneth M. Jackson \\ Jeff Moore
}

\begin{abstract}
Communication Research Center
School of Communication DS -40

University of Washington

Seattle, Washington 98195
\end{abstract}

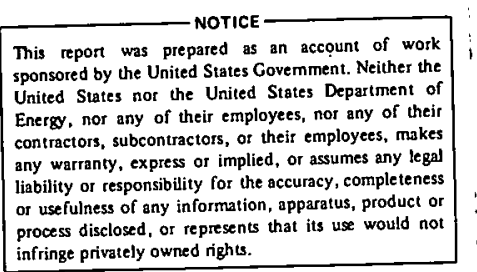

May, 1978

This report was prepared by The University of Washington under subcontract $89 \mathrm{Y}-22337 \mathrm{~V}$ with Union Carbide Corporation, Nuclear Division, under contract number $w-7405-e n g-26$ with the Department of Energy. The subcontract was administered by the office of Waste Isolation.

\section{NOT ICE}

This report was prepared as an account of work sponsored by the united States Government. Neither the United States or the Department of Energy, nor any of their employees, nor any of their contractors, subcontractors or the ir employees makes any warranty, expressed or implied, or assumes any legal liability or responsibility for the accuracy. completeness or usefulness of any information, apparatus, product or process disclosed, or represents that its use would not infringe privately owned rights. 
CONTENTS

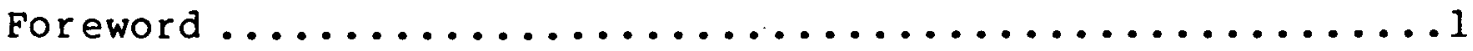
Introduction $\ldots \ldots \ldots \ldots \ldots \ldots \ldots \ldots \ldots \ldots \ldots \ldots \ldots \ldots \ldots \ldots \ldots \ldots \ldots$ Research Overview

Attributes of Sources and Receivers ..............

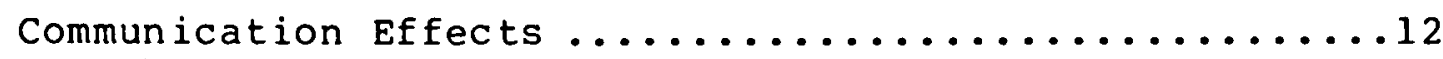

Relations Between Senders and Receivers ..............

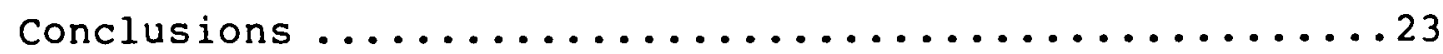

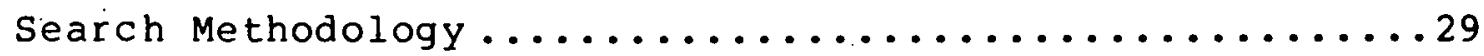

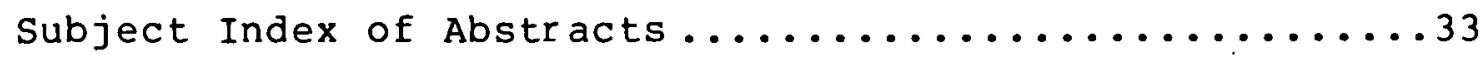

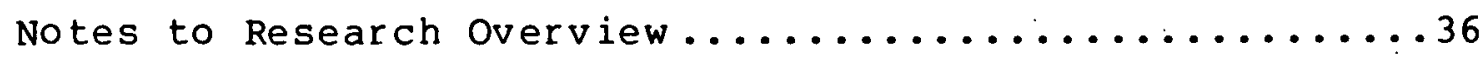

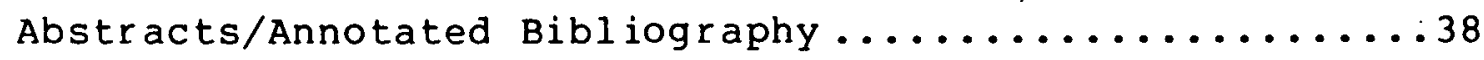




\section{FOREWORD}

One of the objectives of the National Waste Terminal storage (NWTS) Program is to provide terminal storage facilities for commercial radioactive wastes in various geologic formations at multiple locations in the United States. The activities performed under the NWTS Program will affect regional, state, and local areas. Therefore, widespread public interest in this program is expected. Since a large part of the NWTS Program deals with technical information it was considered desirable to initiate a study dealing with possible methods of effectively transmitting this technical information to the general public. Therefore, this study was commissioned with its objective being to prepare a state-of-the-art report on the communication of technical information to lay audiences. The particular task of communicating information about the NWTS Program to the public was to be discussed where appropriate. The results of this study will aid the NWTS program in presenting to the public the quite diverse technical information generated within the program so that a widespread, thorough public understanding of the NWTS Program might be achieved.

The authors of this study have long-standing interests in the problems of citizens as they confront communication about technology. Such communication connotes problems in information and understanding to many of these citizens and suggests that only individuals with advanced academic standing and established scientific or technical credentials can interpret and use this kind of information. But the problems of nuclear energy, environmental depredations, finding new energy sources and the encroachment of technology into commonplace products and neighborhood environments no longer restricts technological issues to government and academe. Thus the quality of the communication link for information on technology mounts in importance. We attempted to locate and review appropriate research on communication in circumstances of this kind.

Our literature search made extensive use of computerized retrieval systems provided by the National Technical Information Service, Sociological Abstracts, Psychological Abstracts, and ERIC. The collections of the University of Washington's Suzzallo and Engineering Libraries and the library of Battelle Human Affairs Research Centers were of invaluable assistance. The authors' personal collections of research papers were thoroughly used as well.

The authors wish to express appreciation to Lisa Fortini-Campbell and Fletcher Frisch, two capable graduate students in the School 
of Communication, who sacrificed weekends and a considerable portion of their Christmas vacations to assist in abstracting research articles. Thanks are also due Hank schilling of Battelle Human Affairs Research. Center, Seattle, and Arvin Quist of Union Carbide Corporation, Oak Ridge, for their help and assistance in monitoring the progress of this effort. Special thanks must also go to Baiss Magnusson of the University of Washington Learning Resources Center for his able programming which provided the indexing, sorting and preliminary typesetting of this report. Finally, a debt of gratitude is owed The School. of Communications' Gannett Computer Lab for its editing and typesetting facilities. 


\section{INTRODUCTION}

Communication is a part of nearly any attempt to coordinate activity, so we expected to locate a substantial amount of research in the area. However, it became quickly apparent in our literature search that most of the research missed our needs in a major respect. Its typical focus was on the particular action or effect that communication was designed to facilitate in contrast to our interest in communication procedures -- how to communicate complex techinical information. When communication procedures are discussed, the preoccupation of much applied research with effects limits its applicability. For example, much advertising research relates message content and structure to affect ( $1 \mathrm{iking} / \mathrm{disliking}$ ) and purchase. This research doesn't tell us how to best communicate information about the product to the audience. This lack of appliable research becomes apparent in reviewing the variety of traditions and topics we searched for relevant bibliographic materials. Several of these traditions deserve special mention.

Advertising and public relations concentrate on the marketing of products and the creation of images, respectively. The effort typically is to enhance acceptance, accentuate the positive and downplay or innoculate against the negative. Message elements. which arouse, interest, improve credibility and so on, typically reduce to prescriptive advice centered on the notions of "grab 'em, tell. 'em, sell 'em."

A related but perhaps more systematically exploited area concerns the diffusion of technological innovations, primarily to developing nations. Here again, the interest of researchers is directed toward the innovation, which may be seen as a "product" of sorts. The central concern of those involved is how best to communicate about technology in order to obtain and sustain use of it. The nearly universal assumption made is that innovations (these range from "modern" math to tractors) are beneficial, so the goals and procedures of this research tend to parallel those of advertising: how to obtain positive consequences for their product through communication. In a qualified sense, scholars in this field have taken a more comprehensive view. They conceive of messages being disseminated on more than a one-to-one basis. They are concerned with dissemination through interpersonal networks, with the relationship between informal and formal media channels, and with communication effects and who attends media messages. This combination typically results in a more sophisticated view of communication processes.

Another major tradition is expressed by the social psychologist who examines communication in the context of such situations as 
disaster, risk-taking and so on. Their interests range from such concrete applications as how many "warnings" suffice to elicit evacuation to more esoteric questions concerning how group composition affects risk-taking. Seldom are communication procedures developed or discussed, with the exception, perhaps, of persuasive techniques and their impact on attitude change.

We also examined closely the "public opinion" literature, commonly an outgrowth of the social-psychological interests of political scientists. These studies focus on attitudinal products of communication rather than communicating (the kind of interaction with individuals or the media which lead to certain attitudes and opinions). Communication is often cast as an independent variable that can be related to the kind or direction of opinion (e.g. opinion holding and exposure to TV news; perception of issue importance vs. media coverage of issues). Research here tends to be issue contingent--data are organized more around issues than particular communicative events or procedures. There is growing awareness of Iimitations in this issue-oriented focus, but there is little change yet apparent in new research.

Two other major areas encountered in our literature search are "reading behavior" and "science writing". Both focus squarely on communication procedures which enhance understanding. Reading behavior is more limited in its concerns; dealing almost entirely on printed communication particularly as it affects reading skills of elementary and secondary level students. Too, the perspective taken in these studies is from the decoder's (receiver's) point of view. This contrasts with science writing where attention is given those who must prepare messages -- to relate unfamiliar concepts to a lay audience without doing violence to the intent of the scientist-source.

As unconnected as these several origin points may appear, there is a growing group of scholars whose interests transcend these earlier divisions. They are perhaps more identifiable by their publishing and academic affiliations in communication, journalism or speech. Communication, perhaps most indicative of growing synthesis, is a loose combination of once separated interests in social psychology, mass media use patterns and interpersonal communication behavior. With this heritage, communication scholars have tended to examine communication as an independent variable producing differential effects (e.g. attitude change, product purchase, etc). For the most part, they have not considered it as a dependent variable which has resulted from some prior condition, such as confusion, understanding or problem solving. Because of such restrictions, many questions aimed at improving communication procedures stmply have not been asked.

Our discussion and summary of the literature searched is organized 
into three broad areas. The first, concerning attributes of sources and receivers, discusses research which characterize audiences, the ir attitudes and communication characteristics. The second area is devoted to effects; the "results" expected or obtained from various public communication efforts. Finally, we review research which characterizes the relations between sources and receivers and methods which assess the quality of these linkages.

In all three areas, the media receive attention because they are important to the central theme of each. Certainly, as well, there is some necessary overlap of discussion among these major topics. It is difficult, for example, to discuss relations of sources and receivers without some reference to their attributes or to the effects each desire. We will also refer back to major scholarly roots of communication in an effort to better explain uneven coverage of communication of technology. Most research referenced in our discussion can be found listed in the annotated bibliography. In a few instances, we reference more general works not annotated in our bibliography, but 1 isted at the end of it. Our methodology in searching relevant articles together with the definitions used in developing retrieval keys are discussed at the end of this section. 


\section{ATTRIBUTES OF SOURCES AND RECEIVERS}

In the lore of professional communications, one of the repeated prescriptions is the importance of "knowing your audience." It would seem that the adage is taken seriously, if we can judge from the volume of research dealing with the audiences of technical information. Our review of the technical communications literature. shows more research aimed at audience description than any other type. Some studies were located dealing specifically with. opinions, attitudes, and various other orientations of individuals toward nuclear power. The bulk of the studies located deal with individual's orientations toward various related environmental concepts and issues ,such as "energy crisis," and "environmental quality."

How do such studies contribute to questions about improving communication of technical information with lay audiences? Do they tell us anything about what should be communicated, how to communicate, or identify conditions that are favorable to improving communication? One of the prevailing notions is that attitudinal information can tell you how to communicate more effectively with a prospective audience. Generally speaking, we may expect people to be more receptive to information that is consistent with existing attitudes; the so-called "preference" for "supportive information" that is reported in the social psychological literature (for example, Festinger, $1957 \& 1964)$. But what if the communicator has nothing to say that is consistent with existing attitudes? Should he then remain silent? On the other hand, if existing attitudes are consistent is he assured that communication will work out no matter how he does it? Answers to these questions rest most definitely on the communication purposes involved. In some circumstances, having attitudinal information about individuals is an improvement in communication in and of itself. This would be the case when an agency seeks some direction from members of the public. But to be most useful, the attitudinal information should bear on a range of problem solving alternatives, or even help in creating those alternatives from which the agency and public will choose. Attitudinal data seem less likely to be helpful for improving communication in situations where the agency already has a solution it wants accepted. Here the data may serve only to suggest what attributes of policy the agency might stress to maximize public acceptance. But this use smacks more of PR or engineering of consent, $r$ ather than useful dialogue with the public.

One of the significant aspects of the attitudinal data in relation to technical issues is that it directs our attention to individual differences that (hopefully) hold across situations. The attitude is assumed to reflect an individual's stance in a number of situations and therefore to indicate the direction of eventual behavior. We can then use this information as a basis for segmenting an audience into attitudinal types. Such an attitudinal typology 
would presumably apply to any number of related, similar issues. Thus, for example, attitudes identified in connection with one nuclear power plant siting might be expected to be the same as for any other. The communicator is being instructed to keep track of the individual differences, not the situational differences. As communicators, we learn that the audience for any issue is made up of different types, but (fortunately) the typology can be generalized across situations. Therefore, once we know the individual types, we can employ the same communication strategies from one situation to another.

This is a powerful idea, but there are problems. For one thing, the attitude that is stable or unchanging from one situation to another appears to be a very special case. In a recent study of attitudes toward environmental quality, six distinct attitudinal clusters were identified in an initial study of 490 undergraduate students and 170 adults (Lounsburg \& Tnrnatsky; 1977). But a follow-up study of 207 housewives yielded only 3 of the original six clusters. Another study has shown that the same individual may express very different attitudes across a set of what the experimentors define as related issues, and that between-issue variance in attitude was greater than between-individual variance (stamm and Grunig, 1977).

It is difficult to pull together much from the various attitudinal studies of nuclear power and related environmental issues; most don't add up in very clear or useful ways. Each investigator indentifies his own attitudinal dimension without much attention to attitudes that have been identified by other investigators. In most cases there is little prior conceptualization of the attitudes involved. The investigators develop a pool of items that appear to be "in the ballpark," then proceed to use statistical techniques to factor out attitudinal clusters. Such clusters tend to be unique to both the set of items employed and the subject pool used in testing. Under these circumstances, it is difficult to develop powerful attitudinal approaches. If progress is to be made, more extensive work needs to be done with a carefully developed, common set of attitudinal dimensions, demonstrating that these have applicability to a number of nuclear power situations. One effort to find attitudinal dimensions transcending various nuclear power situations is a recent analysis and synthesis of over 100 existing surveys by Melber et. al. (1977). The power of even the best synthesis to reconcile diverse intentions and methods of these many researchers must necessarily be limited. But the authors have made an important step to make sense of a considerable diversity of research, providing a useful composite of nuclear attitudes.

If we try to go beyond the details of any specific audience study, we find that the audience for technical information is highly dif- 
ferentiated. It can probably be best characterized as fairly distinct "audience segments," differentiated in terms of their properties, such as income, education, occupational status, opinions, attitudes and level of technical knowledge. The major implication of such segmentation is that communicators of technical information must deal with a number of distinct audiences, varying their communication strategy for each audience segment. We shall return to this implication after discussing some of the distinguishing characteristics of audiences so far revealed by audience research.

Where the impact of technology is at issue, research has often shown that publics can be usefully segmented in terms of proximity to the impact. Those residing in close proximity to the impact have been shown to have greater concern, different opinions (Kroners \& Venes, 1976), and greater understanding of the impact (Tichenor and others, 1971). For example, it appears those closest to a pollution impact from technology feel quite differently than those close to the source. Tichenor and his colleagues have suggested that economic self-interest is strongly involved. Those close to the source are often benefitting economically from the technology, while those experiencing the effects often are not. This difference in concern is sometimes reflected in mass media coverage of the environmental impact of technology by a tendency to concentrate on distant problems rather than those closer to home (Hungerford \& Lamont, 1973).

The "economic self-interest" hypothesis appears to apply to concern and attitudes about nuclear technology only in certain cases and for certain aspects. Most of the research has not distinguished clearly between the positive and negative aspects of proximity. A nearby development boosts the economy in terms of jobs, retail sales and other dollar benefits. It also brings real or anticipated risk from accidents, effects of poor design and the usual "commercial fallout" of economic development. The environmental studies have dealt with reactions to established technologies that are already embedded in the economic structure of the community. New technologies do not have such status. Therefore, instead of finding that people living in close proximity are the most accepting of the technology, research shows that opposition is negatively related to proximity (Tanaka, 1977). It is also very difficult to alleviate fears about anticipated consequences of nuclear power. Proximity to the effects of technology, therefore, is one way of predicting individuals' involvement with technological issues. As Grunig (1977) has found in reviewing public opinion on environmental impact of technology, people do not generally perceive themselves as being directly involved in these issues. Typically, it is only the more highly educated and knowledgeable "activists" who perceive themselves as being involved, and who actively seek to communicate about such issues. Proximity to the effects of technology provides the exception to this general rule. When the 
effects of technology are close at hand, then involvement with the problem is widespread and no longer differentiated along socioeconomic lines. Given these conditions, the agency responsible for the technology must be prepared to communicate with all members of the local community, and to use the mass media in doing so.

Proximity to and involvement with a technological issue are probably better indicators of public behavior than opinions expressed about the effects of technology. And again, such proximity can contribute to favorable or unfavorable views. As Grunig (1977) has pointed out, people will give an opinion to a pollster, even when they are not involved in the issue and would not support any particular outcome. If the issue has been covered in the media, they are likely to say that it is an important problem simply because they have heard about it in the media.

Extensive efforts have been made to describe a type of individual who is negatively oriented to technology where adverse environmental impacts are involved. This is the so-called "environmentalist" segment of the audience. Most studies have described this audience segment as being comprised largely of individuals who are: (1) Upper middle class, (2) above average education, (3) liberal in political orientation, (4) employed in "non-resource exploiting" institutions, (5) above average in level of general social concern.

The various studies which seek to indentify the attributes of an environmentalist type beg the question of whether there is a consistent attitudinal disposition underlying the type. koenig. (1975). for example, doubts that environmental concern represents a distinct attitudinal type, concluding that concern for the environment is part of an overall liberal concern for socio-economic issues, and is not a separate attitude in itself.

Stamm \& Grunig (1978) have raised an even stronger objection to a prior acceptance of an environmentalist type. Their research experience showed the search for an environmentalist type to be unproductive. They found that there were always some individuals who would take a strong environmental position on a specific issue, but were unable to document that this was a consistent pattern of behavior across a broad sample of issues. These authors suggested that peoples' issue or ientations were not as attitudinally based as commonly supposed.Putting it another way, there is no clearcut "environmental type" that can be identitied across situations, but there are clusters of attitudes that suggest environmental leanings.

Meanwhile, the literature shows that the search for attitudinal types is continuing, but there is no consistent conceptual framework underlying this quest. As a result, it appears that any number of attitudinal dimensions have been "discovered." The dimen- 
sions that are identified are more a product of the investigators choice of items and analysis model than of any theory about the dimensionality of environmental attitude.

If we are generous and project that meaningful dimensions of environmental attitudes will eventually be isolated, we must still ask whether this will mark a great breakthrough for communication practitioners. The general assumption is that if attitudinal types can be identified, communicators will then know how to construct messages that are most appropriate for different types. There are several problems with this. The first is that attitudes are not readily observable, so practitioners won't be able to segment audiences along attitudinal lines until more visible "locators" are discovered for the attitudinal types. Second, there is the critical and still unanswered question of whether attitude can be either formed or significantly changed through public information programs. However, there is an advantage to an agency in being able to locate potential support so that it can be nurtured and consolidated.

While many studies have been found which seek to describe public concern and attitudes about the environmental impacts of technology, very few were found which deal with orientations toward technology itself. This would seem to bias the picture against technology, since less attention is given to the potential advantages of new technology. So far we have been talking about technology, such as nuclear power, that is adopted and maintained by large organizations. Clearly, the individual has by comparison less control over this kind of adoption process. And the basic communication problem has been one of convincing the individual to go along with what the organization thinks is best. Consequently, the individual's disposition toward the technology and its effects have been the focal points of research.

However, there is a vast literature on the diffusion of technology ("innovations") that takes a different perspective and is concerned with if, when and how new developments are adopted and used by the individual. With this different focus, the problem is not to simply persuade the individual to go along, but $r$ ather to incorporate the technology into an established social and economic process. Thus, in this context the focus is on the individual's readiness and capability to adopt and use new technology. Several roles are seen for communication in this process: creating awareness, establishing utility and social acceptability, developing the necessary technical expertese, etc.

A significant observation we might raise from the diffusion of innovations literature is that not everyone is ready to adopt a new technology at the same time. Typically, adoption begins very slowly and gains momentum only after a substantial segment of the pub- 
lic has already adopted. Organizational adoption of technology works differently, however. Generally, it assumes that everyone (or at least most) should be ready at the same time. In effect, organizations are trying to severely compress the adoption process of individuals. It is not surprising that individuals sometimes aren't ready. The public does not adopt a nuclear technology or projects in the same sense that it adopts personal-use technology such as television.

Similarly this temporal perspective also suggests that public opinion studies are too time and situation-bound to have much generality. They usually deal with isolated issues at a single point in time (Dillman \& Christenson, 1974). What is needed is research that follows the development and change of public opinions toward important technological issues. The tendency is to take a few polls at the same point in time, perhaps in different places, and conclude that the public will never favor nuclear energy development. Those few studies that have followed public opinion over time, however, have shown that such views are notoriously unstable. Two recent examples demonstrate the decline in concern about environmental pollution in the U.S. between 1970 and 1975 (Dunlap \& Dillman, 1976), and diminishing "nuclear allergy" among young Japanese (Tanaka, 1970). 


\section{EFFECTS}

Those who have studied the communication of technological issues have been much more interested in secondary effects from communication than in communication itself. Few studies have been reported that deal specifically with how technical concepts can best be communicated. Nor have most dealt with the levels of understanding that can be achieved by such communicating. There are a number of studies that deal with the effects of message manipulations, of different communication channels, of information strategies on opinions, attitudes, and behavior. The focus in these studies is upon the effect desired, not upon the communication process which is assumed to intervene between a given message and its effect.

This gap in the literature is a serious one for the communication practitioner. It suggests how to obtain certain presumed effects through communication without any explanation of how to communicate effectively. To make matters worse, the literature also portrays a pessimistic view of the likelihood of being able to obtain anything beyond rather 1 imited effects.

In two reviews of research on environmental çommunication, Stamm (1972, 1973) concluded that there was little support for the assumptions that increased knowledge changes attitudes, or that attitudes predict behavior. Still, the prevailing assumption behind information campaigns, environmental and otherwise, is that if the issue is covered sufficiently and "properly" in the mass media the public will develop "proper attitudes" toward the issue (Grunig, 1977).

Another common view about the effects of public information programs regarding technological issues is that the level of public knowledge can be increased and that this will result in greater acceptance of a proposed project. A number of researchers have cautioned that this may not be the case. The effects of information efforts are seldom that straightforward. Here are just a few examples. Tichenor (1971) found that those who perceived their self-interest to be affected by new environmental controls were often the most knowledgeable, and the most opposed to controls. In a study of knowledge and attitudes concerning a proposed reservoir project, Bultena and Rogers (1978) found that the more knowledgeable persons held the most intense attitudes both pro and con. There is a question of order and possible causality. Does the knowledge or attitude come first? The studies don't help much here.

Even the simple proposition that information programs increase levels of public understanding must be qualified. It depends, 
among other things, upon the nature of the program and upon the audience. Tichenor and his colleagues (1971) observed that information programs often increase the gap in knowledge between the least and most informed members of the public. In other studies, several deficiencies in public knowledge were reported despite agency efforts to inform the public: (1) Citizens knew the potential benefits of a proposed flood control project, but not the disadvantages (Stamm \& Bowes, 1972). (2) Persons who were aware of a proposed reservoir did not know the rationales for its construction, what agency had proposed it, how to have input on the decision, why the project was opposed by some, or what local groups were actively involved (Bultena \& Rogers, 1978). (3) Citizens and community leaders both tended to see a major water diversion project in simplistic terms of one big advantage or disadvantage, rather than the complex of benefits, costs and consequences that such a project entails (Bowes and Stamm, 1974).

Studies of the effects of such agency information programs have often led to criticisms of how they are conducted.Here are some of the faults that have been pointed out: (1) Citizens not adequately informed of the rationales, objertives, technical procedurcs, and likely impacts on proposed programs; involving the public without trying to raise the informational base that citizens bring to their participation (Bultena and Rogers, 1978). (2) withholding negative information about environmental damage, and over-promoting the positive aspects of new projects (Stamm and Bowes, 1972; Grunig, 1977). (3) Information provided about the existence of problems without supporting information about solutions and the means of eliminating constraints (Grunig, 1977). (4) Citizens allowed to merely express opinions, but not to actually influence decisions about what shall be done (Richardson, 1974). (5) Providing for public "input" only after the agency is committed to a preferced solution; not providing any mechanism for incorporating public input in agency decisions (Stamm, 1978). Such deficiencies generate suspicions that some sponsors of technological change would not see it in their best interests to do things any differently. Given that information dissemination holds the potential of sensitizing people to consequences of projects that they $f$ ind undesirable, it may be unrealistic to expect agencies to pursue more viable public education programs.

Even though the effects of improved information dissemination may at timcs opposed to lhe spunsorling agency's objectives, it can still be argued that such efforts are in the long-range interests of all concerned. Public demands for involvement are intensifying, confronting agencies with increased demands to participate in planning and decision-making. There is considerable doubt that the "public interest" is served very well by decisions arrived at by the agency alone, and in which the public is not involved. The eventual offset of such decisions can be a serious public "back- 
lash" for the agency.

Fortunately, not all conscientious information programs have effects that work against the interests of the agency. And it should be remembered that the failure to communicate can also have such effects (Stamm and Bowes, 1972). Yavanovich (1974) reported that the Mitchell Energy and Development Corporation convinced hostile environmental and community groups that it could drill safely for off-shore oil. The Company accomplished this by tackling the negative consequences of the project head on. Grunig (1972) documented that a number of corporate information practitioners have adopted the position that their role is to fully and accurately report the environmental effects of proposed projects, and to explain what the organization is going to do about it (e.g.., the Riegel Paper Corp. described by weil, 1970 and by Weichmann, 1971; the W. R. Grace and Co. reported by Moore, 1970; Trans-World Airlines, reported by Corris, 1971; and the oil industry, described by King, 1967). In addition, several practitioners have provided advice on how to best work with news media (Pastorious, 1971), with environmental organizations (Paluszek, 1973), and with the environmental press (Chambliss and Walsh, 1973).

A few researchers have pursued the possibility that the design of the message will be an important variable in the effective communication of technical information. This has been pursued primarily with respect to written messages, as compared to other forms or modes of communication. The criterion for evaluating the "effectiveness" of the message has generally been comprehension of the message, or improved score on a knowledge test.

Most of this research represents an extension of the general field of readability research to the area of technical information. Readability research began among educators who wanted to improve the appropriateness of grammar school readers for various grade levels. This research program resulted in the identification of a relatively few style variables (primarily word difficulty and sentence difficulty) that were useful predictors of the "reading difficulty" of written material. A number of regression equations were developed. (e.g., the Flesch Formula) for use in efficient estimation of reading difficulty with a wide range of literature.

The message variables and validation criteria employed in research on technical writing are very similar to those employed historically in readability research. To a large extent, it has been a matter of showing that what makes a difference in grammar school textbooks will also make a difference in technical documents and science news articles. To some extent it has been demonstrated that some style variables do make some difference in comprehension in such material as science news stories. The difference is that the audiences for technical information are much more homogeneous 
than the subject pools used in validating readability formulas. Therefore, the overall variance due to style variables is not as great because the typical reader of technical articles is capable of comprehending very difficult writing. The major improvement is obtained with those readers who are infrequent users of technical information. In other words, it isn't worth worrying that much about style variables unless you are trying primarily to reach an audience of "infrequent users." However, these are the sort of users that make up the bulk of the "public" that technical change agencies are attempting to reach, inform, or influence.

A second approach to the presentation of technical information is what we would call "interpretation." This involves making technical ideas more understandable by relating them to familiar events, or to similar, more familiar ideas. The professional literature on technical writing generally advocates the use of examples and of analogies. The skillful use of analogy and metaphor is often found in the writing of such science interpreters as Asimov, Leopold and Dubos. Some research has been attempted to test the effectiveness of these interpretive devices. Funkhouser and Maccoby $(1972,1974)$ obtained some evidence that the comprehension of science news was improved through the use of analogy, but use of the device had the greatest effect on inexperienced readers of science news. Grunig (1974) later developed the hypothesis that analogy and parable would be more effective devices than use of examples. He argued that examples simply produced an operational definition for an idea, but not the idea itself. Analogies and parables, on the other hand, maintain the same "level of abstraction." The new (technical) idea is associated with a familiar idea that is similar in some respect(s). It should be noted that the use of these devices presents hazards as well. The "familiar" idea may not be as universally understood as the writer supposes. Also, analogies provide only approximations to the new idea being communicated. Obviously, if the old idea was equivalent in every respect there would be no new idea to communicate. Grunig's results also provided only modest support for the effectiveness of analogy, even though it was shown that analogy and parable were more effective than examples. Grunig showed at the same time that the reader's relation to the idea (such as whether it would be useful in making a decision or solving a problem) made more of a difference in his communication behavior than did inter pretive devices.

Results from these few studies on the effects of message variables particular to technical information parallel these message variables generally (e.g.. Hovland, et. al., 1949). Manipulations of message variables generally makes a difference in communication (against a wide number of criteria), but these effects are strongly mediated by what the receiver (reader, 1 istener, viewer) brings to the situation. And whatever effects there are tend to erode over time. 


\section{RELATIONS BETWEEN SENDERS AND RECEIVERS}

of pivotal importance to the understanding of technical information is the extent to which both the sources and receivers strive toward a shared understanding of technology. Message creators have a continuing problem with evaluating the sophistication of audiences in handling scientific abstraction, with judging the ability to cope with scientific terminology, and with determining what stories should capture interest. Add to this the potential for confusion by the information consumer in the face of fast-moving and controversial change, and the quality of source-receiver relations assumes paramount importance.

Much of the available research speaks in terms of the media, with their consumers and message construction as isolated components. This is understandable specialization given the diverse origins of communication research, but one which often ignores the interdependence of these elements in communication processes. Many such examples are found in our review of sender-receiver attributes. Some research may consider linkages, but will do so anecdotally about certain situations that are fixed in time and have questionable generality. There are few research projects on technical communication processes which illustrate generalizeable models of communicating technological information. Most work is situational, applied and subject specific-- such as agricultural innovations and nuclear power station controversies.

The most effective studies of linkages in communication of scientific information involve the use of multiple populations, each representing elements joined in a technical information network. Research of this kind typically attempts to measure "agreement" among competing interests in a technological controversy. For example, Muchinsky (1976) compared ranking of important public issues between oil company executives and college students and found a high level of correlation. or agreement. In contrast, assessing the ability of groups to understand content and recognize differences in orientation among themselves to technological issues represents a more productive trend. If communication about technology is to inform and create understanding, the "snow job" aimed at impressing and fostering compliance among the lay audience is wasteful and misleading. It appears more emphasis should be placed on the communicating itself and on the degree to which senders and receivers have the same understanding of the material that is communicated.

One well-studied 1 ink is between the scientist-source and the reporter-mediator. The implication is that the reporter serves as translatior of scientific complexities, making them compelling and understandable to the general population. This link is checked by having the scientist source evaluate either reader understanding 
of the media report or the reporter's original story. As an example of the first method, Tichenor and his colleagues (1970), sampled newspaper accounts of scientific and technical subjects. These stories were then given to lay subjects to read and summarize in their own words. Summaries were returned to scientists quoted in the articles who then rated their adequacy. The proportion expressing satisfaction indicated a given article's "communication accuracy." Typical of the second approach, Tankard \& Ryan (1974) directly sent newspaper science articles back to the scientist sources to be checked for accuracy. Similarly, Broberg (1973) gauged the "accuracy" of science stories by the amount of editing given them by scientist-reviewers. Few were free of error.

Recognizing a problem, NSF's 1973 seminars sought to improve acuracy between scientists and the editors of science stories. They recognized as a result of the conferences a divergence between scientists and editors--editors wrote of science what they believed would interest their audience or what they believed the audience wanted to hear. Scientists held to the academic tradition of trying to teach people what was new and important...whether they wanted to listen or not. Similarly, Tannenbaum (1963) recognized problems in the scientist-editor link because each values different story elements. Scientists react to what is being said, while editors value how it was said. ConsequentTy, science reporting tends to be $c l i c h e r i d d e n$ and inaccurate, reacting to what appeals, in the editors estimate, to the public's imagination.

But technology when, it promises strong impact on life style is given to more complex communication linkages than are occasional stories of remote scientific accomplishments. Several studies have consided more than one linkage in an effort to better represent communication outcomes of major technological impacts. Bowes \& Stamm (1973, 1974) examined the orientations among three major groups -- the public, community leaders and state officials -- toward the characteristics of a large water management project. Measuring agreement among these groups on impact characteristics was of major interest. But of central importance was each group's ability to estimate orientations for the other major groups involved. The discrepancy between estimate and actual group response gave precise measures of accuracy -- the degree to which groups could share the view of impacts held by other, perhaps competing, interests. It was clear from the results that the public was illserved by their leaders, who were in close accord with development agencies and officials but had little idea of their community's preferences. Similar measurement approaches were employed by Groot (1970) and Jain (1970) to show the effect of person-to-person network patterns on the quality and direction of communication with scientific communities. Kearl and powers (1961), in an earlier variant, asked researchers, extension workers and agricultural journalists to rate the soils knowledge of a "midwest farmer". 
When compared to the actual scores from farmers, these groups were "accurate" in their estimates.

Generally, results of such studies are contradictory, failing to account for conflict inherent in the subject matter or the heterogeneity of the groups compared. It does seem generally true, however, that personal impact of technology increases potential dischord and confusion.

Information specialists would do well to segment their audience by impact and direct their efforts accordingly. However, these efforts show clearly a break with more traditional persuasion based research aimed at securing or explaining "agreement" or compliance with programs. Clearly the problem with technological issues is that individuals hold diverse orientations. Conceptual structures and methodologies which are not sensitive to this divergence miss a major point.

The conditions -- social, individual and message style -- which presumably promote accuracy or agreement have been heavily researched. Many of these have been discussed in previous sections on source, message and receiver attributes. Others we have ignored because they are really the sort of anecdotal "helpful tips" on message style or the organizing of meetings and campaigns which fill elementary advertising and Public Relations texts, but lack generality and controlled verification. Comparatively few studies have taken up the special case of technical information and have directly investigated its influence on audience understanding in a controlled, generalizable manner. A few are notable.

Donahue, Tichenor and olien (1975) were concerned with the differences ("gaps") in knowledge about local issues (environmentally threatening industry, nuclear plants) in small Minnesota communities. Social conflict, smalliness and homogeneity of population were forces reducing gaps between the most and least knowlegeable. Funkhouser and Maccoby (1971) investigated the influence of textual variables on the understanding of science writing. In a series of experiments, Grunig (1974) examined stylistic, individual and social system influences on the understanding of scientific information by the lay public. Central to this discussion was the problem of conveying understanding of scientific abstractions. Often, the author suggests, one is made aware of the implications of scientific research, but has little comprehension of the principles from which the research has been developed. Grunig also considered the ability of the individual to perceive problems (open-mindedness) and alternative solutions. Tichenor and his colleagues (1976), reconciling the themes of several studies, examined the duration of intense media coverage given local issues and the distribution of issue knowledge throughout the community. Intense coverage for long periods equalized knowledge among citizens while 
short-term exposure reached the highly educated but was. not visible long enough to spread to the remainder of the community. But such long-term coverage by the media is rare, since it is in direct conflict with the traditional journalistic news value of timeliness, which is usually associated with a particular event or happening.

Accurate, effective communication also has been predicated upon the similarity of source and receiver in terms of personality and social characteristics. As previously described, Tichenor and his colleagues (1976) found that community heterogeneity increased knowledge "gaps" among its citizens. But more typical of this genre are studies tracing the diffusion of innovations. For example, Alpert \& Anderson (1973) and Rogers \& Bhomick (1970), rate the similarity and dissimilarity of senders and receivers in information networks. Similarities improved diffusion rates while dissimilarities had the reverse effect. The characteristics upon which senders and receivers were matched tended to be demographic, not more elusive attitudinal and personality dimensions which directly bear on the quality of interpersonal relations. We know little about those personal attributes where matching is most critical to the accuracy of scientific information transfer and whether unique circumstances apply to the case of technical information as opposed to other kinds. Also, many studies equate "effectiveness" with extent of diffusion, taking little notice of quality or accuracy of messages received.

Similarity of orientation and the accuracy of communication that results would seem strongly dependent on level of conflict among competing interests. Certainly conflict is a common setting for resolving issues in technology, so it's reasonable to ask how this conflict context interacts with communication of scientific information. In one attempt to explain conflict arising from technological issues, Robinson. (1963) suggests that scientific advances which have little personal impact are viewed favorably. But news stories of technology which threaten to control elements more personal to one's lifestyle are more likely to be seen as "against God and nature". Stories based in the natural sciences would be more believeable than those arising from the medical and social sciences. Cole (1975) hypothesizes that as a society becomes more pluralistic and differentiated, the more likely it is that media serve a watchdog function, reporting more readily on technologybased conflict. He notes that press accounts of conflict based on technology issues has grown steadily over the past 20 years. But few of these studies suggest the role of media or person-to-person communication activity in reducing the level of conflict. Bauer (1977a, 1977b) reflects this by suggesting that models of conflict, mostly based in industrial disputes, are not suited to the "social movement" character of environmental and anti-nuclear conflict. More account needs to be given the phases of conflict -- 
movement from individual tension to collective activity and finalIy to compromise with adversaries -- particularly in terms of communication mediaries and intervenors who help make these events a rational process. There is evidence that nuclear controversy takes more time, more stages and more intervenors to resolve than many other forms of social conflict.

Several researchers have taken up parts of this broad question. The role of community media as managers of conflict has, for example, been investigated extensively by Tichenor and his colleagues (1973). They found local media a pivotal force in the management of community tension. Other research offers advice on conflict resolution. Bauer (1977a) recommended creating trained intervenors who can enter conflicts and act as community organizers, change agents and mediators. Richardson (1974) suggested a workshop setting to manage conflicts over nuclear plant siting. Phillips (1976) advocated specialized sampling and "trade-off" questionnaires as a method of speeding compromise and resolution through by-passing the usual hearings process, which often is contentious and confusing to the average citizen. These are useful approaches, since persistent emphasis on adversary argumentation may not be the most effective way of building understanding of complex issues or developing workable compromises. Ebbin and his colleagues (1974) examined public hearing procedure, with its primarily adversary argumentation and circumscribed rules of participation. They conclude that such hearings are "neither fair nor expeditious, nor particularly revealing of scientific truth or technological fact." Because of these failures, they recommend creation of independent agencies to adjudicate and arrange for impartial analysis of effects from major nuclear installation sitings. This suggests that proponents of nuclear power projects should give more attention to communication relations between themselves and mediating groups and between these groups and the public. Perhaps the most direct communication route is not the shortest--at least not in time.

Risk, is perhaps a significant force in creating conflict in power site situations, but it has not been discussed explicitly in relation to the techniques of communicating understandably about it. The hazards of nuclear energy, however, have long been debated with widely varying impressions of the risk such installations bring about. The few available studies examine $r$ isk in several contexts. First, the methodology of risk assessment has been reviewed and debated (Baldewicz and others, 1974) as has its place in decision-making models (Herson; 1977). But these say little about optimum methods of communicating risk beyond improving assumptions underlying its actuarial assessment. Perhaps the most useful study was the approach taken by Montague and Beardsworth (1974), who analyzed the subjective methods Americans use to assess $r$ isk-to-life. They found respondents used three major crite- 
ria: (1) individual control over accident occurences, (2) whether or not accident occurrence automatically means fatality to those involved, and (3) whether the individual can modify the results of accident by his subsequent actions. These considerations tended to weigh more heavily on individuals than did statistical indications of risk. These criteria suggest better ways of discussing the concepts of risk to non-experts. Those active in analyzing diffusion of technical innovations often cite $r$ isk as an impediment to adoption of the innovation (cf Rogers, 1970). Suggestions made to lower perceived risk include dividing use into "trial sized" amounts, providing field assistance for social support and individual advice, and using existing social networks for social support and peer pressure. However, the application of these techniques to nu= clear dangers seem tenuous. After all, there is little visible advantage to sell and potentially emotional dangers to downplay. Discussion of $r$ isk, however small, may excite problems $r$ ather than reassure, unless such talk considers how the public may subjectively evaluate risk. Nuclear dangers likely seem far from the personal control and clear understanding of the citizen.

A frequent assumption imposed on the source-receiver link is that simply presenting information will promote desired behavior changes. In some research, knowledge and desired attitude are considered synonymous with behavioral outcomes. Others speak rarely of attitudes, but simply assume exposure to messages has changed attitudes when desired effects are seen. Both assumptions are careless. Lounsbury and Tornatzky (1977), for example, investigated the relationship between attitudinal and behavioral involvement in the maintenance of environmental quality. The authors conclude, not surprisingly, that verbal involvement is stronger than behavioral: that the attitude--behavior link was weak at best. Chaffee \& Linder (1969) suggest that communication research is more productive when focussed upon value changes and their communication antecedents than upon value changes and subsequent alterations in behavior.

Communication leading to subsequent value and behavior change has been extensively examined in the context of disseminating new technologies to developing nations -- measuring swiftness in adopting western industrial trappings. Shortcomings, however, were abundant, both in the premise and desired outcomes of this research (cf. Rogers, 1976). An important criticism involves the concentration of this research on personality and lifestyle characteristics of those quick or laggardly to change, such as empathy, risk-taking, use of media, contact with opinion leaders, etc. In contrast, Grunig (1974) comments on the situational constraints of environmental problem solving. Government regulators and the media in many ways restrict the awareness and practicality of alternatives to environmental problems. Stamm and Bowes (Ludtke and others, 1971), note in their study of a North Dakota water diver- 
sion project that technologically complex alternatives are rarely posed by a lay public, but are developed and publicized by expert agencies and special interests. As such, little initiative is possible for the non-expert. The individual, at least in the research forum, has taken much of the blame for not making needed changes. Save for the few exceptions noted, it's ironic that on one hand so little research explains the situational constraints of individuals, yet; as discussed in an earlier section, proposes so few variables which are useful accross situations to explaining the effectiveness of communication of technology. In short, we are left with little that is systematic or that synthesizes earlier findings. 


\section{CONCLUSIONS}

Communication of technical information to non-experts is, at best, an incompletely researched and understood field. Our intention to discuss only research directly bearing on technical information was partly thwarted by the diffuse nature of existing studies. Systematic, cohesive programs of research, carefully building upon each other, are a rarity with this specialized topic as they tend to be with the general field of communication itself. Certain traditions, such as the innovation diffusion literature and the debates it has spawned, have some of the gualities of specialized inquiry. But the carryover of the visible, largely benign technology at the basis of this research to nuclear power and waste disposal is small. The mass education approach suggested by diffusion research, given audience differences which frustrate mass appeals and social system constraints 1 imiting individuals' initiative, have Iittle firm advice to offer those ready to discuss nuclear energy with the public.

Attitudinal studies show little cumulative pattern of inquiry on stable, widely accepted attitudinal dimensions. Generality across various nuclear controversy situations is limited. Some traditional areas of communication research, such as source credibility, are rarely applied to communication about nuclear energy. Attempts at effective categorization of audiences, to search out those most sensitive to nuclear energy issues, have been frustrated because these efforts seem heavily tied to politics of an immediate situation, rather than to generalized attitudinal types.

The motives of such studies also lead to difficulty. By looking at attitude change, many agencies involved with technology simply are measuring public acceptance of foregone conclusions reached long ago by agency bureaucrats. Little effort is directed to seeking public participation and the methods for best eliciting this type of input during the formative stages of considering technological alternatives. Polling, the dom inant methodology of assessing opinions, typically takes place at the peak of controversy and rarely recurs to test persistance or whether individual action toward nuclear technology subsequently develops. Even panel studies and recurrent political polls are typically administered at intervals designed to coincide with elections or other major event which are cyclic in nature. Nuclear issues are not so accommodating in the ir regularity. Many of these surveys define the field of concern by tightly structured questions. It's likely that many miss the point of what the public has to say merely because they didn't offer opportunity for the public to express concerns in their own terms.

Effects desired from communication are widely discussed, but little is done to examine the linkage of specific communication activities to effects. Studies tend to (a) assume desired behaviors 
will result from measured attitude shifts which in turn are presumably the result of prior communication activity; or (b) assume that effects measured must be due to some pre-existing attitudinal set which is the product of prior communication. This "logic" leads to faulty prescriptive advice on communicating about technology. It ignores what becomes abundantly clear to many skilled communication practitioners: their target audience members typically are the ones controlling the communication situation. The receiver decides how, when and whether to attend to the sender's message.

The source-receiver 1 inkage has been widely studied, mostly indirectly through examination of verbal material or messages. part of this attention comes because the prevailing common sense impression that science writing deals with subject matter and concerns that are difficult for common people to understand. Thus advice is sought on how to clarify presumably indigestible scientific jargon for a mass audience without doing violence to the intent of the scientist-source. Descriptive techniques and stylistic hints on improving "readability" abound, but their effectiveness is often tested in a simplified experimental setting on subject matter which is neutral to the test audience. The emotional aura surrounding many nuclear issues seems lacking in many such studies. It seems a common expectation in many that people are rational problem-solvers and that messages given may make this assumption. What is ignored is the likelihood that nuclear projects may be seen with a considerable emotional overlay--expectations of injury by invisible phenomona, of catastrophe. Several studies examined do a creditable job of checking the quality of information as it passes from scientific source through reporter to the public. But little attention is paid to what kind of scientific information or the involvement of the audience in the subject matter. Similarly, not much is known about what kinds of images people have of nuclear projects (for example, their attributes) as a result.

Several situational characteristics have been examined (for example, risk and conflict), but it is difficult to be content with these dimensions as the total relevant set. What conditions, for example, arouse curiosity and an appetite among the public for information? Many studies we have reviewed seem to assume the public is interested in the subject at hand. In reality, professional communicators zero in on only a small time/space slice of the receiver's experience. More systematic investigation of situational characteristics affecting source-receiver communication is needed, given the emotional and policy implications of nuclear issues.

The media-source 1 ink has received some specific attention, particularly the relations between press and scientist. But very little information details the stylistic problems of describing nuclear technology. Typically, a range of scientific topics are 
screened in research with little attention paid to their subject matter. Too, we know little about the reporter's attitudes toward scientists and whether specialization (for example, a science reporter vs. general assignment reporter) makes much difference. The scarcity of research in this area is critical since since journalists act as "gate keepers" and screen much of the technological material that is aimed at the lay audience. These reporters and editors determine which materials or stories are to be disseminated by the media. So all of the communication problems considered in other contexts are compounded when the journalist is added as a mediator or middle-person.

Other links between the source and the audience--such as opinion leaders, organizations, informal word-of-mouth networks -- have not really been examined as to their effect on receipt of nuclear information. Little is known about regularities in communication networks which attend nuclear energy issues and the interplay of mass and interpersonal communication channels. Rumoring and crisis communication patterns seem promising directions, but have been rarely investigated in the context of nuclear projects. Further, the standing opinion held by message receivers of various scientific information sources has been little examined.

To be sure, some important matters relevant to communicating about nuclear technology have received attention. The techniques of polling attitudes, of measuring source-receiver agreement and accuracy, and of investigating stylistic criteria seem well established. But these methodologies in good part do not offer conceptual structures which further explain the difficult case of communication about technology. Much attention also is devoted to attributes of audiences, for example "enviromentalist types," and the qualities of agency information programs. Too, the "effects" of programs have been heavily researched (through such approaches as diffusion studies). But, ironically, we are left with results frequently bound to specific situations, without conceptial tools which enable much cence to be made about those situations.

To summarize, the literature available shows only partial applicability to what we believe are major unanswered questions concerning communication about nuclear energy. The situation of complex technology negates the relevance of much research directed at more commonplace, routine events. Too, the prevailing view of communication as an independent variable yielding "effects" denies a useful alternative perspective where communication is dependent on prior events. Nuclear energy as a subject matter adds a complex overlay of low visibility and possibly high emotion to an already complicated communication situation. So far, the research is not addressing well the difficult questions posed by these circumstances. And all of these shortcomings are magnified when we include communication through the media. Then not just the original 
sources and receivers must be considered, but also the media personnel as they take on both these roles while acting as transmission agents who interprete and transform messages.

Although the science implicit in communication research doesn't provide any unqualified answers, there are guides offered by those who practice communication as a craft -- public relations, journalism and advertising. Often research serves merely to confirm the common sense practices of professional communicators which are performed without awareness of their verification by the research community. For example, one practitioner-oriented newsletter distills the contents of a anti-nuclear power group's public relations manual which advises its members to (a) coordinate the communication networks of existing nuclear power interest groups (b) link the nuclear power issue to other familiar issues such as weapons (c) train organization workers in small, "affinity" groups to overlay political interests with friendship ties, (d) adopt a "totally open" information policy to key reporters and maximize participation from outside of the immediate community (PR Reporter, 6/12/78). These basic techniques have underpinnings demonstrated by prior research in propaganda and advertising.

Similar practical advice can be extracted from the research reviewed above -- if one is willing to make extrapolations and accept a certain lack of precision. A number of suggestions of this kind can be made to assist communicators responsible for explaining nuclear projects:

* Segment audiences by the impact expected from nuclear projects. Write to each segment with pertinent examples and matcrial addressed to their particular concerns.

* Communication efforts should be spread over long time periods. Short time periods differentiate the educated from the uneducated, resulting in a well-informed minority, but not widespread awareness.

* An individual's ability to perceive control in a situation has much to do with how $r$ isks are evaluated. The higher one's apparent personal control, the better risks are accepted. Communicators should acknowledge the particular problems they have in this respect with nuclear energy. If elements of control are possible, such as through citizen advisory groups, these aspects might be stressed.

* Realities such as proximity to a nuclear plant, while they suggest danger to many, also serve local 
interests (e.g. those who have plant-related jobs, who supply materials). These competing reactions may split communities, frustrating efforts to write with a homogenous audience in mind or even assess their opinion in a clear fashion.

* Phrasing of questions or simply expressions used may significantly affect public acceptance of nuclear information. For example, Melber and her colleagues (1977) found different acceptance levels between those expressing support for more nuclear energy vs. more nuclear power plants.

* The role of newspapers, particularly in communities near nuclear projects, seem to serve an important role in airing community disagreements over such developments. Awareness by those who are responsible for public communication of this for um and its importance should be a starting point for informing a community.

* The difficulties of scientists and technicians have in communicating directly with the public, and perhaps more importantly in a mutually satisfactory manner with reporters/editors, should be recognized early by those responsible for explaining nuclear projects. In-house editorial help in preparing materials would seem to be a useful step to take to lessen gaps and friction between. scientist sources and the ir audiences.

* The intent of much nuclear information in creating favorable responses among the public may work in ignorance of powerful institutional forces (family, community associations, government, etc.) which could restrict one's freedom to change. This suggests the rather obvious point that communication must consider the situation of the receiver. By speaking realistically to what one individual can do within imposed constraints, the effectiveness of the message may be enhanced.

* The likely circumstance that many polls create or suggest opinions for people to hold rather than measure the ones they have must be taken quite seriously by those investigating public attitudes and problems in coping with nuclear projects. Polls done in ignorance of this possibility may confuse public opinion with results that echo concerns of the sponsoring agency. 
* The use of "interpretive devices" such as parable and metaphore have utility in explaining complex technical material to non-experts.

* However, exisiting audiences for technical information have probably learned to cope with complex language and abstraction or have left this group. In this sense, advice geared towards improving readability may have little effect on existing audiences. The prime value would be in better accommodating the infrequent attender, the novice or non-expert as an addition to the audience. The costs of these efforts should be weighed in terms of likely audience gain. There is no evirience which suggests experts may be alienated by language suited for lay groups, but since the circumstance is untested, it may be a possibility.

* Because so much of the advice on communication of technology, whether the product of controlled observation or mere anecdote, derives from tests or experience of 1 imited generality, regular effectiveness testing of information programs is especially important. This may include tests of diffusion, understanding, source-receiver agreement, credibility and an ability to form conclusions based on information given.

* Finally, there is the obvious suggestion made in many studies that an open information policy by those developing nuclear power generally would work in their interests. Rumoring and "crisis" conmunication may result from growing public anxieties and vital information withheld for too long. The enduring animosities and distrust aroused in these circumstances probably far outweigh disclosure of short-term problems and inconvenience.

Recognition of "practical" advice and stratagems such as the above are at the heart of most successful advertising or public relations programs. But blind, prescriptive acceptance of this advice as "effective" and universally useful may contribute more to the failure than to the success of communication. It is wise to remember the slim, situationally constrained bases upon which much of this advice has been developed and tested. 
METHODOLOGY

Terms required careful definition, owing to the variation in useage they encounter not only in common parlance, but in the research literature as well. Each term comprising the subject matter of this study -- "Communication of Technology to Lay Audiences" -potentially encompasses a vast amount of material. Carefui definition of search terms and close attention to the quality of what machine retrieval brought forth was necessary to insure relevance and proper subjugation of materials to the purposes of the study. Our definitions and the procedures for abstracting are given in the following outline:

I. Definitions:

A. Technology:

a. Quantification common to the statement and explanation of relationships.

b. Concerned with applications of natural sciences, especially the applied fields which derive from them (e.g. engineering, applied physics).

c. Fairly high level of abstraction and tolerance of abstraction required for mastery. Explanations may be devoid of situational distinctions, the interplay of social variables.

d. Explanatory models typically show low rates of error. Social variables often are not considered owing to the complexities they impose on this orientation.

e. Specialized training (typically post-graduate) often necessary to proper understanding of data. Explanatory materials typically anticipate this skill level from the reader.

f. Effects of technology are often subtle; visible only via special instrumentation, testing and calculation, or over long periods of time.

B. Lay Audiences:

a. Non-expert, having little expertise with technology in question.

b. Not normally in contact with specialized, technical sources of information.

c. Generally do not have convenient, low cost access to expert advice for interpretation of complex isues of technolo- 
gY.

d. Have 1 imited time and attention to devote to information about technology; considerable competition from other source for leisure time.

e. Potentially affected by technological change, directly or indirectly.

f. Vulnerable to arguments not based on established scientific findings, but on speculation, rumor and unsubstantiated counter-claims.

g. Heterogenous: not necessarily part of readily confined and identifiable populations.

c. Communication:

a. Concerned with the adequacy of meaning transfer on technology and its effects.

b. Concerned with efficacy and adequacy of dissemination for various audiences within lay publics.

c. Concerned both with formal communication (documents, statements) and informal communication (rumor, discussion)

d. Concerned with checking and testing of communication quality on technology (readability, convenience ur access, distortion)

e. Concerned with situations in which communication about technology is most needed (crises, referenda, conflict resolution, legislation).

f. Concerned with mass and interpersonal channels and their comparative strengths and weaknesses.

g. Concerned with the attitudes and prejudices of protessional communicators (journalists, news cameramen, etc) towards portreyal of complex and controversial technology.

h. Concerned with stereotyping nf major technological issues among professional communicators and their audiences.

i. Concerned with the functioning of: communication systems; the interactive effects of many social and informational interdependencies converging upon complex, controversial technology. 
II. Guidel ines for Abstracting:

The length and detail supplied by abstracts varied according to the detail of the source article and its importance. In a few cases, with minor entries, a "short form" abstract was used which rarely exceeded 100 words. More typically, detailed abstracts vary from 300 to about 500 words in length. These provide sufficient detail for evaluation and noting limitations. The "NOTES" section of each abstract show the abstractors' evaluation of and unanswered questions about an article. Articles abstracted should generally provide enough basic information so that:

a. The conceptualization of the study is described. Its relationship to earlier or convergent studies is often identified and basic conceptual models used may be described

b. A basic methodology and data base are described to permit preliminary evaluations of the findings.

c. The principal findings are described, their qualifications and strengths. Have the researchers strayed from or strongly qualified their hypotheses? Are the hypotheses substantiated?

d. The conclusions; the inferences or inductions to be made based on findings. What generalizations or inferences are made; what recommendations made?

e. Abstractor's evaluation of study's adequacy on the above points. Reviewed are basic flaws and strong points; threats to internal and external validity and sample adequacy.?

The abstracts are divided into distinct sections, partly for reasons of machine processing, but, as well, to assist the reader. While we developed our own bibliographic software for this report, the format of entries is compatible with the FAMULUs bibliographic system. Further information on machine compatibility may be obtained by writing the authors. The sections are defined below:

a. Sequence Number (SEQ\#): This indicates the order of the citation as it is 1 isted in the annotated bibliography. These numbers are keyed to the index which appears at the end of this introductory section. Higher numbered references will appear toward the back of the bibliography. The fundamental ordering basis of this document is alphabetical, according to the primary author's last name.

b. Author (AUTH): Full citation of authors' names.

c. Title (TITL): Full title, both primary and secondary. 
d. Publisher (PUBL)

e. Date (DATE) of publication (volume, no., month, season-if citation is a periodical and season is normally indicated).

f. Key (KEY): The key is used primarily for machine sorting and random access file formation. The key is composed of the first four letters of the primary author's last name, the last two digits of the year of publication and, if two or more works by the same author are listed for a given year, they are sequenced: $a, b, c$, etc. For example: Kearl, B. and Powers, R.D., "Estimating Understanding of Scientific Terms", Journalism Quarterly. 38, 2:221-23, Spr 1961 would translate into the following key: kear6la.

f. Search Terms (SRCH): terms which are central descriptors of the article's contents are indicated under this category. These terlls form llue basis of index construction and key word retrieval.

9. Abstract (ABST): Abstracts average 250-300 words. Exceptionally informative articles were given increased attention. Bad quality did not necessarily exclude an article from consideration if there were redeeming portions or a particularly important situation was covered, however poor articles did receive briefer treatment.

h. Notes (NOTE): any additional information the abstractor deemed important about the article which didn't fit well in the above categories was included here. Especially useful are abstractors comments which may serve as a guide to the quality and applicability of the research. 


\section{INDEX}

attitude-change $43,110,113,133,144$

attitudes-ecology 69

attitudes-energy $8,14,23,90 \mathrm{~A}, 93$

attitudes-environmental 3, 4, 33, 83, 90A, 103, 112, 134, 138, 139,156

attitudes-nuclear $57,71,90 \mathrm{~A}, 143,144$

attitudes-political/environmental 12

attitudes-pollution $10,46,70,90 \mathrm{~A}$

attitudes-technology 56,72 ,

audiences $23,37,44,52,53,54,96,114,129,146$

communication effectiveness $5,60,98,122,137,146$,

communication systems $82,88,121,139,148$,

community $7,14,38,40,42,43,46,51,57,64,70,113,134$, $138,142,150,151$

conflict $11,12,13,24,31,42,44,62,65,75,94,141,150,163$ conservation problem solving 155

conservation $8,83,136$

content analysis $26,44,64,97,108,153$

cost-effectiveness 18,83

decision-making $57,62,92,106,137,139$

diffusion $16,17,22,38,48,51,68,79,80,81,107,115,118$, $120,131,159,163$

dissemination $6,7,18,43,63,64,81,82,87,89,105,113,133$, $137,146,150,151,158,161$

electricity $8,36,46,105,106$

environmental education 4,121 ,

environmental knowledge utilities 57

environmental knowledge $33,85,112$

environmental movement $11,24,69,90 \mathrm{~A}$

heterophily-homophily 5 ,

information processing $4,21,29,30,84,90,99,130,152$

information services $2,25,74,86,88,161$

information sources $2,20,80,82,86,137,148,154,157,159$

innovation(s) $16,22,38,48,49,51,68,79,80,107,120,163$

interest groups $10,11,18,24,25,47,57,69,83,93,95,105$, $114,134,151$

interpersonal communication $14,64 \mathrm{~A}$

1 and use $18,36,46,47,55,71,106,113,128,142,143,144$

local media 14

magazines $96,97,154$

mass media methodology 21

mass media 23, 35, 42, 43, 47, 64, 89, 96, 97, 131, 135, 146, 150, 154,161

médià use 129

methodology land use 92

methodology pollution 38

me thodology $9,26,27,28,34,36,51,61,62,66,71,77,83,85$, $87,89,91,127,147,152,153,157$

national surveys $1,119,129,154$

newspapers $15,35,37,135,145,148,154$ 
nuclear energy 53

nuclear site selection 108

nuclear waste 71,144

nuclear $11,47,113,128,144$

pollution $10,40,69,70$

power plants $47,90 \mathrm{~A}, 113,128,144$

problem solving $31,65,96,105,111,139$

psychological distance 13

public opinion polls 76, 90A, 127

public opinion $1,14,23,39,45,50,55,64,71,76,90 \mathrm{~A}, 114$, 119,143

public participation $18,47,106,125$

public policy $14,47,49,127,134$

public relations $36,122,137$

public 18, 23, 36, 50, 52, 53, 54, 72, 88, 102, 113, 114, 119, $129,133,143$

publics 12,138

radio 143

readability $26,27,28,52,61,67,77,84,99,100,109,130$, $147,152,153,162$

review-advertising communications 62

review-communication feedback 120

review-communication models and concepts 161

review-conflict $12,65,94,141$

review-conservation communications 157

review-decision-making 84

review-diffusion $16,79,118,156$

review-dissemination 34,61

review-environmental attitudes $4,90 \mathrm{~A}$

review-environmental communications 162

review-environmental perceptions 139

review-environmental public relations research 159

review-innovation 153

review-methodological environmental 139

review-public opinion methodology 50

review-public opinion polls 51, 90A

review-reading behavior 67,91

review-reading comprehension 74

review-risk/benefit 122

review-science communication 146

review-verbal learning 95

risk 9, 92, 111

science coveragc $35,64,64 \mathrm{~A}, 97,114,122,135,148$

science writing $15,20,35,37,52,53,54,66,74,97,108,114$, $135,145,146,148,162$

scientists' peer networks $64 \mathrm{~A}$

site selection $18,36,47,55,90 \mathrm{~A}, 102,105,106,113,128,142$, 144

television $6,47,131,150,154$

textual variables $52,130,162$

understanding $52,66,114,136$ 


$$
-35-
$$

utilities $8,36,113,144$

values $30,36,39,50,51,102,119,151,155$ 
NOTES

These notes correspond to references made in the literature review chapters which are not contained in the annotated bibliography

Bultena, G.; Rogers, D.; Webb, V., "Public Response to Planned Environmental Change: A Study of Citizens Views and Actions on the Proposed Ames Reservior," Sociology Report 106, Iowa State University: Ames, Iowa, 1973

Chambliss, D.: Walsh, D.J., "Working with the Environmental Press," PUBLIC RELATIONS JOURNAL, 29. pp.22-24.1973

Corris, J.J., "Come Fly with Me," puBtic RELAtions JOURNAL, 27. pp22-26 1971

Festinger, L., A THEORY OF COGNITIVE DISSOANCE, Evanston, I11.: Row, Peterson, 1957

Festinger, L., "Behavioral Suppport for Opinion Change," PUBLIC OPINION QUARTERLY, 28. pP.404-4171964

Groot, H.C., "Coorientation in Agricultural Development: The Interrelationship Between Farmers, Change Agents and Scientists," Paper presented to AEJ: Washington, D.C., 1970

Grunig, J.E., "Communication in Community Decisions on rroblems of the POÜ.," JOURNAL OF COMMUNICÁl'IUN, 22 . pp. $5-251972$

Grunig, J.E., "Communication Behaviors Occur ing in Decision and Nondecision Situations," JOURNALISM QUARTERLY, 53. pp. 252-2631976

Grunig, J.E., Personal communication with authors regarding forthcoming publication, 1977

Hovland, C.I., Lumsdaine, A.A.; sheffield, F.D., EXPERI= MENTS ON MASS COMMUNICATIONS, Princeton: Princeton University Press, 1949

King, K., "Crisis of Concern: Air and Water Pollution," PUBLIC RELATIONS JOURNAL, 23. pp.12-14 1967

Moore, R.L., "Enviroṇment--A New PR Crisis", PUBLIC RELATIONS JOURNAL, 26. Pp.6-9 1970 
Paluszek, J., "The Eco Organizations: They are Legion," PUBLIC RELATIONS JOURNAL, 29.'pp.25-27 1973

Rogers, Everett. M. and Floyd shoemaker COMMUNICATION OF INNOVATIONS, New York: Free Press, 1970.

Stamm, K.R., "Strategies for Evaluating Public Relations", PUBLIC RELATIONS REVIEW, 3. pp. 120-129 1977

Weichmann, R., "Pollution Control: The Role of Communication in Ecology," MANAGEMENT REVIEW, 60. pp.43-45 1971

Weil, A.W., "The Role of PR in Environmental Action," PUBLIC RELATIONS JOURNAL, 26. p.10-141970

Yovanovich; J.J., "The Controversy Over Energy," PUBLIC RELATIONS JOURNAL, 30. Pp.20-22 1974 


\title{
ANNOTATED BIBLIOGRAPHY
}

\begin{abstract}
SEQ\# 1
AUTH not indicated by ERIC

TITL Public Opinion and the Environment

PUBL Nature study

DATE 28. 2:7-12 1974

KEY ????74a

SRCH national surveys, public opinion

ABST According to a public opinion survey conducted by the president's council on Environmental Quality, environmental isssues remain very important in the minds of the public and the energy crisis appears to have had little effect on public opinion. A summary of the results of each topic polled is included.

SEQ
AUTH
TITL
PUBL
DATE
KEY
SRCH
ABST

2

not ind icated

Much Ado About Decision Making

Environmental science and Technology

9. 5:404-05 may 1975

????75a

SRCH information sources, information services, cost effectiveness

ABST A National Academy of Sciences study for the Environmental Protection agency will provide insights into the accquistion and utilization of scientific and technical information for making environmental regulatory decisions. The output of EPA's decision making process will be analyzed through a series of case studies.

NOTE This apppears to be about proposed research.

\section{SEQ\# 3}

AUTH not indicated

TITL National Wildife Readers Rank the Top Ten Environmental Issues

PUBL National wildife

DATE 15, 3:35 Apr/May 1977

KEY ????77a

SRCH attitudes-environment

ABST In a study conducted the National wildlife Federation in the fall of 1976, readers were asked to rank ten key environmental issues in order of their importance. Fighting water pollution was regarded as the top overall priority, but encouraging population control received the most first place votes.

NOTE Data produced, reader ship sample.
\end{abstract}

SEQ\# 4

AUTH Abrams, S.G.; Zuber, B.L.

TITL Some Temporal Characteristics of Information processing Dur.ing Reading

(The following sequence numbers are not used in this report: $19,41,58,73,78,116,117,123,124,126$, $140,149,1611$ 
PUBL Reading Research Quarterly

DATE 8. $1: 40-511972$

KEY

SRCH

abra72a

ABST

information processing

Eye movements during reading consist of a series of pauses (fixations) separated by saccadic eye movements which move the eye along the line. Characteristics of eye movement patterns recorded during reading are examined in an attempt to separate those characteristics attributable strictly to oculmotor functions from those attributable to the processing of text information during reading. When primarily eye movement, or position information, is processed, the eye pauses in the text for a significantly shorter time than when both text and position information are processed

NOTE Data produced, reading processes.

SEQ\# 5

AUTH Alpert, M.I.; Anderson, W.T.

TITL Optimal Heterophily and Communication Effectiveness: Some Empirical Findings

PUBL Journal of Communication

DATE 23. 3:328-43 sep 1973

KEY alpe73a

SRCH heterophily-homophily, communication effectiveness

ABST A fundamental principle of human communication is that source-receiver similarity promotes communication effectiveness: But do perceived source-receiver dissimilarities have instrumental value in enhancing the effectiveness of communication? This study demonstrates the application of a method for gauging the relationship between heterophily or sourcereceiver similarity and communication effectiveness and for identifying relevant dimensions of homophily-heterophily in achieving effective rommunication. 192 subjecte vicwcd 3 slides of widely-differing college males, to whom 3 prescaled neutral statements were randomly attributed. Measures were obtained of subjects ratings of themselves and these "sources" along 21 personal attributes, as well as their aqreement (or disagreement), with the attributcd atatements. Perceived source-receiver distances varied across the three sources, as did the agreement measure of communication effectiveness. The moderately-distant source achieved the highest agreement, lending support to E.M. Roger's notion that optimal heterophily produces commumication effectiveness. The pattern and directions of the perceived dimensions of interpersonal differences gave further understanding of the relative communication effectiveness of communication sources.

SEQ\# 6

AUTH Alper, S.W. and Reidy, T.R.

TITL The Impact of Information Transmission Through Television

PUBL Public Opinion Quarterly 
KEY alper69-70a

SRCH attitude-change, dissemination, television

ABST Information need not lead to attitude change, but attitude change is improbable without any input of information. In this study of the effects of one of CBS-TVs "audience participation" series, the authors document changes in knowledge, changes in attitude, and persistnece of both these changes, six months after exposure to the original program. The data collection procedure was a four-page, 51 item quesitonnaire administered in the field measuring knowledge of constitutional rights and obligations and attitudes towards these rights and obligations. The items were classified as either experimental (questions involving laws and attitudes discussed in the TV program) or control (questions involving laws and attitudes not discussed in the TV program). It was administered to $5400 \mathrm{high}$ school students one month before the broadcast and to 11,000 high school students one week after the broadcast: 1505 of the 11,000 students had viewed the program and so these students were matched with 1505 nonviewers and 1505 pretest takers. Results showed no significant differences among the three groups on control knowledge or control attitude items. However the viewers scored significantly higher on the experimental knowledge questions and expressed more agreement on the experimental attitude questions. Six months after presentation, the effects of the televison program had dissipated but had not disappeared.

NOTE Data produced, field experiment with high school students who had or had not viewed a.TV broadcast on law. Study measured effectiveness and persistence of information presented. on televison. Knowledge, attitudes.

SEQ\# 7

AUTH Anderson, W.A.

TITL Disaster Warning and Communication processes in Two Communities

PUBL Journal of Communication

DATE 19. 3:92-104 jun 1969

KEY ande69a

SRCH

ABST

community, dissemination

This paper is based on a study of disaster warning in the communities of Crescent City, California and Hilo, Hawai, both of which have had a history of tsunami threats and warnings. Disaster warning is viewed in the paper as a process consisting of a number of interrelated activities and procedures in which a variety of organizations and individuals become involved. The study indicates that local officials such as those in Crescent City and Hilo are responsible for evaluating incoming information concerning potentially disruptive environmental changes and for determining if a public warning is to be issued. Among the problems that local offi- 
cials may face while attempting to meet such responsibilities is the lack of adequate information on which to base critical decsions aand the difficulty of maintaining public willingness to comply with requests for evacuation when there have been repeated alerts not followed by disaster. Although both the communities in the study have undergone major tsunami disasters, the data show that this has been followed by significant change and improvement in warning procedures chiefly in Hilo. For example, evacuation areas have been predetermined in Hilo and a variety of mechanisms for transmitting tsunami warning signals and information to the public have been devised. These changes came about largely because local officials in Hilo received considerable feedback from scientific experts and others regarding the kinds of improvements needed in the community's warning system. Such a fepdhark process did not develop in crescent city follnwing the major tcunami disaster in that community and thus less change occurred in i.ts warning prooedures.

SEQ\# 8

AUTH

Ayers, J.B.

TITL

Rural Elementary Children's Attitudes Toward the Energy Crisis

PUBL School Science and Mathematics

DATE 76. 3:238-40 mar 1976

KEY ayer $76 a$

SRCH electricity, utilities, conservation, attitudes-energy

ABST Reports on the results of a survey of the attitudes of rural fith - seventh grade students toward the energy crisis. Among results, it was found that children at this age level appeared to understand some of the problems and implications of electricity generation from fossil and nuclear fuele, and that overall, older children and females were more cautious in their views concerning the generation of electricity.

NOTE Data produced, survey. Sample = ruraljunior high students.

$\begin{array}{ll}\text { SEQ\# } & 9 \\ \text { AUTH } & \text { Baldewicz, W.; Haddock, G.; Lee, Y.; Prajoto, ; Whitely, R.; } \\ & \text { Denny, V. } \\ \text { TITL Historical Perspectives on Risk for Large-scale Technological } \\ \text { PUstems } \\ \text { PUBL Battelle Institute }\end{array}$

DATE NOV 1974

KEY bald74a

SRCH methodology, risk

ABST An empirical study of historical trends in the risks sustained by participating populations for various large-scale technological systems is presented. Results are reported for three system categorizations: Natural Hazards (floods, torna- 
dos, and lightning), Man-Made Hazards (commerical aviation, rail transportation and rail grade crossings, and Occupational Hazards (fire fighting, steel working, coal mining and railroading). A new model for $r$ isk assessment is introduced which avoids the problems associated with assessing the value of a human life in $r$ isk-benefit decision making. Essentially, the model treats $r$ isk in terms of loss of life expectancy (the sum of the differences between the victim's ages and their expected "normal" Iife expectancy) divided by the total number or exposure hours to the risk. For nonfatal insults (e.g. injury, illness, property damage) calculational procedures are suggested and typical results are given in the case of property damage. In addition, a methodology is presented for dealing with deferred risk, and illustrative calculations are reported for coal workers. pneumoconiosis. values of the average lost years of 1 ife expectancy per fatality, are found to range from a low of 24 (rail passengers) to a high of 43.6 (lightning victims) for the ten risk systems studied, and are found to be essentially invariant over the past two decades. From historical trends in the rate of losss of life expectancy for the risk systems studied, it is concluded that (i) appreciable disparities exist in the rate of loss of life expectancy for occupational hazards, despite nearly similar benefits for the populations at risk, (ii) federal legislation can have a significant impact on $r$ isk abatement, as has apparently been the case for coal mining, (iii) federal safety legislation efforts appear to be most responsive to highly publicized disastrous accidents $r$ ather than to chronic, low level hazards (both accidents and disease) which actually contribute more significantly to the rate of loss of life expectancy, (iv) the introduction of a new technology (as in commerical aviation, 1956-60), as well as lack of maintenance of old technology, (as in rail transportation) can result in risk level increases, and (v) natural hazard risk levels are extremely low and can further be reduced in some cases, either by collective or individual precautionary measures.

NOTE Data produced, historical analysis of the rate of loss of life expectancy for various $r$ isk systems. The life expectancy measure of $r$ isk may $r$ un into the same problems as the \# of human lives measure in that: a) a value the lost years for a particular individual or group, b) both these measures treat risk something incremental (increased-decreased probabilities) rather than as present vs not present--that is, probabilities offer little help for the individual case, and c) the probalities used as a basis for estimating the risk of a nuclear site must be renderend pertinent to the object-event to which these risks are attributed--example; other studies have had respondents estimate how much "risk" they would to- 
lerate in terms of the \# of years of life expectancy lost -again a concept of little use in the individual case) that might be lost. In this form the estimate is of little revelance to actual loss of $l$ ife possibilities; such as the nuclear isssue where the crucial concern is more focused on the MAGNITUDE of loss (potentially thousands from a major nuclear accident rather than the average per year, or the probability of its shortening ones life over the long $r$ un.

\begin{abstract}
SEQ\# 10
AUTH Barker, M.1.

TITl Information and Complexity: The Conceptualisation of Air Pollution by Specialist Groups

PUBL Environment and Behavior

DATE 6. 3:346-77 sep 1974

KEY bark74a

SRCH attitudes-pollution, pollution, interest groups

ABST Much environmental policy is determined by professionals involved in a single problem area. Described is a study of the differences between individuals of five professions with respect to their cognitive structure of environmental thinking and their ability to integrate a number of complex concepts while maintaining a flexible attitude.
\end{abstract}

SEQ\# 11

AUTH Bass, B., Bass, R. \& Shapiro, Z.

TITL Environmentalists' and Business Executives' Attitudes and 'Information about the Nuclear Power Controversy

PUBL The International Journal of Environmental studies

DATE 10 January 1977 pp. 79-83

KEY bass77a

SRCH interest groups, environmental movement, attitudes- nuclear, conflict, nuclear, environmental knowledge, utilities

ABST The study examines the attitudes and information possessed by two groups of people - environmentalists and business executives. It concerns their attitudes toward and knowledge of the issues of building nuclear power plants. To examine the ir attitudes and information, 38 environmentalists and 64 husinéss executives completed a 24 item questionnaire (consisting of 12 attitudinal and 12 informational items). The differences between environmentalists and executives were distinct and significantly different on all 12 attitudinal items. While environmentalists were very unfavorable toward the construction of nuclear plants, business executives tended to be neutral on this issue. Executives tended to accept the intervention of concerned citizen groups and reject the idea that utility companies have no responsibility to provide information to concerned citizens. On almost every item, environmentalists were considerably more informed than the executives, although both groups were ignorant about specifics of 
licensing, criticality and capacity. After minor revisions, an attitudinal and informational questionnaire was administered to 49 college seniors in business administration. Here, there were strong similarities to the responses of the business executives: Of possible interest: the researchers could predict quite well (multiple correlation .60) how favorably disposed a student was toward nuclear power from just two pieces of information about him: A student was more favorable toward nuclear power the less he stated that he kept up with the news and the higher he scored on a short scale of assertion or social boldness.

NOTE Data produced, survey. Samples $=38$ environmentalists, 64 business executives, 49 college seniors No sampling technique specified.

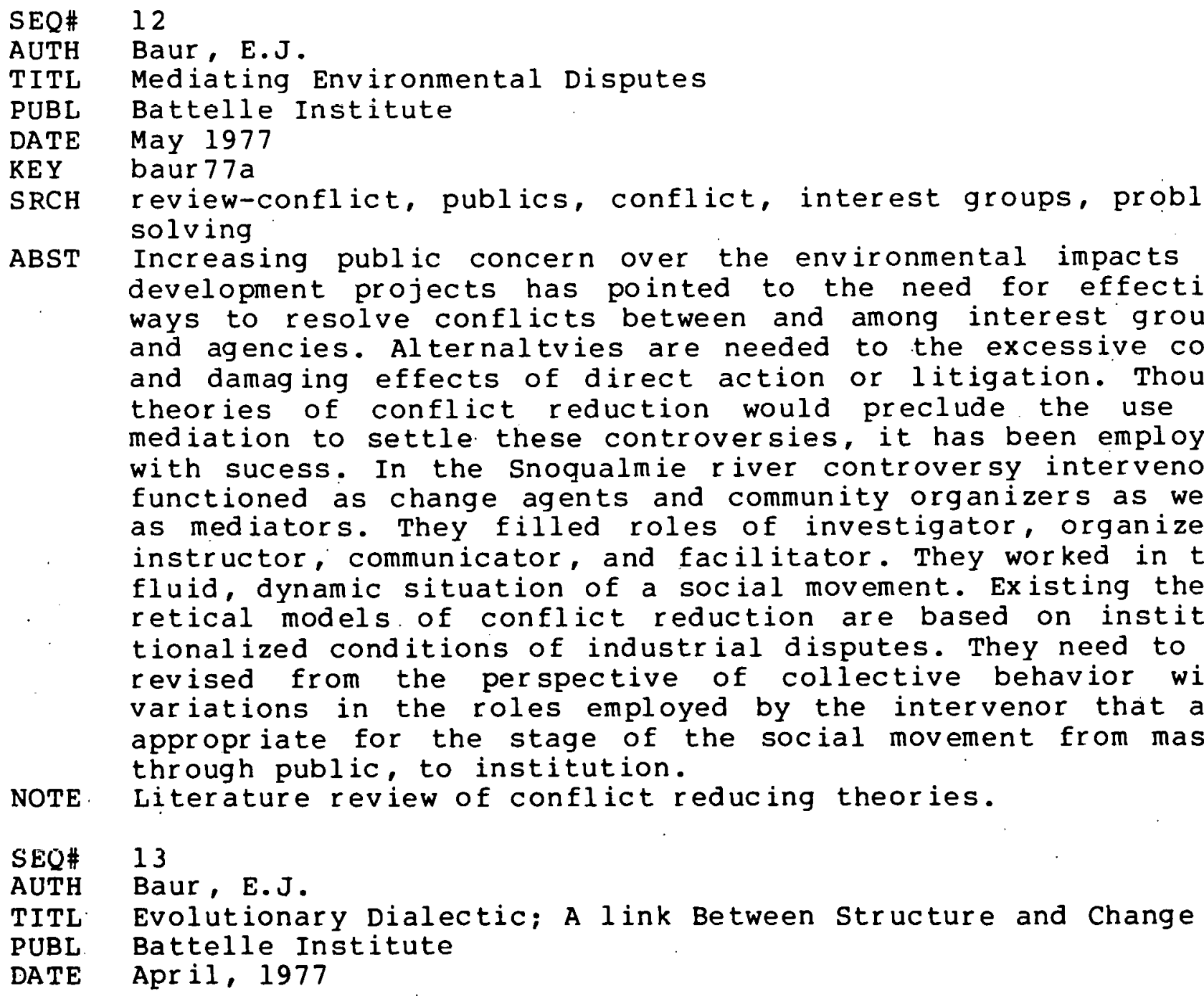


$\mathrm{SRCH}$

ABST

NOTE

SEQ\#

AUTH

TITL

PUBL

DATE

KEY

$\mathrm{SRCH}$

ABST

\section{KEY baur 77b}

conflict

Mechanisms of social evolution are inadequately conceptualized. One way that societies become more complex is a consequence of conflict reduction. Of three paradigms of evolution, cultural, dialectical, and functional, the latter two emphasize the importance of conflict or stress and mechanisms for their regulation, but fail to explain how the mechanisms increase complexity. In the individualistic phase, individual efforts are ineffective in reducting tensions generated by competition and rivalry. In the associational phase individuals having like interests untie to reduce friction among themselves and oppose others having incompatable interests. Their common objectives are implemented through new norms, offices, and institutions. In the collaborative phase, orqanized. antagonists neqoiate agreements to reduce conflict. procedures and agencies for dispute settlement are created. These steps bccome possible when antagonists realize their dependence on one another, and the intensity of conflict forces them to entertain innovative proposals. Negotiation is often facilitated by intervention through mediation, arbitration, adjudication or legislation. Agreement may be reached by compromise or through an innovative solution out of which new agencies of integration become establ ished.

Discussion of mechanisms and conditions of social evolution.

14

Blakely, E.

Enerqy, Public Opinion and Public Policy - A Survey of Urban, Suburban, and Rural Communities

California Aqriculture

$30 \quad 8: 4-5$ pp. 4-5 August 1976

blak76a

attitudes-energy, public policy, community, public opinion In this study three groups of California residents living in the Sacramento valley were polled in the spring of 1975 to determine whether place of residence (urban, suburban, rural) affected: attitudes about the causes and potential consequences of the energy crisis; energy- related community behavior and lifestyles; and preferred alternatives for public policy on energy. A fourteen page questionnaire covering citizen attitudes over a wide range of energy-related areas was mailed to 800 randomly selected people in metropolitan sacramento, 600 in the town of winters and 200 in rural Capay valley. The return rate of the questionnaire was 62.58 . The results revealed that respondents, regardless of residence or income levels, held relatively similar opinions on the energy crisis and its overall consequences for themselves and the nation. There was little difference among metropolitan, 
small-city and rural respondents on four principal issues: cause of the energy crisis; potential duration of the crisis; capacity of public official and institutions to respond to the crisis; and preferred alternatives to resolve the energy crisis.

NOTE

Data produced, survey. Sample $=800$ metropolitan residents, 600 town residents, 200 rural residents, sampling technique: $r$ andom. The article is sketchy, filling only two pages.

SEQ\# 15

AUTH Blankenburg, W.B.

TITL News Accuracy: Some Findings on the Meaning of Errors

PUBL Journal of Communication

DATE 20. 4:375-86 dec 1970

KEY blan7øa

SRCH science writing, newspapers

ABST More than 300 local news stories from 2 West coast dailies were reviewed for accuracy by the persons who had been reported on. Accuracy rates in this study generally replicate those found previously. The closer the aquaintanceship also appears to ameliorate the impact of errors on the newsmaker. so-called subjective and objective errors do not appear to be distinguishable by their seriousness.

NOTE Data produced, accuracy analysis by source of story. Sample = news stories from 2 dailies.

SEQ\# 16

AUTH Bordenave, J.D.

TITL Communication of Agricultural Innovations in Latin America PUBL Communication Research

DATE 3. 2:135-54 apr 1976

KEY bord76a

SRCH review-diffusion, diffusion, innovation

ABST This article reviews the eras in the development of communication as a discipline in Latin America, and then concentrates on the recent period when agricultrual diffusion became the most frequent type of communication research. The author is critical of diffusion research in Latin America because of its too-close copying of the "made-in-the-USA" classical diffusion model. The theoretical approach of Paulo Freire's "conscientization" is recommended as one corrective influence on the diffusion model in Latin America and elsewhere.

SEQ\# 17

AUTH Bose, A.B.; Saxena, P.C.

TITL Opinion Leaders in a Village in Western Rajasthan

PUBL Man in India

DATE 46. Pp.121-301966 
SRCH

ABST

SEO\#

AUTH

TITL

PUBL

DATE

KEY

SRCH

ABST

KEY bose66a

diffusion

From statistical data, the following conclusions are drawn: 1) there is centralization of leadership in farm matters; 2) all opinion leaders do not participate equally in the multiple steps through which communication flows; 3 ) informal interpersonal communication is more important among other farmers than opinion leaders; 4) not all opinion leaders are innovators; 5) almost all information-seeking relationships are directed towards innovators; 6) opinion leaders are more modernizing, better off and more literate; and 7) very little overlapping exists between leadership in farm matters and in non-agricultural spheres.

\section{8}

Bowes, J.E.; Stamm, K.R. Development Priorities in the West River Region, North Dakota A Social Attitude and Communication Analysis

Communication Research Centers, University of North Dakota \& University of washington

October 1974 1-146 pp.

bowe 74 a

public, public participation, site selection, dissemination, interest groups, land use

The major purpose of this study is to assess communication about and public understanding of development of the west River Region, North Dakota. To assess these concerns, the researchers surveyed three groups of individuals involved in the development of the West River Region - 310 residents of the area, 40 community leaders and 94 development agency personnel. The residents and community leaders were selected randomly in a stratified fashion, based on $r$ ural/incorporated residences and community populations, respectively. The development agency personnel comprised all supervisory personnel working in state and field offices. The questions asked of each group focus on eight major areas, including knowledge and evaluation of the project, priorities and their evaluation for regional development, and communication between citizens and agencies. Several findings of this study are: 508 of the general sample was aware of the project (thus, publicity about the project needs to be directed at the general public as well as agency staffs); priorities assigned to solving problems varied somewhat between groups (these discrepancies may suggest future problems in unifying community effort to deal with these problems); and community leaders generally are ineffective information brokers between the public and agencies. Using a communication based approach, the authors attempt to provide a conceptually sound predictive base for estimating public understanding and satisfaction with the outcomes of development of the West River Re- 
NOTE Data Produced, survey. Sample = 310 area residents, 40 community leaders, 94 development agency personnel stratified sampling techniques.

SEQ\# 20

AUTH Broberg, K.

TITL Scientist's Stopping Behavior As Indicator of Writer's Skill

PUBL Journalism Quarterly

DATE 50.4:763-67 win 1973

KEY brob73a

SRCH science writing, information sources, mass media, methodology

ABST This study explored for factors that lead to message accuracy in news stories about scientific research. A variation of Carter's Signal stopping Technique was used. Scientists were asked to correct/edit press relèses written by reporters about that scientist's research. Each change made by the scientists on the press release was considered to effectively indicate where scientists wished to stop, and their reason for stopping. The changes made by scientists were grouped into 6 categories; 1) additions 2) deletions 3) corrections (grammer,titles, disease descriptions, terminology changes) 4) single word changes 5) revisions, reorganizations 6) no changes. Changes for each category were calculated on a $1 / 2$ page unit basis. The total number of changes per unit constituted the "score" for the author of that press release. Writers were grouped into 2 categories; a) accurate writers (high scorers) b) inaccurate writers (low scorers) and comparisons made between them. Additions constituted the dominent category of changes introduced by the scientists, accounting for about 508 of the changes made for both accurate and inaccurate writers. It was also also found that scientists changed more technical terms to lay terms than the reverse. Inaccurate writers were found to add more superflous material (more deletions, except for applications and extentions of the research), did not distinguish fine shades of meaning in some words (more word changes) and did not organize the material as well (more revisions) when compared to accurate writers. Accuracy as used in this study is relative to the scientist's point of view and not based on any specified objective measure.

NOTE Data produced, content analysis of signal stops in press releases.

$S E Q \# \quad 21$

AUTH Brooks, L.R.

TITL The Suppression of Visualization by Reading

PUBL Quarterly Journal of Experimental Psychology 
KEY

DATE $19.4: 289-991967$

SRCH information processing.

ABST Demonstrates a conflict between reading verbal messages and imagining the spatial relations described by them. Listening to the same messages did not produce comparable interference with visualization. The conflict between reading and visualizing was obtained even when the subjects previously had seen the referent of the message. In contrast, when the subject was induced to treat the messages as rote strings of words instead of visualizing their referents, reading was a more effective means of presentation than was 1 istening. Two interpretations of the results are proposed: 1) visualization and reading compete for the use of neural pathways specialized for visual perception and 2) the prosess nf reading hinders the conversion of input material into any nonverbal form, i.e. reading forces the subject to deal with information in a morc exclusively verbal form than does 1 istening. This method, nevertheless provides a means of investigating the internal processes underlying concrete verbal references.

$S E Q \#$

AUTH

TITL

PUBL

DATE

KEY

SRCH

ABST

NOTE

SEQ\#

AUTH

\section{2}

Brown, L.A.; Malecki, E.J.; Spector, A.N.

Adopter Categories in a Spatial Context: Alternative Explanations for an Empirical Regularity

Rural Sociology

41. 1:99-118 spr 1976

brow $76 a$

diffusion, innovation

Previous research on adopter categories has found several relationships between time of adoption and various social, economic, and demographic characteristics of the adopters of innovations. This paper extends the focus to include the spatial dimension in the context of two appproaches to explaining innnovation diffusion. The communications approach emphasizes information flows, whereas the market and infrastructure approach stresses the availability of the innovation to potential adopters. The study produces two major findings: 1) that locational characteristics are an important aspect of both explanations and therefore should be considered along with the traditional set of variables in describing adopter categories; 2) that the conceptual model associated with adopter categories should be broadened to reflect. marketing strategy characteristics as well as innovativeness characteristics.

Data produced, relation between location and adoption of innovations.

23

Brunner J.A.; Bennett, G.F. 
TITL Coping with the Energy Shortage: Perceptions and Attitudes of Metropolitan Consumers

PUBL Journal of Enviornmental Systems

DATE $6.3: 253-68 \quad 1976-77$

KEY brun $7677 a$

SRCH mass media, public opinion, attitudes-energy, public, audiences

ABST The energy shortage in the United States became a crisis with the imposition of an embargo on oil shipments by OPEC. A survey of six hundred residents of a metropolitan area was made in 1974 and again in 1976. The data have been analyzed and illustrate differences between concerned and unconcerned citizens and to show how time has affected perceptions of both groups. Although exposed to extensive media converage of the energy problem and its related developments, there was no significant change in the attitudes of the population in the time period involved--about 658 agreed or strongly agreed, in both surveys there was a problem. Many of the respondents indicated they had changed their life style to reduce energy consumption, but significant differences were indicated between 1974 and 1975. As time lenghtened from the severe crisis period, people conserved less; much of the conservation was tied to economic factors rather than an energy ethic.

NOTE Data produced, energy $c r$ isis attitudes. Sample $=600$ SMSA residents.

\section{SEQ\# 24}

AUTH Buttel1, H.

TITL The Environmental Movement: Consensus, Conflict, and Change

PUBL

DATE

KEY

Journal of Enviornmental Education

7. 1:53-63 1975

SRCH environmental movement, interest groups, conflict

ABST

NOTE This study examined the social bases of support for the environmental movement in wisconsin between 1968 and 1972. Initially the movement had wide public support in the social structure. The counter-movement emerged comprised of groups dependent on industrial, resource-exploiting jobs. support reverted again to upper-middle class non-resource exploitive workers.

Data produced, state survey. Sample (appears to be of the general wis. population).

SEQ\# 25

AUTH Caplan, N.; Barton, E.

TITL Social Indicators 1973: A study of the Relationship between the Power of Information and Utilization by Federal Executives

PUBL Institute for Social Research, University of Michigan

DATE September 1976 1-43 pp. 
SRCH

ABST

NOTE

SEQ\#

AUTH

TITL

PUBL

DATE

KEY

SRCH

ABST

KEY capl76a

information services, interest groups

The main purpose of this study was to assess the use of "Social Indicators 1973" (SI '73) in policy-related decisions among upper level federal executives. To examine the use of SI 173, the researchers attempted to interview 270 uppper level federal executives by mail questionnaires and/or personal,in-depth interviews. Questions covered such areas as: the number of respondents who were aware of and had used SI 173; the ways in which they had become aware of SI 173; estipates of ehe potential utility of SIf'73 in i c policy areas; and whether utilization of SI 173 had stimulated other agency activities. Although there was a response Iate uf only 438, the researchers came to several findings. Only 48 of the respondents reported that they had actually used SI '73, and of these 48 most reported using it as background reference to help prepare speeches. Only 228 of them were even aware of the existence of SI 173. Its potential usefulness was viewed mainly in terms of supplying data for report writing and offering justification for policy decisions. SI 173 offered little or no basis for policy making. The researchers found two main reasons for the failure of SI 173 - 1) organizational and bureaucratic factors impinged on the utilization process 2) there was a perceived lack of power of information in SI 73. In regard to the latter finding, the researchers write, "the non-impact of SI. 73 demonstrates that information without specified relatedness to a shared set of goal commitments lacks policy-shaping power because the data are not seen as relevant to the needs of policy makers."

Data produced, survey. Sample $=270$ upper level federal executives.

\section{6}

Carter, R.P.

Evidence for the Invalidity of the Miller-Coleman Readability Scale

Journal of Reading Behavior

4. $3: 42-47$ sum 1971-72

cart $7172 a$

content analysis, methodology, readability

It was hypothesized that readability as indicated by the Miller-Coleman scaled paraqraphs would be related to the reading rate for the paragraphs. An almost 1 inear relationship was found between reading rate and readability for the paragraphs. However, when reading rates for each or the 150 word paragraphs were controlled for the physical lenght of the words, all paragraphs were read at approximately the same rate except for the most difficult paragraph. These results were interpreted as suggesting that the paragraphs can be validiy represented as a scale of difficluty but not as a 
scale of readability

NOTE Data produced, experiment testing a readability instrument.

SEQ\#

AUTH

TITL

PUBL

DATE

KEY

$\mathrm{SRCH}$

ABST

SEQ\#

AUTH

TITL

PUBL

DATE

KEY

$\mathrm{SRCH}$

ABST

27

Carver, R.P.

A Computer Model of Reading and Its Implications for Measurement and Research

Reading Research Quarterly

6. 4:449-71 sum 1971

carv7la

methodology, readability

Reading is a complex thought process and the information processing approach to reading offers great potential. The computer-model of reading invloves an analogy between each of the following: a) computer and the individual, b) input data for the computer and printed verbal material, c) a computer program and the steps executed by an individual when reading, and d) computer running time and the time that an individual engages in reading. The reading-program on an individual was analyzed into two components, reading-input and reading storage. Reading-storage involves an "understanding" of the material. There is no output component of a reading-program and this has implication for research and measurement which focus upon reading behavior. The computer model also has implications for reading development and instruction. The model has stimulated two new measures which seem to offer potential for investigating reading input and reading-storage.

\section{8}

Carver, R.C.

Measuring Prose Difficulty Using the Rauding Scale

Reading Research Quarterly

11. $4: 660-851976$

carv76a

readability, methodology

A new technique for estimating the difficulty of reading material has been developed and evaluated. The technique, called the Rauding scale, invloves the subjective ratings of qualified experts who use a set of anchor rating passages at grade levels $2,5,8,11,14$, and 17 . The reliability of the scale was high, $r=.97$; and the expected $r a t i n g$ error is only about 1 grade. With respect to validity, this scale correlated higher with the actual grade levels of passages that were used in school than did cloze, Flesch, Dale-Chall, and 3 other readability formulas. Passages sampled from basal reading materials, newspapers, curriculum materials, and graduate school materials suggest that the scale provides valid grade level scores throughout the entire school range (grades 1 through 18). It was concluded that the Rauding Scale is more 
reliable and valid than other readability measurement techniques because it is more sensitive to the idea or concept difficulty of a passage.

NOTE Data produced, comparison of several readability instruments in terms of reliability and validity.

\begin{abstract}
SEQ\# . 29
AUTH Carver, R.P.

TITL Toward a Theory of Reading Comprehension and Rauding

PUBL Reading Research Quarterly

DATE 8. 1:8-63 1977

KEY carv77a

SRCH information processing

ABST Presents a theory which describes the process of reading comprehension under typical reading conditions. The theory purports that the rate of reading is constant and that the accuracy of comprchension during reading can be predicted from a measure of material difficulty and individual ability. The per cent of a reading passage that will be comprehended may be predicted given a knowledge of 2 characteristics of the reader, 2 characteristics of the passage being read, and the amount of time spent reading the passage. Techniques for measuring all the important variables in the theory are described, and empirical data supporting parts of the theory are presented. Typical reading comprehension is considered to be a special case of a more general language comprehension phenomenon called "rauding".
\end{abstract}

\title{
SEQ\# 30
}

AUTH Chaffee, S.H.; Linder, J.W.

TITL Three Processes of Value Change wi.thnut. Rehavinral rhange

PUBL Journal of Communication

DATE 19. 2:30-40 mar 1969

KEY chaff69a

SRCH information processing, values

ABST Two experiments on information processing replicate earlier $f$ indings that a person's evaluation of an object changes as a function of its salience to him, its pertinence relations with other objects, and the reduction cognitive dissonance. However, these effects do not carry over to corresponding changes in his directed behavior toward the object. It is suggested that communication research might 1 imit itself to value change and those cognitive processes that precede it, $r$ ather than try to predict behavioral change directly from value change.

NOTE data produced; experimental

SEQ\# 31

AUTH Cheney: J.; Harford, T.; Solomon L. 
TITL The Effects of Communicating. Threats and Promises Upon the Bargaining process

PUBL Journal of Conflict Resolution

DATE 16. 1:99-197 mar 1972

KEY chen72a

SRCH conflict, problem solving

ABST This study sought to examine the effects of communicating threats and promises upon cooperation in a modified version of the Deutsch and Krauss two-person trucking game. S's could communicate promises or threats as differentiated from implementing rewards or punishment. The subject sample consisted of 160 female college students. Eighty dyads were formed and randomly assigned to one of the four experimental conditions; a) Positive Option Only, b) Negative Options Only, c) All Options Available, and d) No communication (control). The results. indicated that the highest levels of cooperation were achieved under All options condition, then Positive only, then Negative Only and were lowest for the No Communication condition. The frequency of message transmission was highest under the All option condition and lowest for Negative Options Only. Players in the All Options condition used promises four times more often than threats

NOTE data produced; bargaining experiment. Sample = 160 female college students

SEQ\#. $\quad 32$

AUTH

32

TITL

Clement, D.A.; Frandsen, K.D.

PUBL Communication

DATE 43. 1:11-28 mar 1976

KEY clem76a

SRCH review-communication feedback

ABST This paper describes major discrepancies that exist between the empirical and theoretical treatments of feedback in human communication. Its purpose is to offer some conclusions with both descriptive and heuristic value for future development of an informed and useful theory of feedback in human communication. In the paper, feedback is discussed with reference to 1) the contribution of theoretical literature to the concept, 2) the contribution of empirical reports, 3) the relative consistency of theoretical and empirical treatments, and conclusions about the role of the concept in the study of human communication.

SEQ\# 33

AUTH Cohen, M.R.

TITL Environmental Information vs Environmental Attitudes

PUBL Journal of Environmental Education

DATE 5. 2:5-8 win 1973

KEY Cohe 73a 
SRCH attitudes-environment, environmental knowledge

ABST The environmental information $454 \mathrm{high}$ school students possessed was compared to their environmental attitudes. Students with more information had more favorable attitudes and were also more willing to express their attitudes.

NOTE date produced; sample $=$ high school students

SEQ\#

AUTH

TITL

PUBL

DATE

KEY

$S R C H$

ABST

NOTE

SEQ̄\#\#

AUTH

TITL

PUBL

DATE

KEY

$\mathrm{SRCH}$

ABST

34

Coleman, E.B.; Miller, G.R.

The Simplest Experimental Design That Permits Multiple Generalization

\section{Journal of Reading Rehavior}

6. $1: 32-401974$

cole $74 a$

methodology, review-verbal learning

Recently, several methodological critiques have pointed out that most experiments in verbal learning fail to present statistical evidence that their results could be replicated using a different sample of language materials. Consequently, many of the studies have little scientific point because their conclusions have to be restricted to the specific language items used in the experiment. All these critiques are summarized, the various solutions to the problem are evaluated, and procedures to arrive at the simplest solution are described. This solution should present no difficulties to anyone who has had a course in analysis of variance.

methodological review of verbal learning experiments

\section{5}

Cole, B.J.

Trends in science and Conflict Coverage in Four Metropolitan Newspapers

Journalism Quarterly

52. 3:465-71 aut 1975

cole75a

science writing, science coverage, mass media, conflict content analysis, newspapers

This study is based on implications stemming from the proposition that as a social system becomes more differentiated and pluralistic, the more likely it is for the mass media to perform a "feedback control" or "watchdog" function. Two hypotheses were tested; 1) as the scientific community has recently grown more diverse and pluralistic, it has performed a "watchdog" function to a greater degree (presumably stories about conflict reflect this watchdog function), 2) that science writers who depend on open channels to scientists for their articles will mention the conflicts of science less often than general staff writers do in their (infrequent) science stories. To test these notions, a content analysis was made of all science news stories $(n=1074)$ in a sample of 252 editions of 4 major dailies from the years 1951, 1961, and 
1971. Science stories were coded as containing conflict if there was a mention of at least 1 antagonist and a reason for the conflict or something of its nature. The results support the hypotheses. The percentage of stories containing conflict attributes increased from 16.48 in 1951 to 17.68 in 1961 to 28.38 in 1971. Further, both headline and story length increased faster across the sampled years for stories containing controversy compared to those science articles that did not. Bylined science writers wrote proportionately fewer controversial science articles (26.98) than did bylined staff writers (41.88), though part-time science writers (25-508 of their stories are about science) reported the greatest amount of controversy $(62.58)$.

NOTE data produced; content analysis of newspaper science articles with a focus on controversy attributes

\section{SEQ\# 36}

AUTH Cordaro, M.C.; Malloy, W.T.

TITL A Methodology for Power plant site selection At the Reconnaissance Level

PUBL Journal of Environmental Systems

DATE 3. 4:257-66 win 1973

KEY cord73a

SRCH values, site selection, land use, public relations, public, methodology, electricity, utilities

ABST A methodology was developed and applied to identify the principal candidate sites at which major steam electric generating facilities to serve the Long Island area could be located. The selection criteria included not only economic and engineering considerations but social and environmental factors reflecting changing and often intangible public values. From a total of 168 candidate sites, five were selected through a series of steps in which analysis and judgment were combined to overcome the problems of preliminary information and uncertainty. These successive steps eliminated unsuitable sites on the basis of a qualification review and a preference review. A refined analysis of the favorable sites revealed patterns of value-free dominance among them.

NOTE article entered due to its reference to ascertaining public values in conjunction with potential site reconnaissance

SEQ\# 37

AUTH Culbertson, H.M.; Somerick, N.

TITL Quotation Marks and Bylines --what Do They Mean to Readers PUBL Journalism Quarterly

DATE 53. 3:463-67,508 aut 1976

KEY culb76a

SRCH science writing, audiences, newspapers

ABST

This study examined the effects of 2 tangential elements of 
news articles on readers. These elements are the use of quotation marks and bylines. The relationship between self-reported frequency of noting bylines and story impact, as well as the extent of audience understanding of the use of quotation marks was investigated. 283 persons were sampled from 3 towns; one suburb and 2 rural. Differences among these communities were so small that the data were pooled for this analysis. The results indicate that 808 of the respondents had a basic knowledge of what quotation marks mean (verbatum reproduction). About 708 reported noticing bylines. "usually" or "sometimes". The authors report that the data suggests that quotation marks and bylines tell readers more about the author of a story than about the news contained therein.

NOTE data produced; survey of understanding of news articles. sample= community residents

SFO\#

AUTH

TITL

PUBL

DATE

KEY

SRCH

ABST
38

Dasgupta , S.

Communication and Innovation in Indian Villages

Social Forces

43. $3: 330-3371965$

dasg65a

diffusion, innovation, community

Dasgupta draws on the research of Rogers (Rogers \& Beal, "The Importance of Personal Influence in Technological Change," Social Forces, 36 (May 1958)) and Wilkening (Wilkening, "Sources of Information for Important Practices," Rural Sociology, 15 (March 1950)). From their research on the dissemination of information in rural America, Dasgupta develops three hypotheses: 1) Innovators and early adopters are influenced more by certain sources of information than are the late adopters 2) Farmers of higher socio-economic status utilize institutionalized sources and those of lower socio-economic status utilize non-institutionalized sources 3) Information for the new farm practices which are associated with older farm enterprise are sought from non-institutionalized sources and information for improved farm practices which are entirely new to the farmers' experience are sought from institutionalized sources. To test these hypotheses a survey was conducted, involving 246 farmers from 4 .villages in West Bengal. Each farmer was asked a series of questions, including how many years he had been following a practice, how he became aware of the practice and from whom he got the information about the practice. From the collected data, support was given to the hypotheses. Institutionalized sources of information such as extension agencies were utilized more by the innovators and early adopters than by the late adopters. Non-institutionalized sources of information such as neighbors and relatives were more frequently reported as sources 
of information by late adopters than by the early adopters and innovators. Farmers of higher socio-economic status got information from the institutionalized sources more than farmer $\dot{s}$ of the other two status groups. Farmers of lower socio- economic status depended more on non-institutionalized sources of information than farmers of the other two status groups. Although there was insufficient data to test the third hypothesis, a positive relationship seemed to exist between newer farming practices and institutionalized sources of information. The findings of the investigation tend to show some similarities with the findings in western countries; they are consistent with those of Rogers and Wilkening.

NOTE Data produced: field survey, systematic sample, sample $=246$ Indian farmers...Although the two-step flow theory is not directly applied in the study, it is referred to as a model for the dissemination of information.

SEQ\# 39

AUTH Dillman, D.A.; Christenson, J.A.

TITL

PUBL

DATE

KEY

SRCH

ABST

Toward the Assessment of Public Values

Public Opinion Quarterly

38. $2: 206-21$ sum 1974

dil174a

public opinion, values

Efforts to measure trends in citizen preferences have been curtailed by the tendency of public opinion analysts to study ephemeral issues, to depend upon single questions, and to analyze issues individually $r$ ather than in relation to competing concerns. An illustrative analysis uses conceptualization of opinions in a value framework and factor analysis to overcome these limitations.

NOTE data produced; statewide (WA) survey, sample = dwelling units (multistage probability sample)

SEQ\#

AUTH

TITL

PUBL

DATE

KEY

SRCH

ABST

40

Donohue, G.A.; and others

Communities, Pollution, and the Fight for Survival Journal of Environmental Education 6. $1: 29-371974$

dono74a

attitudes-pollution, pollution, community

Field studies indicate that attention to environmental issues and involvement in them depends upon community structure. Smaller homogenous communities tend to choose those alternatives that are perceived to be in the community self-interest. Larger, more pluralistic communities choose attitudes in line with general societal beliefs and more often favor environmental restrictions. 
NOTE Pertinent to attempts to locate possible waste removal sites.

SEQ\#

AUTH

TITL

PUBL

DATE

KEY

SRCH

ABST

NOTE

SEQ\#

AUTH

TITL

PUBL

DATE

KEY

SRCH

ABST
42

Donohue, G.A.; Tichenor, P.J.; Olien, C.N. Mass Media and the Knowledge Gap: A Hypothesis Reconsidered Communication Research
2. $1: 3-25$ jan 1975

dono75a

conflict, community, mass media

A principal consequence of mass media coverage about national public affairs issues, particularly from print media appears to be an increasing "knowledge gap" between various social strata. Previous data presented by the alithors were concerned with issues largely external to the local community. More recent work raises the question whether social conflict about a community issue will tend to open the gap further, or close it. Survey data from 15 Minnesota communities experiencing conflicts of varying magnitude indicate that as level of conflict about local issues increases, the knowledge gap actually tends to decline. Level of interpersonal communication about the issue appears to be a major intervening variable. Thus it appears that the knowledge gap hypothesis needs to be modified according to the type of issue involved and the conflict dimensions of the issue within the community.

Data produced, survey. Sample $=15$ communities experiencing various degrees of conflict.

\section{3}

Douglas, D.F.; Westley, B.H.; Chaffee, S.H.

An Information Campaign That Changed Community Attitudes Jounal ism Quarterly

47. 3:479-87 1970

doug $7 \emptyset a$

mass media, local media, interpersonal communication, dissemination, attitude change, community

The proposition was tested that public information campaigns can produce significant changes in attitudes and values. It is noted that there is 1 ittle evidence to support this proposition to date. The general research hypothesis is that a media information campaign can increase information levels and change attitudes, that these changes are interrelated, and that they are augmented by person to person influence. Several hypotheses were made. Importantly, 1) that attitude change should be positively correlated with information gain 2) that attitude change should make a larger positive shift in the experimental compared to control sample 3) that local media should be cited more than non-local media as sources of information 4) and that interpersonal sources (friends) should 
be cited more often as a source of information in the experimental compared to control sample. A before-after study was conducted in two comparable communities, one of which conducted a 6 month local information campaign on mental retardation utilizing local newspapers, radio, posters and community organizations. A systematic sample of households was made in the respective communities. Before the campaign one adult member of each household was contacted and interviewed face to face regarding demographics and media behavior; the remainder of the Questionnaire was left to be mailed to the investigators. Initial response rates were 818 and 448 for the experimental and control communities. The post-campaign questionnaires were mailed to respondents with a 788 and 858 return rate for the experimental and control communities respectively. All of the mentioned hypotheses were supported by the data. Inter personal sources were the most cited source of information about mental retardation in both communities. It is suggested that successful campaigns might be 1 imited to topics on which "informed" persons are unlikely to differ.

NOTE Data produced, survey. Sample $=2$ comparable towns. Competent authors.

\section{SEQ\# 44}

AUTH Dunlap, R.E.

TITL

The Impact of political orientation on Environmental Attitudes and Actions

PUBL Environment and Behavior

DATE 7. 4:428-54 dec 1975

KEY dunl75a

SRCH audiences, attitudes-political/environmental

ABST Research supports that both political ideology and party preference are correlated with environmental concern. A sample of a university population revealed that Democratic and Liberal Left students held more pro-environmental attitudes, engaged in more pro-environmental behavior, and viewed environmental problems as more serious than their Republican counterparts.

NOTE Data produced, survey. Sample = university students.

SEQ\#

AUTH

TITL

PUBL

DATE

KEY

SRCH

ABST
45

Dunlap, R. \& Dillman, D.

Decline in Public Support for Environmental Protection: Evidence from a 1970-1974 Panel study

Rur al sociology

41 pp 382-390 Fall 1976

dun176a

public opinion

The purpose of this study was to detect any changes in public concern for the environment between 1970 and 1974. Earlier 
studies (Buttle, 1975a) had focussed on public perceptions of environmental degradatin. Dunlap and Dillman, however, wished to measure changes in public commitment to environmental quality. To do so, they conducted a panel study which focussed on public preferences for allocating tax funds among various governmental expenditure areas, including environmental protection. The first survey was taken in 1970; a sample of 3,101 respondents who were "reasonably representative" residents of the state of washington completed the questionnaire. The second survey was taken in 1974; only 538 of the original respondents completed the questionnaire. The researchers claim, however, that, "the results should be fairly representative of the entire 1970 state-wide sample." To assess their priorities for funding governmental programs, the respondents were presented (in.both 1970 and 1974) a list of general funding areas. This 1 ist included such areas as crime prevention and control, pollution control, protection of forests and other natural. areas, and job training and development of employment opportunities. The respondents were asked to indicate whether they favored less, the same, or more government spending in these areas. The findings of the 1970 and 1974 surveys showed a decline in support for environmental problems. In 1970, 708 of the respondents favored more government spending for pollution control; in 1974, only 328 of the respondents favored more spending in this area - a decline of 388 . Also, in 1970, 528 of the respondents favored more government spending for protection of natural forests and other natural areas; in 1974, only 378 of the respondents favored more spending in this area a decline of 15\%. Additional evidence of the decline in public support for environmental protection was found in a more detailed survey which accompanied the one discussed above. This second survey asked the respondents to prioritize thirty-six specific governmental programs, with "no priority" "low priority", "medium priority", or "high priority." Again, there was a marked decline of support for such programs as control of industrial air pollution, control of air pollution from motor vehicles and prevention of serious industrial pollution of water. The decline of support for these programs varied from 88 to 258 . Overall, the data indicate a substantial decline in public support for environmental protection from 1970 to 1974, as measured by priorities for allocating governmental funding among expenditure areas. Concern for environmental protection lost considerable ground to other programs, especially those concerned with the welfare of the general public; that is, retirement benefits, health and medical care and social security benefits.

NOTE Data produced, panel study. Sample $=3,101$ in 1970 and 1,634 in 1974. No sampling technique specified. 
$\begin{array}{ll}\text { SEQ\# } & 46 \\ \text { AUTH } & \text { Eastman, C.; Randall, A. : Hoffer, P.L. } \\ \text { TITL } & \text { How Much to Abate Pollution } \\ \text { PUBL } & \text { Public Opinion Quarterly } \\ \text { DATE } & 38.4: 574-84 \text { win } 1975-76 \\ \text { KEY } & \text { east76a } \\ \text { SRCH } & \text { electricity, attitudes-pollution, }\end{array}$ pollution, land use

ABST This study attempted to measure the concern of affected citizens over the aesthetic environmental damage created by a coal-based electricity generation plant in the 4 corners region of Arizona and New Mexico. "Concern" was measured in terms of the amount of money affected citizens indicated they would pay in order to clean-up the environmental damage caused by the plant. Three. categories of affected persons were selected via a stratified random sample; l) residents of Indian reservations $(n=71), 2)$ non-reservation residents of the affected region $(n=526)$ and 3$)$ visitors to the area ( $n=$ 150). Data was collected through personal interviews, using a questionnaire that included "bidding games" to determine the extent to which respondents were willing to pay for the abatement of environmental damages. Various bidding game techniques used to estimate "willingness to pay" for pollution abatement are discussed. Depending upon the bidding game utilized, the amount non-reservationists were willing to pay per year ranged from a mean of $\$ 23.00$ for the "electricity bill game" to $\$ 85.00$ for the "sales tax game". However, high levels of non-response (partly attributable to respondent reEusal to play due to objections to the game) for some games may render those results untenable. Further, 508 of the nonreservation residents and 558 of the visitors indicated that they felt that the responsibility for paying for pollution abatement should be distributed (not necessarily evenly) among: 1) local residents and visitors, 2) the final users of the electricity, and 3) the mining and electricity companies. However, the Indian reservationists (many of whom do not use electricity) were split between having the final users (42.8) and the electric and mining companies $(54.8)$ pay for the environmental damage.

NOTE Data produced, survey of persons affected by environmental damage. Sample = residents and visitors of the affected region. The "bidding games" utilized in this study are discussed in relative detail, and may be a useful research idea-though their ability to arrive at valid estimates of the amount one would actually pay is suspect, along with the refusal to play problem mentioned in the abstract.

SEQ\# $\quad 47$

AUTH Ebbin, S.; Kasper, R. 
TITL Citizen Groups and the Nuclear Power Controversy Uses of Scientific and Technological Information

PUBL The MIT Press

DATE $1974 \quad 1-307$ pp.

KEY ebbi74a

SRCH interest groups, nuclear, power plants, public participation, site selection, land use, mass media, television, public policy

ABST This report is directed towards analyzing citizen input into the nuclear power plant controversy. Its findings and recommendations are developed from the transcripts of several siting hearings, the dockets of several cases (ie. the construction permit hearings for the Midland plant, the operating 1 icense proceedings for the Vermont Yankee plant and the rule making hearings on criteria for emergency core cooling systems), interviews with various participants, and a review of relevant literature. From the data collected from these suurces, the authors wr 1te, "we have looked hard and carefully at a process, essentially a public hearing process, that takes place within circumscribed rules of participation for all parties, which we conclude, is neither fair nor expeditious, nor particularly revealing of scientific truth or technological fact." Because of these failures in the AEC proceedings, the authors offer several recommendations: 1) the formation of independent assessment centers to perform and arrange for analysis of the impact of technology on the physical, social and human environments 2) the formation of governmental bodies of adjudicators independent of any mission- oriented agency to hear and rule on the arguments of competing interests in nuclear power licensing cases 3 ) the developmental and regulatory roles of the AEC be separated by the formation of two independent agencies, one concerned with the development of nuolear cncrgy and the other concerned solely with the regulation of nuclear energy 4) the public be informed of any plans for the construction of a nuclear power plant at the earliest time possible so that citizen groups might become involved at the time that preliminary application for permits is first submitted 5) the hearings be made accessible to a broader public by requiring evening or weekend sessions when possible and by encouraging the use of community cable and public television and radio for local broadcasting of hearings. These (and other) recommendations represent an "attempt to devise mechanisms which would prom vide a means of achieving a greater public understanding of scientific and technological issues, which would ensure the fair and judicious consideration of matters of concern to the public and which would allow for more adequate public participation in the decision-making process."

NOTE Data produced, information collected from interviews, hearings, dockets and 1 iterature. 
SEQ\# 48

AUTH Engel, J.F.; Blackwell, R.D.; and Kegerris, R.J.

TITL How Information is Used to Adopt an Innovation

PUBL Journal of Advertising Research

DATE 9. 4:3 dec 1969

KEY enge69a

SRCH diffusion

ABST This study set out to answer such questions as: Do innovators learn of new things earlier than the population? How important are commercial media compared to word-of-mouth? Do innovators act on impulse or do they use a planned orderly decision-making process? Individuals were questioned with regard to an auto diagnostic certer, newly opened, in columbus, Ohio. Personal interviews with 249 people who had come to use the center were conducted from the opening day. "Innovators" was operationally defined as those individuals who used the center within the first three months of its operation. A sample of 173 Columbus residents was drawn for comparative purposes. Results showed that innovators read significantly more magazines than the general public; that they rated themselves as significantly more innovative; and that they had already heard of dignostic centers prior to any local announcement of a local center. They described themselves as careful planners before adopting something new., significantly more so than the general public. Innovators sought significantly more information about an innovation once they had heard of it locally. The sources of information stimulating initial interest and awareness in innovators were most frequently popular and technical magazines, and friends, relatives, and associates. The authors concluded that the first users of a new automobile diagnostic center were individuals who carefully planned their adoption of the innovation and searched for information for that purpose. Word-of-mouth was the most important information source, but mass media also played an important part. Local advertising also proved effective for informing prospective customers of the presence of the center.

NOTE Data produced, survey. Sample = customers of automobile diagnostic center compared to sample of Columbus area residents. There are some problems with the sampling procedure and interviewing techniques particularly with the comparative columbus population. The questionnaire administered to the patrons of the auto center seemed biased in favor of allowing the respondents to describe themselves as innovative.

\section{SEQ\# 49}

AUTH

Feller, I. Menzel, D.C.

TITL

PUBL

Diffusion Milieus as a Focus of Research on Innovation in the Public sector

DATE 8. $1: 49-68 \operatorname{mar} \cdot 1977$ 
KEY fel177a

SRCH public policy, innovation

ABST Presents an approach to the diffusion of technological innovations in state and local governments that is organized around the concept of "diffusion milieus."

$\begin{array}{ll}\text { SEQ\# } & 50 \\ \text { AUTH } & \text { Fields, J.M. Schuman, H. } \\ \text { TITL } & \text { Public Beliefs About the Beliefs of the Public } \\ \text { PUBL } & \text { Public Opinion Quarterly } \\ \text { DATE } & 40.4: 427-448 \text { win } 1976-77 \\ \text { KEY } & \text { fiel76a } \\ \text { SRCH } & \text { values, public opinion, public } \\ \text { ABST } & \text { Perceptions of the opinions of others are examined on a vari- } \\ & \text { ety of issues using data from } 3 \text { sample surveys of metropoli- } \\ & \text { tan Detroit. A great deal of inaccuracy in such perception is } \\ & \text { evident. Three broad tendencies or patterns can be discerned: } \\ & \text { "looking glass perceptions," the general propensity to be- } \\ & \text { lieve that other's opinions are the same as one's own: "con- } \\ & \text { servative bias," the belief that the population is more con- } \\ \text { servative on racial issues than it acutally is; and limited } \\ \text { response to reality constraints. The overall findings suggest } \\ \text { that perceptions of public beliefs and attitudes are person- } \\ \text { ally and socially constructed to a much larger degree than is } \\ \text { often assumed. }\end{array}$

NOTE Data produced, 3 surveys of Metropolitan Detroit (1956, 1969, $1971)$ on the perception of others opinions. Sample = dwelling units (multistage probability sample).

SEQ\# 51

AUTH Flinn, W.J.

TITL Influences of Community values on Innovativeness

PUBL American Journal of Sociology

DATE

KEY

SRCH 75. pp.983-91 1970

ABST flin7øa

diffusion, methodology, innovation, community, values

The concern is with determining the influence of structural effects on innovativeness. Data suggest that social values that prevail in a farm community do exert external constraints upon the thinking and actions of its members. If pro-innovator values prevail in a community, old-fashioned truck growing practices meet with social disapproval, while new techniques gain approval and respect. But this is not the case if pro-innovator values are not as prevalent. Only 248 of the farmers who neither had pro-innovator attitudes nor were in communities where pro-innovator values prevail were innovative, vs 828 of those with pro-innovator atttitudes, most of whose neighbors shared these values. Analysis suggests that these results may be attributed to the farmer's perception of a community-wide value system on innovative- 
ness. Methodological suggestions are made for further research.

NOTE Data produced, relationship of community values to innovativeness.

SEQ\#

AUTH

TITL

PUBL

DATE

KEY

SRCH

ABST

NOTE

SEQ\#

AUTH

TITL

PUBL

DATE

KEY

$\mathrm{SRCH}$

ABST

\section{2}

Funkhouser, G. R.; Maccoby, N.

Communicating Specialized Science Information to a Lay Audience

Journal of Communication

21. $2: 58-71$ mar 1971

funk 71 a

science writing, readability, textual variables, public, audiences, understanding

In spite of widespread concern over the state of public science knowledge, relatively little empirical research has been done toward improving the communication of science information to laymen. This paper reports the results of an empirical, quasi-experimental study on textual variables in science writing and their effects on a lay audience. Strong relationships were found between textual variables such as readability and use of example, and audience variables such as information and attitude favorability toward the topic (in this case, enzymology). The second phase of this study, a true experimental design in which the results of the first phase are currently being tested, is described.

Data produced, quasi-experimental observation of the effects of manipulation of textual variables. Subjects = university students.

53

Funkhouser, G.R.; Maccoby, N.

Tailoring Science Writing to the General Public

Journalism Quarterly

50. $2: 220-26$ sum 1973

funk73a

science writing, public, audiences

An attempt was made to create science articles, via science writing modules, with controlled manipulation of textual variables, while at the same time keeping the content constant from one version to another. Each article on 1 of 3 selected topics was constructed to contain enough information to provide a basis for answering a multiple choice information/knowledge test correctly. Using this test as a basic criterion, 10 "information variables" were manipulated. Each manipulation was tested with 3 of the 30 modules by writing each module twice--one version for each part of the module. The effects of the manipulations tested on 3 audiences; de- 
scribed as low (junior college students), medium (prestige school students) and high (professional scientists) on science aptitude. Each person was given a $r$ andom selection of 3 articles, one on each topic, and tested on information gain, attitude toward topic, perceived author competence, and difficulty of the article. The difference between these 3 samples in terms of the effects of the variable manipulations are discussed. In general manipulations that improved communication of material for one group did so for the other 2 groups as well. The results suggest several "rules" of effective science writing: a) decide what it is that you want to communicate, b) use examples, analogies, general rules and exceptions to general rules when appropriate, c) be explicit, d) use as little scientific terminology as possible, e) use shorter sentences and words, f) introduce, intersperse and end your material with something other than "hard science", g) indicate practical applications, h) there is plenty of latitude for varying vocabulary, sentence lenght, and organization if the effort is made.

SEQ\# AUTH TITL

PUBL DATE

KEY

$\mathrm{SRCH}$

ABST

NOTE
54

Fun khouser, R.G.; Maccoby, N.

An Experimental study on Communicating Specialized Science Information to a Lay Audience

Communication Research

1. $1: 110-28$ jan 1974

funk $74 a$

science writing, audiences, public

An experiment was done to test the effects of stylistic and rhetorical manipulation in specialized science writing on audience variables surh as enjeyment, attitudes, and informaltinn gain. Articles on enzymology, polymer chemistry, and plasma physics were prepared, and, with content held constant, variations were made in textual variables such as sentence length, vocabulary difficulty, the amount of analogy used, and so on. 'l'he effects of these manipulations were tested on 3 audiences: junior college students, university students and professional scientists. Among the study's findings were: some stylistic and rhetorical manipulations do have effects on audience variables, but more with less qualified audiences; a given body of content can be varied across a wide range of vocabulary and sentence length; student's at.titudes toward science are nearly as favorable as those of professional scientists; and professional scientists appreciate a simple style of presentation as much as students do.

Data produced, experiment manipulating article content and form (the authors report that content was held constant, but actually what was held constant was a core of information (facts) that were communicated via different presentations 
and descriptions). Sample = students $(2$ "kinds") \& scientists.

SEQ\#

AUTH

TITL

PUBL

DATE

KEY

$S \mathrm{RCH}$

ABST

NOTE

SEQ\#

AUTH

TITL

PUBL DATE

KEY

SRCH

ABST

55

Geertsen, R.H.; Bylund, B.H.

Land Use and Related Environmental Issues in Utah Cornell Journal of Social Relations

10. 1:97-109 spr 1975

geer $75 a$

public opinion, site selection, land use

A sample of 1,643 individual household heads were interviewed in Utah in the Fall of 1973 to find out how people feel about land decisions and similar issues currently facing the state. For the sampling procedure, the state was stratified into planning districts and different sample sizes were determined for each of the areas. Standard area sampling techniques were used involving blocks and segments of the districts proportionate in size. Specific persons were randomly selected to be personally interviewed. Eighty-five percent of the potential interviewees were able to participate. The interview lasted about $3 \emptyset$ minutes. $R^{\prime} s$ were asked questions pertaining to basic demographics, land use planning, and environmental issues. Respondents rated the seriousness of each problem from a list of potential problem areas. The people of Utah are concerned about the environmental problem of air pollution, loss of agricultural land, water pollution, and highway strip development. Over 508 felt that air and water pollution and loss of agricultural land will become serious problems of the future. Thirty-three percent felt that overpopulation will also be a serious future problem. The people would be willing to financially support efforts to improve and protect their environment.

Data produced, survey. Sample $=$ Utah residents. Perceptions of environmental problems and their importance.

\section{6}

Goland, M.

Public Attitudes Toward Technology - Enlightened or Disruptive?

SRA Journal of the Society of Research Administrators

73 pp. 12-18 winter 1976

gola76a

attitudes-technology

This paper was given as the keynote address to the SRA/NCURA meeting in Dallas, Texas in April, 1975. In it, Goland contends that "we have inextricably bound our national future to progress through technology, (but) no coherent public policy has yet emerged." Furthermore, he claims that this lack of national commitment has led to a decline in the growth of 
various technologies - parti cularly nuclear technology. He argues for $a$ reversal of this trend and for the construction of more nuclear power plants. He concludes by saying, "it is time for us to demand (a) return to the balance of technological real ism."

\section{SEQ\# 57}

AUTH Grunig, J.E.

TITL Three Stopping Experiments on the Communication of Science PUBL Journalism Quarterly

DATE 51. 3:387-99 aut 1974

KEY

SRCH grun $74 a$

science writing, methodology, communication effectiveness, information processinq, decision- making, rnmmuniration systems, understanding, audiences, prohlem snlying

ABST Reported are the results of 3 experments designed to test the impact of several writing techniques on lay audience understanding of scientific concepts. Understanding as a criterion for effective communication is conceptualized as a process whereby one persons "picture" (in this case the scientist's) is transmitted to another (via science writers) in such a way as to enable the reciever to reconstruct the same "picture", i.e. set of relations. Part of the difficulties inherent in the communication of scientific information is due to the fact that some concepts cannot be explained in simple terms. Thus often the use of "plain English" to communicate scientific concepts results in the expression of these concepts in terms of lifeli operational detinitions, instead discussing these concepts at their actual level of abstraction. As a result the public is often aware of the implications of science but do not understand the meaning of the concepte from which the implications were derived. It is suggested that science writing would be most effective if it could compare the new (scientific) concept with an appropriate familiar one (referent criterion) at the same level of abstraction. Insomuch as analogies and parables (referent criteria) operate on the same abstract level as the introduced unfamiliar concept, it is expected that the uses of these two techniques should result in better understanding than would be achieved through the use of examples which operate at a lower level of abstraction (at the operational level). Further, a decisionsituation model. of communication behavior was introduced to more fully account for the behavior of science readers. The model predicts that individuals will seek information when it is relevant to objects or alternatives that they recognize in their situation. The model also predicted that persons will seek information only about alternatives that are not excluded from them by situational constraints. Problem perception (open-mindedness) and available alternatives (open structure) 
combine to yeild four decision-types: 1) problem solving (open mind and structure, 2) constrained decision (open mind, closed. structure) 3) routine habit (closed mind, open structure) and 4) fatalism (closed mind, closed structure). For each experiment the author wrote a series of stories on technical economic subjects. The articles were identical except for the consistent use of either analogy, parable or examples throughout the story. Observations were made utilizing Carter's Signal stopping Technique, where subjects are asked to read a story and instructed to mark a slash wherever they wished to stop while reading and to indicate their reason for doing so. Subjects were Maryland University students in Communications.

Across the 3 experiments a clear pattern of results emerged. The decision situation was the most predictive variable regarding the extent to which subjects would stop to consider the implications of the story --a necessary condition for understanding : unfamiliar concepts. "Problem solvers" were most likely to think about implications, to feel that they understood the article and report they would seek more information in the future. Overall, analogies appear to be the most effective means of evoking a referent criterion to aid understanding, though parables were quite useful to problem solvers. However, the results indicate that the style of a science story is less important than whether the content is relevant to the percieved situation of the reader.

NOTE Data produced, signaled stops while reading stories about complex matters. Sample = University students. An original, skilled treatment and discussion of science. writing.

\section{SEQ\# 59}

AUTH Grunig, J.E.

TITL A Review of Research on Environmental Communication and PubIic Relations

PUBL Foundation for Public Relations Research and Education

DATE 1976

KEY grun76a

SRCH review-environmental public relations research

ABST Reviewed are studies on environmental communication with a focus on; 1) how do public relation practitioners respond to environmental issues, 2) how concerned is the public with the environment, 3) how do the media cover environmental issues, and 4) can communication theories explain effective environmental communications? The review indicates that any simple public opinion poll can not adequately describe the attitudinal stance of a practitoner's public; people will give opinions to a pollster when they don't have any, and, they will cite an issue as important because they have read about it in 
the mass media. Most people, according to the reviewer, do not perceive many environmental situations (e.g. whale killing, West-virginia strip mining) as issues involving them personally. Only when a large population is directly involved can a public relations practitioner arouse more than a superficial consciousness about an environmental situation. Thus, a public relations practitioner need not worry as much about adverse publicity if only a few people are affected. A further implication is that "information campaigns" (positive publicity) should also have little effect on the general population. However, public relations practitioners must concern him/herself with educated activists-- who will seek and process environmental information; if not from the focal organization, then from perhaps less reliable sources. Specialized media are much more effective means of rearhing these activists than the mass meida. The $k$ ind of information about environmental issues that can be provided are; 1) information about the problem--to get people to think about it, to become involved, and 2). information about potential solutions to provide referent criteria for particular problems. Most media coverage and public relations campaigns provide more information about solutions. The author concludes that while existing studies are instructive with regard to practitioner-public communication, they offer little information to help the practioner facilitate practitioner-employing-organization communications.

SEQH

AUTH

TITL

PUBL

DATE

KEY

SRCH

ABST

\section{0}

Gunderson, D.F.; Hopper, R.

Relationships Between Speech Delivery and Speech Effectiveness

Communication Monographs

43. 2:158-65 1976

gund $76 a$

communication effectiveness

Six speech delivery variables--volume, rate, voice quality, posture, gesture, and bodily movement--were varied within a five minute persuasive speech. The speech was delivered in each of ten conditons by the same speaker in the same environment. The resultant video-tapes were validated and shown to more than 220 subjects. The findings of this phase of the research indicated that speech delivery, as operationally defined in this study, had virtually no effect on attitude change, recall-comprehension, or ethos. Fur ther investigation using vitiated evidence in the speech indicated that in "composition ineffective" conditions, delivery contributed significantly to some measures of speech effectiveness. However, the greatest variance in most measurees emerged in connection with the composition of the speech, with speech delivery be- 
ing an augmenting variable in "ineffective composition" conditions.

NOTE: Data produced, experiment examining the influence of modes of speech delivery on attitude change, recall and comprehension. Subjects $=220$.

\section{SEQ\# 61}

AUTH Harker, J.W.

TITL

PUBL

An Evaluative Summary of Models of Reading Comprehension

DATE Journal of Reading Behavior

KEY 5. $1: 26-34$ win 1972-73

$\mathrm{SRCH}$ hark7273a

ABST

review-reading comprehension, methodology, readablility

Models of reading comprehension are evaluated as to their utility in facilitating research in comprehension. The criteria employed are: Articulation, Differentiation, Prediction, Creativity and Flexibility. The models are evaluated as models in the abstract since many models of "comprehension" in fact attempt to explain different phenomena, thereby preventing direct comparisons. Models of comprehension vary considerably in the extent to which they meet each of the criteria. The value of models in the investigation of comprehension lies in their capacity to provide testable hypotheses which can lead to scientific prediction and understanding. However, models of comprehension remain untested and therefore 1 imited in the degree to which they have facilitated the scientific understanding of comphehension.

\section{SEQ\# 62}

AUTH Herson, A.

TITL Trade Off Analysis in Environmental Decisionmaking: An Alternative to Weighted Decision Models

PUBL Journal of Environmental Systems

DATE 7. 1:35-44 1977-78

KEY

SRCH conflict, methodology, decision-making, review-decision making

ABST This paper reviews the weighting and aggregation of project impacts in weighted decision models commonly employed for environmental decisionmaking, and proposes an alternative method, the systematic analysis of project impacts, for certain decision problems. Advantages of weighted decișion models include the explicit quantification of decision-maker values and the usefulness of systems analysis techniques for optimizing decisions. Disadvantages include the assumption of unanymity of values among affected publics and unresponsiveness to the needs of many participants in the decisionmaking process. For controversial decision problems with substantial implication for different social groups, explicit analysis of 
trade offs among impact areas or project goals is advanced as a method superior to the quantitative weighting and aggregation of impacts.

NOTE Literature review of selected environmental decision making models.

SEQ\#

AUTH

TITL

PUBL

DATE

KEY

SRCH

ABST
63

Howe 11, J.

The Use of Television in Agricultural Extension

Educational Broadcasting International

4. pp.103-9 1970

howe $70 \mathrm{a}$

televison, dissemination

The problem of communicating new ideas and promoting the application of new techniques is becoming recognized as a main barrier to agricultural and economic development. The recognition of the importance of extension work has in recent years led to an increased concern with the development of communication techniques and the training of agricultural extension workers in their use. Too frequently, however, communication media are inadequately used, the social and psychological processes of communication and change insufficently understood, and the effectiveness of extension campaigns not evaluated. And new media of communication may be used with an exaggerated belief in their efficiency because of a fashionable preoccupation with their advantages. The use of television as an instrument of agricultural extension, or adult education, is one example of a medium whose potential is frequently exaggerated, and which could be used to far greater effect if more was known about the conditons under which effective communication by this means occurs. It is the purposc of this paper to cxamine critically the advantages and disadvantages of TV as an extension tool and to make some suggestions about ways in which it might be used to better effect. In the course of this paper reference is made to the sociological and psychological factors which bear on the discussion and to the findings of relevant research. Specificly, the author summarizes seven disadvantages inherent in using a television system for communicating agricultural information: 1) economic disadvantages; 2) the nature of broadcasting systems and the allocation of broadcasting time for minority audiences; 3) inflexibility of timing; 4) the transitory nature of the broadcast image; 5) the absence of rapid feedback; 6) establishing adeguate contact with the intended target group, and 7) limitations due to the operation of selection mechanisms in the individual. Suggestions are provided for dealing with 1) reaching the target audience; 2) arranging for feedback, and the reduction of audience passivity. 


\section{SEQ\# 64}

AUTH Hunger ford, S.E.; Lemert, J.B.

TITL

PUBL

DATE

KEY

$\mathrm{SRCH}$

ABST

NOTE

SEQ\#

AUTH

TITL

PUBL

DATE

KEY

ABST

Covering the Environment: A New "Afganistanism"?

Journal ism Quarterly

50. 3:475-81,508 aut 1973

hung $73 a$

public opinion, content analysis, dissemination, mass media, community, science coverage

Reveals that content analysis shows that media coverage of the environment tends to deal with problems of a community at a distance rather than with local issues

Data produced, content analysis of mass media coverage.

\section{$64 \mathrm{~A}$}

Ja in, N.C.

Communication Patterns and Effectiveness of Professionals Performing Linking Roles in Research Dissemination

Doctoral Thesis: East Lansing, MSU Dept. of Communication 1970

\section{jain $79 a$}

The main objective of the framework suggested in the present dissertation was to provide a perspective or frame of reference that could facilitate both theoretical and empirical analysis of communication patterns of 1 inkers involved in the process of research utilization. Research utilization is the process by which research results are communicated to, and adopted by, the clients. The three social systems involved in the process of research utilization are the research system, linking system, and client system. The term communication pattern is used to include those communication behaviors of an individual, dyad, group or social system that are systematic or exhibit some form of regularilty (as opposed to randomness). The two useful levels of analysis for studyuing communication patterns are the individual level and the dyadic level. At the individual level of analysis, nine categrories of communication patterns are formulated. At the dyadic level, the framework suggests six different categories of communication pattterns. The categories of communication patterns relevant for studying the communication behavior of linkers are: communication patterns dealing with (1) information input behvior of linkers, (2) information-processing behavior of 1 inkers, (3) information output behavior of 1 inkers, (4) communication between 1 inkers and researchers, (5) communication between 1 inkers and clients, and (6) communication among linkers. The framework concludes with some examples of concepts and research questions (underlying each of the six categories of communication patterns) that are relevant for studying communication patterns of 1 inkers. The study was designed to test eight hypotheses about the relationship between the communication patterns and peer-evaluat- 
ed effectiveness of 1 inkers working in a research dissemination organization, the Michigan Cooperative Extension Service. Eight communication patterns variables hypothesized to be positievely related with the common dependent variable of peer evaluated effectiveness are: (1) information input amount, (2) information input diversity, (3) peer-communication amount, (4) peer-communication diversity, (5) linker network centrality, (6) opinion leadership, (7) information output amount, and (8) information output diversity. The field survey design was used in the present study. The sample consisited of fifty specialized linkers (or Extension specialists) selected from seven academic departments of Michigan State University. Most of the data were collected from indivdual specialists by personal interviews supplemented with some pretested and structured interview schedules and self-administered instruments. The data about the biographical information and the information output activities of the specialists were collected from organizational records. Partial correlation technique was used to control statistically the effect of four variables on the hypothesized relationships: age, organizational status, professional experience, and project leadership. Of eight hypotheses in the study, four were suppoted by our data. The communication patterns varables postively correlated with the peer-evaluated effectiveness of linkers (at the .05 level) are (1) peer-communication diversity, (2) linker network centrality, (3) opinion leadership, and (4) information output diversity. One general observaton of the findings is that the communicain pattern variables dealing with the "diversity" aspects of linker's communication behavior tend to be more often correlated with the effectiveness of linkers that are the variables dealing with the "amount" aspcct of 1 inkers' communication behaviur.

NOTE data produced; field survey

\author{
SEQ\# 65 \\ AUTH Johnson, D.W. \\ Conflicts: A Critical Review \\ PUBL Speech Monographs \\ DATE 41. 1:64-78 mar 1974 \\ KEY john74a \\ SRCH review-conflict, conflict \\ SEQ\# 66 \\ AUTH Kear 1, B.; Powers, R.D. \\ TITL Estimating Understanding of Scientific Terms \\ PUBL Journalism Quarterly \\ DATE $38.2: 221-23 \mathrm{spr} .1961$
}

TITL Communication and the Inducement of Cooperative Behavior in 
SRCH

ABST

NOTE

SEQ\#

AUTH

TITL

PUBL

DATE

KEY

SRCH

ABST

KEY kear6la

science writing, understanding, methodology

This study compared the ability of 3 groups of specialists to predict lay audience understanding of scientific/technical terms. Soil science terms were used in the study. The 3 groups were; 1) researchers (soil scientists by training and occupation), 2) extension workers (scientificly trained but having the primary responsibility of helping farmers (lay publics) understand new technology, and 3) agricultural journalist (informed about agriculture but without specialized training in soil science. All 3 groups were asked to rate each of 25 multiple choice questions testing "soil knowledge" in terms of the degree of difficulty it would present for a midwestern farmer. Ratings were made on a $1-5$ scale, with "easy" being the lowest value, "very difficult" being the highest. This test had already been administered to $102 \mathrm{Wis}-$ consin farmers. A second measure of "test difficulty" was obtained by considering questions correctly answered by 908 of the farmers as "easy" (1) through to questions correctly answered by 608 as "very difficult" (5). All 3 groups slightly underestimated the actual difficulty of the test. However, the lowest correlation between estimated and actual difficulty was . 71 for farmer-researcher comparisons, and .77 for both farmer-extension workers and farmer-agricultural journalists. Indicating that at least in this study all 3 groups were quite sensitive of the levels of knowledge existing amoung their audience.

Data produced, rated difficulty of tests employing technical terms.

67

Kibby, M.W.

The Proper study of Readability: A Reaction to Carver's "Measur.ing. Prose Difficulty Using the Rauding Scale"

Reading Research Quarterly

11 . $4: 6861976$

$\mathrm{kibb76a}$

readability, review-reading behavior

Challanges the validity of Carver's Rauding scale on both theoretical and procedural grounds. Although an interesting and possibly relevant technique, the Rauding scale has not been demonstrated well in Carver's study. Although vocabulary and style are considered in the Rauding Scale, Carver advances this scale as the only technique that 1) assesses the reading difficulty of material as reflected by the idea or concept difficulty of the material and 2) is useful in revising written material. No theoretical rationale is provided for idea or concept difficulty. The construction and content of the Rauding scale are challenged because the actual reading difficulty of the passages are in question. Procedurally, 
all 3 of Carver's reliability and validity studies are challenged as flawed by poor conceptualization, inadequate sampling, poor control, and skimpy or inaccurate interpretations of data.

SEQ\#

AUTH

TITL

PUBL

DATE

KEY

$S R C H$

ABST

NOTE

\section{8}

Klonglan, G.E.; Coward, E.W.

The Concept of Symbolic Adoption: A Suggested Interpretation

Rural Sociology

35. 1:77-83 mar 1970

klon $70 a$

diffusion, innovation

Some writers have used "symbolic adoption" to refer to the adoption of a particular class of innovations, so-called nonmaterial innovations. In this article, an alternative usage is suggested--one that makes symbolic adoption part of the proces of adopting any innovation, material or nonmaterial. In this sense, symbolic adoption $1 \mathrm{~s}$ the acceptance of the idea component of an innovation, or the decsion to implement or use the innovation. The symbolic adoption decision has been included implicitly in the literature and our discussion has the modest objective of making the decision a more explicit part of the adoption model. One way to achieve this explicitness is a two-phase adoption model in which symbolic adoption (or symbolic rejection) is conceptualized as one possible outcome of the evaluation stage and as a prelude to the trial stage. It is suggested that this two-phase model has utility in clarifying some basic adoption-diffusion ideas: 1) the two-phase model may be useful identifying lags in the adoption process and in construction a typology of forms of incomplete adoption, 2) the two phase model may be useful in differentiating important sets of explanatory and predictive variablee, and 3) thc two phase model may be useful in clarifying issues related to the rejection and discontinuance of innovations.

A new concept regarding diffusion of innovations is introduced and discussed.

\section{SEQ\# 69}

AUTH Koenig, D.J.

TITL Additional Research on Environmental Activism

PUBL Environment and Behavior

DATE 7. 4:472-485 dec 1975

KEY koen75a

SRCH pollution, environmental movement, interest groups

ABST Research indicates that public concern about pollution is either passive or nonexistent. Concern with pollulion correlated substantially with concern with other socioeconomic issues. Environmental activists were found to not think of 
themselves as working class, to not. feel politically alienated, and to prefer liberal party identifacation.

NOTE Data produced, survey. (Sample appears to be of a general population.)

$S E Q \#$

AUTH

TITL

PUBL

DATE

KEY

$\mathrm{SRCH}$

ABST

NOTE

SEQ\#

AUTH

TITL

PUBL

DATE

KEY

SRCH

ABST

70

Kronus, C.L.; Van Es, J.C.

The Practice of Environmental Quality Behavior Journal of Environmental Education

8. $1: 19-251976$

kron $76 a$

attitudes-pollution, community, pollution

This research analyses the effects of situational factors, along with environmental quality (EQ) attitudes, in understanding why some people become involved in pollution abating activities. Findings indicate that closeness to the effects of polluting behavior stimulate more powerful concern and action than closeness to the source of polluted conditions.

Data produced, survey. Sample type not indicated in abstract.

\section{1}

Lackey; L.L.; Jacobs, T.O.; Stewart, S.R.

Public Attitudes Toward Hazardous Waste Disposal Facilities

National Technical Information Service

September 1973

lack73a

nuclear waste, public opinion, attitudes-nuclear, nuclear site selection, land use, methodology

This project had three purposes; (a) survey public attitudes toward a proposed system of national disposal sites (NDSs), (b) develop a behavioral model as a means of predicting citizen's reactions to a NDS in a particular location, and (c) propose an effective public information campaign. The national survey, sampling randomly and purposefully selected respondents (key influentials), was conducted in 10 counties that were selected as feasible NDS locations. The questionnaire elicited information about three classes of variables considered predictive of citizen reaction to an NDS. These variables, (a) contextual variables (physical-economic environment), (b) situational variables (social environment), and (c) individual variables (personal attitudes/beliefs), constituted the basic structure of the behavioral model. Results showed that most respondents had positive attitudes toward an NDS. Because of the lack of actual citizen reactions to an NDS as a real criterion for validating the behavioral, an intermediate criterion variable (ICV) was developed. Results of an Automatic Interaction Detection (AID) analysis showed that two classes of predictor variables accounted for the predictable variance in the ICV. A generalized public information 
program designed to create public acceptance of NDSs was out1 ined.

NOTE Data produced, survey of attitudes toward nuclear disposal sites. Sample $=10$ possible NDS counties.

\author{
SEQ\# 72 \\ AUTH La Porte, T.R.; Metlay, D. \\ TITL Technology Observed: Attitudes of a Wary Public \\ PUBL Science \\ DATE 188. 4184:121-27 apr 1975 \\ KEY lapo75a \\ SRCH decision-making, attitudes-technology
}

SEQ\#

AUTH

TITL

PUBL

DATE

KEY

SRCH

ABST

74

Lassahn, P.H.

Comparison of Judgements About Agricultural Science News

Journal ism Quarterly

44. 4:702-7 win 1967

lass 67 a

science writing, information services

This study compared the editorial judgements of 5 groups of persons regarding the content of science articles in terms of the extent to which they would be interested in seeing these reports in their local newspapers. All 5 groups may be seen as parts of an agricultural science communication system (extension services). Four of the groups were professionals: 1) university extension specialists, 2) university information service editors, 3) county extension directors, and 4) county newspapers editors. The 5 th group were farmers. Four facets of science news. were identified: 1) value 2) timeliness 3) utility and 4) personalization. Each facet contained either high or low magnitudes of that attribute and thus 16 possible combinations were incorperated into the constructed science news items. Members of each group were asked to perform a Qsort in order from those items $s /$ he would be most to least interested in seeing in the local newspaper. The four professional groups were asked to also sort the items again as $\mathrm{s} / \mathrm{he}$ thought a "farmer" might. The "farmer" sorts were factor analyzed and yielded 3 factors or "kinds" of farmer preferences. A fourth factor constituted those farmers that were not typified by any of the. (3) factors. All farmers tended to accept high value, low-personalization, high timeliness and high utility items. The county newspaper editors and the information service editors best predicted acutal farmer preferences amoung the items in the Q-sort. It is suggested that these 2 groups of professionals function well in the extension system as mediators and are in favorable positions to formulate messages to farmers. 
NOTE Data produced, Q-sort of science items.

SEQ\#

AUTH

TITL

PUBL

DATE

KEY

SRCH

ABST

NOTE

SEQ\#

AUTH

TITL

PUBL

DATE

KEY

$\mathrm{SRCH}$

ABST

75

LaTour, S.; Houlden P.; Walker, L.; Thibaut, J. Some Determinants of Preference for Modes of Conflict Resolution

Journal of Conflict Resolution

20. $2: 319-56$ jun 1976

lato $76 a$

conflict

This expermental study manipulated presence or absence of a judgmental standard, and the correspondence or noncorrespondence of outcomes among disputants in a factorial design to assess their effects on preferences for five. dispute-resolution procedures arranged along a continuum of decreasing third-party intervention: autocratic decision making, arbitration, a moot, mediation and bargaining. Arbitration was the most.generally preferred means of settlement, followed in order by the moot, mediation, autocratic and bargaining pro. cedures. The independent variable modified these preferences, however, such that procedures with a high degree of thirdparty intervention was preferred more when there was temporal urgency, outcome noncorrespondence, and a standard. Interaction revealed that correspondence affected preferences only when there was no temporal urgency, and presence-absence of a standard affected preferences only when there was temporal urgency and outcome correspondence.

resolution.

\section{6}

Levine, R.A.

The Silent Majority: Neither Simple nor Simple Minded

Public Opinion Quarterly

35. 4:571-77 win 1971-72

levi7172a

public opinion, review-public opinion polls, public opinion polls

Public opinion polls in recent years have consistently shown northern whites willing to live in desegrated neighborhoods; at the same time, open housing referenda have been defeatied and stable integrated neighborhoods are hard to find. The explanation, the author contends, is not that people 1 ie to the polltaker, but that their beliefs get translated into behavior in ways that are more complex than might be expected. Some implications for public policy are explored.

SEQ\# 77

AUTH Liau, T.L.; Bassin, C.B.; Martin, C.J.; Coleman, E.B. 
PUBL Journal of Reading Behavior

DATE 8.4:381-86 win 1976

KEY Iiau76a

SRCH methodology, readability

ABST In 1965, Coleman published four readability formulas which yielded relatively high multiple $R^{\prime} s$ in predicting readability for college level adults. Four new formulas that account for an even higher percentage of variance were derived by 1) using a more reliable criterion, and 2) a better selection of predictors. Predictors were selected according to ease of scoring as well as according to percentage of variance explained. In fact, the three major predictiors (certainly the two major predictors) could probably be scored by an easily developed optical scanning device. If such a scanner were developed, it might lower cost to the point that a central agency could routinely score all books for readability. A cross-validation study supported the modified formulas and indicated that they could also be used for readers below college level.

$S E Q \#$

AUTH

TITL

PUBL

DATE

KEY

SRCH

ABST

\section{9}

Lin, N.; Burt, R.S.

Differential Effects of Information Channels in the Process of Innovation Diffusion

\section{Social Forces}

54. pp.256-74 1975

1 inn $75 a$

review-diffusion, diffusion, innovation

past research in the diffusion of innovations has clearly demonstrated that different kinds of communication channels have differential effects on the extent of adoptive behavior exhibited. in a societal system. The inadequacy of present conceptualizations of the part played by channels of communication in the diffusion of innovations is explored. Present thought alstinguishes two types of communication channels: 1) the mass media, vs, 2) interpersonal channels. The inadequacy of this conceptualization -- especially in the underdeveloped areas -- is outlined and rectified by introducing an intermediate type of communication channel: the local media. Using data gathered in El Salvadur, each of the three types of communcaiton channels is placed in a structural model involving antecedent demographic considerations and consequent variables measuring participation in the adoption process. Comparisons of the structural coefficients associated with each type of communication channel not only distinguish the different part played by the three types of channels, but also confirm the importance of the local media in the diffusion of innovations. 
NOTE Data produced, examination, of the roles played by 3 different communication channels.

SEQ\#

AUTH

TITL

PUBL

DATE

KEY

SRCH

ABST

NOTE

SEQ\#

AUTH

TITL

PUBL

DA TE

KEY

SRCH

ABST

\section{0}

Lionberger, H.F.; Francis, J.D.

Views Held of Innovator and Influence Referents as Sources of Farm Information in a Missouri Community

Rural Sociology

34. 2:197-211 jun 1969

1 ion69a

information sources, diffusion, innovation

This study is directed to the conceptualization of views held of farm information sources, and to assessing the differential manner in which farmers in a south Missour $i$ community $v$ iewed personal innovator and influence referents as sources of farm information. Semantic differential and factor analysis techniques were used to conceptualize utility, affectivity, practicality and accessibility views. Although the two referent types were seen as being close in semantic space, influence referents were generally held in higher esteem a: farm information sources than innovator referents.

Data produced, survey of farmer view's of information sources. Sample $=$ farmers in a $S$. Missouri town.

\section{1 .}

Lionberger, H.F.; Copus, G.D.

Structuring Influence of Social Cliques on Farm-Informationseeking Relationships with Agricultural Elites and Non-Elites in Two Missouri Communities

Rural Sociology

37. $1: 73-851972$

1 ion $72 a$

diffusion, dissemination

This study examines the comparative structuring influence of social cliques on four types of farm-information seeking relationships of farmers with agricultural elites and nonelites as sources of farm information; in a rapidly changing and relatively stable Missouri community: findings were 1) that cliques facilitated communication within cliques but less for elites than nonelites, and 2) that the importance of the information to the seeker negated barriers to contacts across clique lines. A contrary finding 3) that clique membership facilitated informational contacts across clique lines was explained by the fact that clique members were better qualified to give advice about farming than those who were not members. A unique method of defining the geographic area in which interpersonal informational relationships could be expected to occur among farmers is presented as a methodological contribution to the study of sociometric relationships. 
SEQ\#

AUTH

TITL

PUBL

DATE

KEY

$\mathrm{SRCH}$

ABST

82

Lionberger, H.F. Organizational Issues in Fàrm Informational Systems for Modernizing Agriculture

Journal of Developing Areas

8. pp. 395-408 1974

1 ion $74 a$

dissemination, communication systems, information sources

Specialized agricultual information is required by many people for a great variety of purposes. For whatever purpose the information is required, it must be developed, transformed, and made available by researchers working in specialized, interrelated organizations. The task of integrating the sperialty information into workablc procedures is mostly le[L to potential users. What is urgently needed is a method for organizing and translating theoretical knowledge into useful practice. Functionalliy, we can start with the ideas that: 1) an information development system independent of, in this case the farmer's own social system is necessary, 2) the knowledge needed is derived mainly from the basic sciences, and 3) its development requires both basic and appllied scientists, the latter being interested in creating from the basic scientific phenomena potentiallly useful innoavations for nonscientists. A major function to emerge is the dissemination of the information that has been locally tested for adaptability, normally as part of the research activity. The skills, organization, and resources needed for disseminating information are quite different from those needed for research and development. Seemingly, information dissemination and interpretation are required even by the sophisticated information users commonly thought to be capable of relating abstract knowledge to their own situation. The complexity of this requirement points to the need for making the information delivered to the user as locally pertinent as possible and for providing help in achieving an appropriate local synthesis for "on farm" use. Through an examinatin of the basic farm information systems in the United states, India, and Taiwan, the article supports the following points of view: 1) the continuing supply of scientific information that farmers need or modernizing agriculture require a specialized system, 2) minimally, such a system must provide for the development, dissemination. and integration of the new knuwledge into ind 1vidual farming operations, 3 ) the degree of functional differentiation and organizational specialization that best serves farmers is clearly related to the current state of agricultural development in that country and the manner in which other support to agriculture is managed, 4) the utilty of organizational arrangements in the system can best be judged in terms of the functional requisites that must be met, recognizing at the same time that there may be many or- 
ganizational alternatives for achieving such goals, 5) information systems themselves require integration into the specific adopting situation; thus the mere transplant of a system and its organization from one country to another should be avoided.

SEQ\#

AUTH

TITL

PUBL

DATE

KEY

SRCH

ABST

83

Lounsbury, J. \& Tornatzky, L. A Scale for Assessing Attitudes Toward Environmental Quality The Journal of Social Psychology

Apr il 1977 pp. 299-305 (vol. and issue \#?) loun $77 a$

attitudes-environmental, methodology, interest groups, conservation

The purpose of this research is to - 1) investigate the dimensionality of attitudes toward environmental quality 2) develop a scale for the asssessment of such attitudes 3 ) explore the relationship of attitudinal and behavioral involvement in the maintenance of environmental quality. To accomplish these goals, Lounsbury and Tornatzky conducted three studies. The first study involved 490 undergraduate students and 170 adults. They were given a 78 item attitude questionnaire which dealt with such issues as overpopulation, pollution and conservation. From a cluster analysis of the results, six distinct cluster domains emerged - environmental degradation, environmental action, overpopulation, visual aesthetics, outdoor recreation and economic materialism. Based on these results, a second study was conducted which involved 207 adult, middle-class housewives. They were given a 26 item questionnaire developed from the items obtained in the six clusters of the first study. Also, they were given a questionnaire which measured the ir involvement in such activities as recycling materials, conserving water and using less detergent. As in the first study, the responses from the questionnaires were cluster analyzed. It was found, however, that only three of the six attitudinal clusters emerged - environmental degradation, environmental action and overpopulation. No clusters emerged for behavioral involvement. The composite attitude variables were correlated with individual and composite behavioral involvement items. No coefficient of correlation exceeded .48. The third study involved 51 members of various environmental action groups.. This group was given an attitudinal questionnaire similar to that used in the second study. It was found that members of environmental groups scored significantly higher in each of the three clusters than the housewives of the second study. The findings of these studies, then, allow the creation of three attitudinal dimensions toward environmental quality - environmental degradation, environmental action and overpopulation. Further- 
more, they indicate that verbal commitment toward environmental concerns was higher than behavioral commitment. Finally, the global attitudes score for concern for environmental degradation and action was typically a better predictor of general levels of behavioral involvement than single activities.

NOTE Data produced, survey. Sample $=660$ undergraduate and adults, 207 middle-class housewives, 51 environmental ists. No sampling technique specified.

$S E Q \# \quad 84$

AUTH Macginite, W.H.; Tretiak, R.

TITL Sentence Depth Measures as Predictors of Reading Difficulty

PUBL Reading Research Quarterly

DATE 6. 3:364-77 spr 1971

KEY macg7la

SRCH information processing, readability

ABST Two summary measures of sentence complexity--depth of postponement and number of levels in a sector analysis--were evaluated as predictors of reading difficulty. Criteria were cloze scores and listed grade level equivalents for $8 \emptyset$ of the McCall-Crabbs standard Test Lessons in Reading. The Lorge Readability Formula was also recalculated, using both the Test Lessons and the Miller-Coleman Readability Scale. The two sentence complexity measures were found to be highly correlated with sentence length and similar to it as predictors of reading difficulty. The revised Lorge Formula is considerably simplified. It omits the ratio of prepositional phrases, which was shown to be an unreliable contributor to prediction when used in combination with vocabulary load and sentence length.

NOTE Data produced, correlations between 2 measure of sentence complexity.

SEQ\#

AUTH

TITL

PUBL

DATE

KEY

SRCH

ABST
85

Maloney M. \& Ward M.

Ecology: Let's Hear From the People - An objective Scale for the Measurement of Ecological Attitudes and Knowledge

28 pp. 583-586 July 1973

malo73a

methodology, attitudes-ecology, environmental knowledge

The purpose of this study is to devise a measure of ecological attitudes and knowledge. By developing such a scale, Malony and ward hope to better predict, modify and control "critically relevant behaviors" or the public. The ecology scale is comprised of four subscales with a total of 130 items. The verbal commitment scale, consisting of 36 items, measures what a person states he is willing to do in refer- 
ence to environment-pollution issues. The actual commitment subscale, containing 36 items, measures what a person actually does in relation to ecological issues. The affect subscale, consisting of 34 items, measures the degree of a person's emotionality related to environment-pollution issues. The knowledge subscale, containing 24 items, measures specific factual knowledge related to ecological issues. The validity of these subscales was tested by a contrasted-groups approach. Members of the sierra Club, undergraduates at California state University at Los Angeles and non-college educated adults were given the scale. A series of t-tests reveals that the sierra Club group scored significantly higher than the college and non-college groups on all subscales. Furthermore, college subjects scored significantly higher than non-college subjects on all subscales. Intercorrelation among the subscales revealed that the knowledge subscale did not correlate significantly with any of the other scales for any of the groups. The affect subscale correlated moderately high with the verbal commitment subscale 1.59 college, .75 non-college, .72 sierra $(\mathrm{lub})$. The verbal commitment scale correlated moderately high with the actual commitment subscale (.40 college, .39 non-college, .45 Sierra Club). The degree of relationship between the affect subscale and the actual commitment subscale for the college and non-college groups was .40 and .39 , respectively. The same relationship was significantly higher, .83 , for the sierra Club group. The authors warn that, "due to the preliminary nature of the present data, conclusions must be tentative." Several interesting trends are noted, however. Most persons given the scale have a high degree of verbal commitment and affect, with lower levels of actual commitment and knowledge. The authors conclude by saying, "from the psychologist's point of view, high levels of concern over ecological issues and high verbal commitment to those issues should make fertile soil for the modification of ecologically relevant behaviors."

NOTE Data produced, scale for measuring ecological attitudes and knowledge. A reprint of full paper may be obtained from authors.

SEQ\#

AUTH

TITL

PUBL

DATE

KEY

SRCH

ABST
86

Marsh, P.; Dolan, R.J.; Riddick, W.L.

Anomia and Communication Behavior: The Relationship Between Anomia and Utilization of Three Public Bureaucracies

Rural Sociology

32. 4:435-45 dec 1967

$\operatorname{mar} 567 a$

information sources, information services

It appears theoretically sound to hypothesize that anomia and communication behavior are related. Since the highly anomic 
individual is by definition uncertain as to norms (i.e., as to what behavior is appropriate), such individuals are probably less likely to make use of public bureaucracies. A negative association was found between anomia scores and extent of contact with the Agricultural Extension service and between anomia and knowledge of area vocational schools. The relationships were in the hypothesized direction regardless of educational level, though the degree of association was quite low in some categories. However, the data did not support the hypothesis of a negative relationship between anomia and contact with the Employment security Commission. Here the realtionships found were either negligible or positive. Thus the hypothesis is supported by the data on contact with the educational agencies but not by the data on contact with the employment service. presumably, the most anomic individuals are most often unemployed and thus more frequently require the assistance of the employment service in filing for unemployment benefits and in locating employment. This greater need may offset any greater predisposition to avoid contact on the part of the more highly anomic.

NOTE data produced relationships between anomic scores and extent of contact with formal information sources.

SEQ\#

AUTH

TITL

PUBL

DATE

KEY

SRCH

ABST

\section{7}

Mason, w.J.

The Communications Effect of an Industrial Advertising Campaign

Journal of Advertising Research

9. 1:35-38, March 1969

maso69a

methodology, dissemination

Anaconda American Brass Company, a large industrial advertiser of coppermetals, wanted to learn from four buying-influence groups: 1. The qualities they want in a brass mill and its products. 2. The degree to which these buyers believe they get these qualities from Anaconda. 3. The extent to which a three year advertising campaign had affected the attitudes of four buying-influence groups. The four groups were: metal working management executives, represented by readers of steel; design engineers, represented by readers of Design News; purhasing managers represented by readers of pur ehasing; and production managers represented by readers of Production. Anaconda's advertising had appeared in all these magazines as well as their major competitors. A random sample of the individual subscribers of all four magazines were sent a questionnaire and cover-letter as well as a 25 cent incentive. A follow-up letter was sent two days later. The researchers realized a 458 response rate which they bel ieved was adequate. Nine qualities and services of brass mills were 
listed and respondents were first asked to indicate four characteristics most important to them. Next they were asked to rate four brass mills on each of the nine characteristics. They were also asked which of the four named mills used the advertising slogan, "Think Copper." Responses were compared between the group which could correctly identify the phrase as part of Anaconda's advertising and that which could not. Those who could correctly associate the phrase with Anaconda rated that company more highly on the nine characteristics than those who could not. The author concludes that it may be wise for an industry leader to carry the ball, in advertising, for the industry as a whole. Respondents seemed to rate that company more highly than competitors. Anaconda used the general phrase, "Think Copper" which boosted the industry as a whole rather than Anaconda in particular.

NOTE Data produced, mailed survey questionnaire. Sample = Random selection of subscribers to 4 magazines This study tried to demonstrate that if an industry's advertising plugged the industry as a whole rather than its own products and services, then individuals who associated that advertising solgan with the aforementioned company would rate that company's products and services highly. Not sure they can conclude that from their data.

\section{SEQ\# 88}

AUTH Maurice, R.

TITL Citizen Utilization of Network Technology: A National Environmental Information system

PUBL Journal of Environmental Systems

DATE 1. 1:37-46 mar 1971

KEY maur $71 a$

SRCH communication systems, information services, public

ABST The effectiveness of citizen participation in complex decision making can be enhanced by citizen acess to modern computer systems. Such systems, refered to as networking technologies, allow for the rapid, simultaneous, interactive manipulation and storage of large numbers of inputs and outputs from and to diverse sources. Citizen groups and public interest organizations are currently involved in a variety of activities whose effectiveness could be increased by participation in a shared national environment information system. Some specific uses of the system, problems of development, and next steps are discussed.

SEQ\# 89

AUTH Mclaughlin, G.; Haskins, J.; and Feinberg, B.

TITL An Economical Technique for Presenting Communications Campaigns

PUBL Journal of Applied Psychology 
KEY

SRCH

ABST

NOTE

SEQ\#

AUTH

TITL

PUBL

DATE

KEY

$\mathrm{SRCH}$

ABS'I'

DATE 54. 4:331-333, 1970

\section{mcla70a}

methodology, dissemination, mass media

Pretesting messages for a public service campaign using the mass media can be expensive if the messages are prepared with all the polish necessary for the final presentation. This experiment indicated that the relative interest of different television messages could be gauged by simply asking people to rate their interest of a printed statement based on the main proposition embodied in each final message. Ten one-minute movies were professionally produced on a variety of public service topics. A two-sentence statement concerning the main message of each movie was prepared to correspond to each film. Availability samples of male college students were used. Group 1, 25 male college students, saw five different films; after each film they were shown a transparency presenting one of the other five topics in propositional form. Group 2, 25 male college students, was also shown all ten topics but they saw films of the topics Group 1 saw in propositional form and vice versa. Group 3, 20 male college students, saw each topic in both forms. After viewing a topic, each subject was required to rate it on an interest thermometer scaled from 1-100. The absolute interest ratings were converted to rank $r$ atings for each subject.. Spearman-Rank Order correlation coefficents were calculated. and showed $r=.68$ for groups 1 and 2 . The coefficient for film vs. propositional statement was .78 . The authors conluded that the relative interest of films can be predicted with fair accuracy from propositions embodied in them. Pretesting propositions by the intest rating technique is advisable as well as economical

Data produced, experimental. Subjects = available male college students.

\section{0}

Mehrabian, A.; Russell, J.A.

A Verbal Measure of Information Rate for studies in Environmental Psychology

Environment and Behavior

6. $2: 233-52$ jun 1974

mehr $74 a$

information processing

ilhe information rate from a stimulus is a correlate. of the arousal elicited by it. To develop a convenient, verbal measure of information rate, 214 undergraduates rated 6 verbal descriptions using 21 paired-adjective scales. In addition, measures of the pleasure, arousal and dominance elicited by each description were obtained. Following data reduction and the elimination of items with an evaluative bias (i.e. associated with pleasure reactions), a 14 item scale remained whose items were significantly associated with arousal but 
not with pleasure or dominance reactions. The association of scale items with arousal was cross-validated in a 2nd study employing photographic slides as targets. Findings indicate the construct validity of the scale through the information rate-arousal hypothesis. The second study also provided reliability information about the scale. It is concluded that the measure should be helpful in assessing information $r$ ate of situations across many modes of presentation.

NOTE Data produced, a verbal measure of information rate. Interesting idea, though underdeveloped conceptually.

SEQ\# 9BA

AUTH Melber, Barbara D.; Stanley Nealey; Joy Hammersla; William Ranken

TITL Nuclear Power and the Public: Analysis of Collected Survey Research.

PUBL. Battelle Human Affairs Research Centers (Seattle)

DATE November, 1977

KEY mel77

SRCH attitudes-energy, attitudes-environmental, atti tudes-nuclear,power plants, public opinion polls, review-public opinion polis

ABST This study is a review and synthesis of over 100 . exisitng surveys dealing with public attitudes towards nuclear power issues. Questions of immediate policy relevance were posed and answered on the basis of the findings. Does the public support nuclear power? The results suggest the majority of the public favors the use of nuclear energy. Support $r$ anged from $4 \emptyset$ to 80 percent, with the average across studies being about 60 percent. This support declined in the short term if the nuclear plant was to be located "nearby". As the plant came closer to being a reality, support increased. There is also a tendency towards strong, polar attitudes on the nuclear power question. There is little indication that those who remain undecided -- typically from 11 to 32 percent of those polled - have either latent pro or anti-nuclear power attitudes. Demographic analysis revealed no group where opposition. exceeded support. However, support was strongest among those who were male, middle aged, better educated, with higher income and who lived in western states. The most critical issue determining one's overall appraisal of nuclear energy was the safety issue. Nuclear explosion and radiation were the prime dangers perceived. Specifically, the question of what to do with nuclear wastes was the most pressing concern. A majority, however, believed technology could eventually solve safety problems, including waste disposal. Most pronuclear advocates saw economic advantages to nuclear power -- a trend apparent since the early 1960's. Since 1973, as concern with fossil fuels has grown, the ability of nuclear energy to 
fill growth needs with limited pollution has become the most cited advantage by this group. Among all respondents, economic advantages predominated. A majority considered nuclear power most likely to become less expensive in the future. However, when nuclear was compared with other sources of energy, solar energy was favored by the largest segment of the public. Coal was least favored. In all studies reviewed, nuclear energy was supported by at least a majority or a plurality of those surveyed. General orientations toward energy affected specific reactions to nuclear power. Those believing in expanding the energy supply tended to support nuclear power, while those favoring conservation were less supportive. Most of the publuc believed conservation in principle was good, but also felt that economic growth and standard of living would be reduced by it.

\begin{abstract}
SEQ\# 91
AUTH Miller, G.R.; Coleman, E.B.

TITL The Measurement of Reading speed and the obligation to Generalize to a Population of Reading Materials

PUBL Journal of Reading Behavior

DATE 4. 3:48-56 sum 1971-72

KEY mill72a

SRCH review-reading behavior, methodology

ABST Although most studies of reading behavior have little scientific value if their conclusions have to be restricted to the specific materials that were used in the experiment, reading researchers have seldom used designs that would enable them to generalize beyond the particular letters, words, sentences, and so on they chanced to use. Data from an experiment by Carver are used to show that it is therefore likely that many experimente could not be replicated if different samples of materials were drawn. Evidence is also given that reading speed, if measured in a fine-grained unit such as letters per second, does not increase as passages become more difficult. but is constant across a range that extends from first-grade texts to technical prose.
\end{abstract}

\footnotetext{
SEQ\# 92

AUTH Montague, Susan \& Beardsworth, Edward

TITL Benefit/ Rick - A Critique and Cultural Analysis for NonQuantitative Risk Assessments

PUBL . Unpublished Paper of Battelle Science and Government study Center

DATE December 1974 1-16 pp.

KEY mont74a

SRCH risk, review-risk/benefit

ABST This paper consists of two parts - first, a critical treat-
} 
ment of some of the risk/benefit literature, and second, an analysis of how lay Americans assess risk to life. The author' discussion of the $\mathrm{risk} /$ benefit literature includes such areas as: the difficulties of defining $r$ isk and benefit; the formulation of statistical and non-statistical risk models; the assessment of publically acceptable levels of $r$ isk for any given project; and the problems of quantitative measurement of $\mathrm{risk}$ and benefit. In analyzing how lay. Americans assess $r$ isk to life, the authors interviewed their families and friends as well as a number of physical scientists at Brookhaven Laboratory. From these informal interviews, the authors found that even scientists tend not to formulate risk assessments in statistical terms in everyday situations. Instead, they seem to hold several "core criteria" with which to assess various risks. For example, when assessing the risks of using different modes of transportation the interviewees consider these criteria - 1) individual control over accident occurences 2) whether or not accident occurence automatically means fatality for the individual 3) whether the individual can modify accident results by his actions subsequent to the accident. Al though many of the interviewees know the statistical risks involved with each mode of transportation, the non-statistical criteria weighed more heavily. They admit that statistics indicate that their ordering of $\mathrm{r}$ isk is incorrect, but they also note that when they act on statistics which contradict their assessment they are quite uncomfortable. The authors conclude that "the brief data analysis presented is hardly conclusive, but offers some possibilities for theoretical refinement of public risk assessment." There seem to be non-statistical calculation systems or formulations which are used by people in American culture for assessing risk. With further study these systems can be more thoroughly examined.

NOTE Data produced, informal interviews conducted with an unknown number of physical scientists.

SEQ\# 93

AUTH Muchinsky, P.

TITL Attitudes of Petroleum Company Executives and College students Toward Various Aspects of the 'Energy Crisis'

PUBL Journal of Social Psychology

DATE 98 pp 293-294 April 1976

KEY much76a

$\mathrm{SRCH}$ interest groups, attitudes-energy

ABST The purpose of this study was to ascertain the attitudes of petroleum. company executives and college students toward various aspects of the energy $\mathrm{cr}$ isis. To do so, 26 executives and 328 undergraduate students at lowa State University were given a 30 item questionnaire. The items dealt with different 
aspects of the energy $c r$ isis and represented four categories of response: 1) causes of the energy crisis 2) solutions to the energy crisis 3) personal involvement with the energy crisis 4) present and future status of the energy crisis. On a separate questionnaire, the subjects $r$ anked the importance of six major problems facing the United States in 1974. A one way analysis of variance was computed for the resposes of the company executives and students to the first questionnaire. A Spearman rank order correlation was computed for the average rank given to the social problems by the two groups on the second questionnaire. Significant differences (p.05) between the attitudes of the executives and college students were found for 13 of the 30 items, involving all four categories of response. In general, students perceived the major oil companies as being primarily responsible for the energy crisis; and petroleum company executives tended to perceive the federal government as being primarily responsible for the energy crisis. Both groups ranked the social problems of economics, corruption in government and the energy crisis as first, second and third, respectively, in importance ( $\mathrm{rho}=$ .848). The major difference (p.001) between the two sets of rankings involved the problem of ecology, which students ranked fourth in importance and executives ranked sixth, or last, in importance.

NOTE Data produced, survey. Sample $=26$ petroleum executives and 328 undergraduates. No sampling technique specified. This article is a summary. For fuller data, contact author.

\section{SEQ\# 94}

AUTH Nelson, S.D:

TITL Nature/Nurture Revisted One: A Review of the Biological Bases of Conflict

PUBL Journal of Conflict Resolution

DATE 18. 2:285-335 jun 1974

KEY nels74a

SRCH review-conflict, conflict

ABST Biologically oriented approaches to the study of human conflict have thus far been limited largely to the study of aggression. A sample of the literature. on this topic is reviewed, drawing upon four major approaches; comparative psychology, ethology (including some popularized accounts), evolutionary-based theories, and several areas of hullan physiology. More sophisticated relationships between so-called "innate" and "aquirred" determinants of behavior are discussed, along with the proper relevance of animal behavior studies for human behavior. Unless contained in a comprehensive theory which. includes soctal and psychological variables, biologically oriented theories (although often valid within their domain) offer at best severely limited and at 
worst highly misleading explanations of complex social conflicts. The review concludes with a list of several positive contributions of these biological approaches and suggests that social scientists must become more knowledgeable about them.

SEQ\#

AUTH

TITL

PUBL

DATE

KEY

SRCH

ABST

\section{5}

Nicholson, S.; Fries, M.

Women, Society, and the Environment

American Biology Teacher

36. 5:275-78 may 1974

nich74a

interest groups

Surveys the importance of women, actual and potential, to environmental problems, and suggests some solutions to women related dilemmas both in terms of present and future roles.

SEQ\#

AUTH

TITL

PUBL

DATE

KEY

SRCH

ABST

96

Novic, K.; Sandman, P.M.

How Use of Mass Media Affects Views on Solutions to Environmental Problems

Journal ism Quarter 1 y

51. $3: 448-52$ aut 1974

novi74a.

audiences, mass media, magazines, problem solving

This study investigates whether reliance on mass mediated environmental information discourages the audience from developing a personal commitment that alternative information sources may foster. Two related hypotheses were presented; 1) respondents who rely more heavily on the mass media for environmental information will consider themselves less informed, the issues less serious, and the appropriate solutions less personal than respondents who rely more on non-mass information sources, 2) respondents who judge themselves more informed and the issues more serious will tend to choose personal solutions only if they are relatively heavy users of non-mass information sources. Eight environmental issues were presented to 158 undergraduate and graduate students. They were asked to select 3 sources from a list of 15 which they felt they had learned the most about the issue. Of this list, 4 were "mass media" and 9 were "specialized". (campus "hip" or environmental publications) as well as interpersonal and "other" sources. Subjects were al so asked to indicate how informed they felt they were about the issue, how serious they perceive the problems to be, and to choose one of 3 (personal = lifestyle change, societal, or mixed) "alternative" solutions. The results support the hypotheses; high mass media users considered themselves less informed, viewed issues as less serious, and preferred less personal solutions to the 
problems

NOTE Data produced, survey of perceived information level, seriousness and solutions to environmental issues. The results are highly suspect due to a lack of attention to some important variables that may confound the data (such as past experience with the issue) and some dubious distinctions made between mass and non-mass sources (--all sources were vicarious and "one-way" except for interpersonal and it was on the basis of this "distance from the issue" that the hypotheses were presumably formulated and results interpretated. Further, the efficacy of the 3 "kinds" of solutions were not comparable.

\section{SEQ\# 97}

AUTH Oats, W. R.

TITL Social and Ethical Content in Science Coverage by Newsmagazines

PUBL Journalism Quarterly

DATE 50. 4:680-84 win 1973

KEY

$\mathrm{SRCH}$ oats $73 a$

ABST An argument was presented for the inclusion of social and ethical content in hard news reporting so that people can become aware of the implications scientific developments have in regard to these human concerns. The study addresses 2 main questions: 1) to what extent does social and ethical content occur in newsmagazine science articles, 2) is there a delayed diffusion pattern for social and ethical content in science news that appears after a newsmagazines initial "hard news" coverage. A case study approach was utilized. A semantic content analysis technique known as word designation analysis was used to measure social and ethical content in 3 national newsmagazines science articles on "heart transplants". Intercoder reliability was 568 . Further, the subjective rankings of social and ethical content by a jury of science writers correlated with the studies objective measure at the $>83$ level. The results indicate that in general newsmagazines tended to provide social and ethical content on a timely basis in proportion to the amount of hard news coverage for a particular story. This content fell off almost as rapidly as aid the hard news itself and thus a delayed dirfusion of social and ethical content was not observed. It was noted that the study was not able to seperate social and ethical content that was an intrinsic element of the news itself from that which was the result of responsible initiative on the part of the press.

NOTE Data produced, content analysis of science news articles. 


\author{
SEQ\# 98 \\ AUTH Orr, J.C. \\ TITL Sponsorship, Self Presentation and Legitimacy \\ PUBL Communication Monographs \\ DATE $43.1: 801976$ \\ KEY orrj76a \\ SRCH communication effectiveness
}

ABST This study examined the influence of oganizational sponsorship and a representative's style of self presentation of the legitimacy of a request, compliance with a request, and endorsement of a sponsor. Social serving sponsorship produced greater legitimacy, compliance and endorsement than profitmaking sponsorship; and a self disclosing representative produced greater legitimacy, endorsement and compliance than a non-self disclosing representative under the condition of profit making sponsorship. Results are interpreted from a social exchange perspective.

\title{
SEQ\# 99
}

AUTH Peters, C.w.

TITL The Effect of Systematic Restructuring of Material upon the Comprehension process

PUBL Reading Research Quarterly

DATE 11. 1:87-111 1975

KEY pete75a

SRCH

ABST

information processing, readability

The Frayer model of concept attainment was used to develop social studies materials which were compared to materials patterned after those found in many social studies textbooks. The experiment attempted to ascertain whether the Frayer model was superior to the textbook approach as a method for defining concepts so that they are comprehended by good and poor readers at the ninth grade level. The Frayer model offers a systematic procedure for defining concepts. It structures material in a manner designed to facilitate comprehension for both good and poor readers. Comparisons were made between the effect of the methods of concept presentation in materials developed according to each method. Three arrangments of material for each method ordered 3 concepts or examples of these concepts in chronological, topical, and reverse chronological presentations. Embodied within the comparison was the additional factor of the influence of organizational patterns of written material exerted on the comprehension process. The results indicated that both good and poor readers who utilized material organized according to the guide1 ines established by the Fryayer model received significantly higher comprehension scores according to the textbook approach. However, arrangement of concepts and concept examples within both the Frayer and textbook methods had no effect on comprehension scores. A test based on the special materials 
NOTE

was developed to measure comprehension.

Data produced, experiment observing the effect of selected readability variables on reading comprehension. Sample = good and poor readers at the 9 th grade level.

\begin{abstract}
SEQ\# 100
AUTH Petrie, C.R.; Carrel, S.D.

TITL The Relationship of Motivation, Listening Capability, Intial Information, and Verbal Organizational Ability to Lecture Comprehension and Retention

PUBL Communication Monographs

DATE $43 \quad 3: 187-94 \quad 1976$

KEY petr76a

SRCH readability

ABST Multiple linear regression analysis was used to determine the relationship of six predictor variables to immediate comprehension and delayed retention of a lecture. Listening comprehension ability and extrinsic motivation accounted for a statistically significant proportion of the variance in immediate lecture comprehension scores; and initial information, aroused interest, and intrinsic interest were found to be the best predictors of delayed retention of the materials. However, intrinsic interest was inversely related to delayed retention. The data suggested that although persons with high initial information and low intrinsic interest did not comprehend the lecture any better than others, they retained more of what they heard. Thus the variables which most influence lecture comphrehension may not significantly influence the delayed retention of what was heard.

NOTE Data produced, experiment examining the relationship between comprehension and retention of a lecture and audience variables (interest level, information level, comprehension ab1lity).
\end{abstract}

\title{
SEQ\# 101
}

AUTH Pettus, A.

TITL Environmental Education and Environmental Attitudes

PUBL Journal of Environmental Education

DATE

KEY 8. $1: 48-511976$

$\mathrm{SRCH}$ pett76a

ABST

review-environmental attitudes, environmental education, attitudeswenvironment

Current research related to the measurment of enviornomental attitudes and factors influencing those attitudes is reviewed. The author concludes that available evidence indicates a number of factors influence environmental attitudes and the environmental problem is more soclal than scientific or technological. 
$\begin{array}{ll}\text { SEQ\# } & 162 \\ \text { AUTH } & \text { Phillips, K.J. } \\ \text { TITL Citizen Participation in the York River Basin Study: The Use } & \text { of the Value Trade-off Questionnaire } \\ \text { PUBL Journal of Environmental Systems } \\ \text { DATE } & 6.3: 243-521976-77 \\ \text { KEY } & \text { phil7677a }\end{array}$

SRCH site selection, public, decision making, methodology, land use, values

ABST Effective environmental plans for a River Basin can only be accomplished by including the public in the planning process. Conventional public participation methods such as hearings cannot by themselves effectively be used as a screening tool, for they rarely represent a true cross-section of the Basin's population, and their results are often chaotic, confusing and difficlut to interpret. A new tool for including the public's values was tested and implemented in the virginia, York River Basin study. A value trade-off questionnaire comprised of four questions was administered to a selected group of twenty-four citizens representing six different groups of people in the York River Basin. Each Question addressed a different trade-off germane to the selection of the York. River Basin Enviornmental plan. The result indicated a strong desire for environmental protection and the willingness to pay for that protection through economic development, if necessary. The questionnaire proved easy to administer, interpret, and provided a quantitative measure of peoples preferences necessary for effective implementable planning

NOTE Data produced, survey of trade-off values. Sample $=24$ citizens. This article discusses another instrument of a genera designed more to produce information for interested parties than to adequately ascertain public attitudes toward a particular project. Questions as to whether the "tradeoff's". represent the full scope of possible ways to deal with the problems created by the River Basin project, or are just artifacts of a particular point of view--those of the developers and what THEY are willing to trade off (i.e. a "set" agenda) are not addressed. Other instruments of a similar nature are most "risk-benefit" instruments (how well can 10 deaths in a 100 years as a value level be meaningfully related to the the acutal kinds of events and issues that are raised by the topic of nuclear power utilization), as well as a good number of "simulation games". Another criticism of this particular study is that the authors would be hard pressed to defend their contention that they are observing public participation, when they have conducted a non-random sample of 6 potential "interest groups" rather than sampling the public at large. 


\begin{abstract}
SEQ\# 103
AUTH Pigg, K.

TITL Part II: A Statement on the state of the Art: Methodologies for Studying Environmental Perceptions, Attitudes, Values, and Beliefs, and the Utilization of Such studies

PUBL Cornell Journal of Social Relations

DATE 10. 1:7-61 spr 1975

KEY pigg75a

SRCH review-environmental perceptions, review-methodological environmental, attitudes-environmental

ABST Reports of working groups during the workshop and parts of the proceedings are discussed in order to explore ideas, problems, sucesses, and failures concerning the environment. Some of the problematic areas included: 1) conceptual distinctions between cognitions, perceptions, attitudes, values, and beliefs; 2) linkages between psychological states and behavior; 3) conceptualizing environmental quality; 4) designing studies and operationalizing concepts to facilitate following change over time; 5) problems and utilities of multimethod measurement of concepts; 6) measuring perception of possible but not currently real environments; and 7) minimizing semantic confusion. Three important topics emerged from the discussion of utiliztion: a) the variation of the contexts with early researcher-user interaction and research expectation of the user, b) the variability meaning attached to research utilization and $c)$ the diversity of potential users. Content and problems of utilization and conditions favoring utilization of research were discussed. Things the Workshop did not do that it should do in the future are: a) the level of detail and depth of examination. was inhibited, b) macro units should be explored because they may provide better understanding for analyses of the decision-making process, c) the research method should be further. explored, and d) the activation of social scientists interested in environmental problems should be explored.
\end{abstract}

\title{
SEQ\# 104
}

AUTH Plummer, J. T.

TITL A Theoretical View of Advertising Communication

PUBL Journal of Communication

DATE 21. 4:315-25. dec 1971

KEY plum7la

SRCH review-advertising communications

ABST It is proposed that advertising research be based less on one-way transmission models of communication and more on multivariate studies with emphasis on receiver's contribution to communication outcomes. A four-level model of the process is presented and several dimensions within each level are 1dentified, based on recent research on commercial effects. The four levels are 1) the unconscious level, 2) the immediate perceptual level, 3) the retention or learning level, and 4) 
the behavior level. Research at each level is discussed.

SEQ\# 105

AUTH Porter, A.; Costello, R.E.E.; Plourde-Gagnon, $S$; McCague, G.A.; Stevenson, W.W.

TITL Outreach Guidebook

PUBL Royal Commission on Electric Power Planning

DATE $1976 \quad 1-108 \mathrm{pp}$.

KEY port76a

SRCH site selection, dissemination, public particpation, electricity

ABST The Royal Commission on Electric Power Planning (RCEPP) is charged with conducting an independent investigation of the future electrical power needs of Ontario province. To determine these needs, the commission has set about to solicit citizen input in a variety of ways. Upon its formation, the Commission made a call for submissions, and initiated a series of preliminary public meetings. At the preliminary meetings a number of concerns were expressed, all of which assisted the commission in defining the major issues and shaping the direction of the inquiry. As a direct follow-up from the preliminary meetings, the Commission encouraged the formation of regional discussion groups, which were to identify regional viewpoints. To stimulate interest in these meetings, the commission distributed literature to various regional libraries and produced a television program on energy in Ontario province. Furthermore, the commission has set up displays and exhibits, sponsored a symposium (aimed at the academic and business communities), and conducted workshops. The "Outreach Guidebook" provides additional ways for public involvement - how to make a submission, how to use the commission's issue papers, media sources available from RCEPP, and a bibliography on energy matters.

NOTE The booklet offers a variety of ideas on how to solicit public input.

SEQ\# 106

AUTH Porter, A.

TITL The Decision-Making Framework and Public Participation Issue - Paper \#8

DATE May $1977 \quad 1-37$ pp.

KEY port77b

SRCH decision-making, public participation, land use, site selection, electricity

ABST This report is an attempt to provide a framework for public participation and decision-making on the future power needs of Ontario province. The report states that involvement of the public in planning presently takes a variety of forms, 
differing at different steps of the planning process: participation in working groups, citizen committees, and public information meetings at the study stage; presentation of briefs at public hearings at the review stage; and comment on the review board's report at the approval stage. The report concludes that the effectiveness of public involvement "shall not be measured by public approval for the study but rather by the completeness of the opportunity for involvement and exchnage of information." The report also suggests that demand, supply and financing of electric power in ontario province "are interrelated and decisions in any one area can not be made in isolation. Therefore, mechanisms for coordinating and rationalizing decisions in their total context should be discussed."

NOTE Data produced, a discussion of public participation and decision-making over future electric power needs of Ontario province.

SEQ\#

\section{7}

AUTH

TITL

PUBL

DATE

KEY

$\mathrm{SRCH}$

ABST

Presser, H.A.

Measuring Innovativeness Rather Than Adoption

Rural Sociology

34. 4:510-27 dec 1969

pres69a

diffusion, innovation

The concepts of innovation, innovator, and innovativeness are discussed in relation to the contexts from which the words derive meanings. Five methods of measuring innovativeness are tested against a criterion of: being categorized as an innovator in any of the practices, twice, once, or never. The total number of practices ever adopted at any time, the total number of practices ever adopted early (within the first $16 \%$ of adopters in any practice), the totals of sten scores, and the totals of sten scores of 9, 8, or 7 only, (all) are not satisfactory measures of innovativeness. A new method of weighting for very early adoption gives higher scores to those who were innovators twice than to any who were never innovators. All who were innovators at least once obtain scores that place them within the first 158 of the population.

SEQ\#
AUTH
TITL
PUBL
DATE
KEY
SRCH

ABST

108

Pul ford, D.L.

Follow-up of Study of Science News Accuracy

Journalism Quarterly

53. $1: 119-21$ spr 1976

pulf $76 a$

science writing, content analysis

In a previous study (Tankard \& Ryan 1974) it was reported 
that science news stories had an average of 6.2 errors per story. This study was designed to determine whether or not error rate is partly a function error type list length (earlier studies, reporting fewer errors also used shorter error typologies) by replicating the Tankard \& Ryan study using a shorter checklist of errors. A second purpose was to investigate the "seriousness" of these errors. The study used a sample of 166 science news articles from 9 Texas daily newspapers. The principle source cited in these articles were sent copies of the articles and asked to indicate the number and kind of errors they perceived in the story. The response $r$ ate for scientist-sources was 86.18. The average error rate was 2.16 per story. This lower rate was partly attributed to the use of a shorter checklist of errors. Performance was weakest regarding "misleading headlines" (32.28) and "mistatements of fact". (28.08). Further, a large proportion of the errors dealt with omissions of information stories. The author suggests running fuller, if fewer, stories to compensate for this and to place the article's contents in a more applicable and pertinent context for the reader.

NOTE Data produced, content analysis of errors in science news stories. The "error checklist" could be useful.

SEQ\# 109

AUTH Pyrczak, F.

TITL Objective Evaluation of the Quality of Multiple-choice Test Items Designed to Measure Comprehension of Reading Passages

PUBL Reading Research Quarterly

DATE 8. 1:62-71 1972

KEY pyrc72a

SRCH readability

ABST The quality of reading comprehension test items may be determined, in part, by computing an index that indicates the extent to which correct answers to such items can be identified in the absence of the reading passages to which they refer. Data obtained in this study indicate that such an index can be determined with an adequate degree of reliability. The data are used to illustrate how the strenghts and weaknesses of paticular items may be determined. Procedures that have been used to varying degrees in the past for poducing reading comprehension items of high quality are discussed.

NOTE Data produced, procedures developed for accounting for the influence of non-test information on reading comprehension tests.

SEQ\# 110

AUTH Quinn, R.E.

TITL Using Value sheets to Modify Attitudes Toward Environmental Problems 
DATE 13.1:65-59 jan 1976

KEY quin76a

SRCH attitude change

ABST Studied the effect of value sheets (short lessons on current environmental problems accompanied by a series of questions) on high school students expression of environmental attitudes. Found that the value sheets did not change the attitudes of students in the experimental group as measured in the study.

NOTE Data produced, experimental. Sample = High school students.

\section{SEQ\# 111}

AUTH Radzicki, J.

TITL The Effect of Some situational Factors on Probabilistic Diagnosing

PUBL Polish Psychological Bulletin

DATE 6. 3:147-56 1975

KEY r adz75a

SRCH risk, problem solving

ABST Tested a probabilistic diagnosing in a risky situation in which the subject could acquire as much information as he wished before stating his diagnosis. Sixteen 22-30 year old females and 44 18-42 year old males were asked to make judgments as to which of a certain number of populations of known parameters a drawn sample belonged. It was found that the number of cognitive responses and amount of acquired information increased, and the subjective probability of corrertness of diagnosis decreased, parallel with a $x$ ise in the number of alternative states of nature. Results suggest that the subjective value of information acquired through cognitive responses drops with the decrease of subjective uncertainty as to the real state of nature.

NOTE Data produced, experiment relating amount of information to subjective certainty. Sample $=16$ females, 44 males. An inverse relationship was found.

\section{SEQ\# 112}

AUTH Ramsey, C.E.; Rickson, R.E.

TITL Environmental Knowledge and Attitudes

PUBL Journal of Environmental Education

DATE 8. 1:10-18 1976

KEY

SRCH

ABST

\section{r ams $76 a$}

environmental knowledge, attitudes-environment

Utilizing a sample of 482 high school seniors, this research further investigates the relationship between four different kinds of attitudes and two types of knowledge (ecological and trade-off) relevant to environmental issues. Research and analyses procedures are detailed. Results indicate that knowledge appears to lead to a moderation of attitudes.

NOTE Data produced, survey. Sample $=482 \mathrm{high}$ school students. 
SEQ\#

AUTH

TITL

PUBL

DATE

KEY

$\mathrm{SRCH}$

ABST

113

Richardson, Robert A. The Selling of the Atom - How Oak Ridge Associated Universities Initiated a New Kind of Informational Endeavor

Bulletin of Atomic Scientists

October 1974 pp. 28-35

rich74a

attitude change, dissemination, nuclear, power plants, land use, site selection, utilities, public, community

The first part of this article is an account of the Midland reactor controversy based entirely on the Oak Ridge Associated Universities (ORAU) publication - "Report on Community Workshops on Radiation and Reactors, Midland, Michigan, November 1970." The second part of the article examines some of the issues raised by ORAU's activities and its published descriptions and appraisal of them. The third part of this article offers several proposals for opening public discussion in future nuclear power plant siting controversies. ORAU initiated a new kind of informational endeavor in October 1970 by preparing and presenting a series of workshops on nuclear energy in the Midland area. Members of the ORAU staff felt that formal speeches confronting the issues directly would promote contention and heighten controversy. Thus, they presented a series of workshops to some 580 citizens and community leaders in small group settings. During the first half hour of each session which was devoted to the basics of radiation, each participant was given the opportunity to do experiments with sources, counters, and shielding materials. The second half of each workshop was devoted to a basic presentation on reactors, radioactive wastes and emission standards. By sticking to. these basic areas, the ORAU team was able to avoid becoming involved in the local controversy. This was in keeping with their wish to engage in "positive, confident, but not contentious exposition." Richardson agrees with the ORAU report that there is a need for educating the public about nuclear power. However, he faults ORAU in its attempt to educate the public. First, Richardson writes, the group might have "announce(d) their presence, state(d) their hopes regarding the outcome of the reactor decision, and indicate(d) their plans for attempting to secure that outcome." Second, Richardson writes, " because of their biases and the nature of the controversy, they were incompetent by themselves to educate the public. (Thus) the ORAU people should have invited the plant's opponents to join with them in the conduct of the workshops...each side might have been more disposed to offer all the facts and do justice to all the uncertainties than either was likely to do when addressing the issues alone." Thus, Richardson suggest a full airing of the facts and issues surrounding nuclear power plant siting. He 
advocates a "full, extended and open discussion of the issues so that the public is given the best possible chance of making an informed and sound judgement." Finally, he calls for "an effective means for the public not merely to express its opinions about what it wants but to make decisions as to what it shall have."

NOTE No new data. Commentary on a report written by ORAU.

\begin{abstract}
SEQ\# 114
AUTH Robinson, E.J.

TITL Analyzing the. Impact of Science Reporting

PUBL Journalism Quarterly

DATE 40. 3:306-14 sum 1963

KEY robíza

SRCH public opinion, science writing, public, science coverage, interest groups, understanding, audiences

ABS'I' 'Three areas of science writing and its relationship to lay audiences are discussed. These are the extent to which persons feel that they understand science news, their perception of science's credibility, and the impact of science news on their behavior. Some 778 of the respondents when asked if they thought that they would understand what was being discussed in a "scientific conference" said they would only understand $1 / 2$ of the conversation or less $(408$ said "little or nothing). Two main reasons for this lack of understanding were offered; a) they felt they lacked knowledge of the subject matter and terminology and b) the respondents questioned whether they were intelligent enough to grasp the ideas that would be discussed. Credibility was measured by showing respondents a science headline and asking them if they believed it and how they would feel if the headline actually occurred. It was found that the physical sciences enjoy a clear super 1ority over the medical and social sciences in terms of perceived credibility. Further, while most appeared to be favorably disposed toward greater scientific control over impersonal matters, they do not reflect this attitude with regard to more personal aspects -- which are seen as against "God" or "Nature". Though 538 of the respondents reported that scientific developments had affected their behavior, a large proportion of them were not able to articulate just how science information had affected them when asked about "effects" in general. When quizzed abuut epccific science information ( $r e$. smoking, polio and seat belts) the respondents were more articulate. The author suggests that while the public appears to be "aware" or scientific developments, they are not "internalizing" this information in a manner such that they could keep abreast of and understand the impact of these developments.
\end{abstract}

NOTE Data produced, survey. Non-probability sample = "all major 
occupational, age, religious and educational categories. Review of a study done by the author for Esso.

SEQ\# 115

AUTH Rogers, E. \& Beal, G.

TITL The Importance of Personal Influence in the Adoption of Technological Changes

PUBL Social Forces

DATE 36 May 1958 pp. 329-335

KEY roge58a

$S R C H$ diffusion

ABST The purpose of the study is to determine if personal influence is more important l) at certain stages of the decisionmaking process 2) for cetain individuals rather than others. To examine personal influence on the decision-making process, the researchers created a five stage adoption process: 1) awareness stage 2) information stage 3) application stage 4) trial stage and 5) adoption stage. To examine personal influence on different individuals they created a classificatory system of adopters (based on time of adoption): 1) innovators 2) early adopters 3) early majority 4) late majority and 5) laggards. Drawing from previous research in the field, the researchers hypothesized that personal influences would be more important at the early stages of decision-making (ie. information, application and trial stages). Furthermore, they hypothesized that personal influence would be most important for later adopters. To test these hypotheses, data were obtained by field interviews with 148 farm operators residing in central Iowa. The data secured from these interviews supported each hypothesis. That personal influence is important in early stages of decision-making was found to be highly significant. That personal influence is important for late adopters was also supported; however, the findings for this hypothesis are not as significant as those for the first.

NOTE Data produced, field survey. Sample = 148 Iowa farmers. Although the two step flow theory was referred to, it did not provide a conceptual base for the study.

SEQ\# 118

AUTH Rogers, E.M.

TITL Communication and Development: The Passing of the Dominant Paradigm

PUBL Communication Research

DATE 3. 2:213-40 apr 1976

KEY roge76a

SRCH diffusion, innovations, review-diffusion

ABST This article describes the dominant model of development, the factors that led to its decline in intellectual circles after 
about 1970, and the emerging alternatives. The implications of this academic shift in thinking on the role of communication in development are discussed in terms of such issues as the communication effects gap, the content of mass media messages about development, and the limitations of the social structure on developmental communication effects. Greater use of field experiments and network analysis is recommended

NOTE 1 iterature review. Part of an entire issue of CRes. devoted to re-examining notions of diffusion and development.

SEQ\# 119

AUTH Rokeach, M.

TITL

PUBL

DATE

KEY

SRCH

ABST

Change and Stability in American Value Systems, 1968-71

Public Opinion Quarterly

38. 2:222-239 sum 1974

roke $7.4 \mathrm{a}$

values, public, public opinion, national surveys

Employing the Rokeach value Survey, the National opinion Research Center measured the values of an area probability sample of adult Americans 1968 and 1971. Most values remained stable but certain vaules underwent significant changes over this 3 year period. To determine whether the changes were manifested in all segments of American society or only in certain ones, the value rankings were further analyzed for Americans varying in sex, race, income, education and age.

NOTE Data produced, survey of values. Sample = adult Americans.

SEQ\# 120

AUTH Roling, N.G.; Ascroft, J.; Wa Chege, F.

TITL The Diffusion of Innovations and the Issue of Equity in Rural Development

PUBL Communication Research

DATE 3. 2:155-70 apr 1976

KEY roli76a

SRCH diffusion, innovation

ABST

Diffusion strategies, as curently practiced by most change agencies, often lead to increased inequity and therefore might be used as guides for devising revised strategies which avoid what currently practiced strategies predict. This view implies that those who seek more equitable development programs should not carry out further surveys of current diffusion practice, but rather experiment to develop and test ncw alternatives to such usual diffusion programs. One such field experiment in rural Kenya shows that diffusion programs can reach successfully the noninnovative "laggards." Not only did this project obtain 1008 adoption among those reached direct$1 y$, but also had an immediate 3:1 dittusion ettect for each

[Page 108 has been intentionally deleted] 
THIS PAGE

\section{WAS INTENTIONALLY LEFT BLANK}


farmer directly reached.

NOTE Data produced, field experiment on agricultural diffusion. Sample. = non-random selection of farmers. Study results are weakened by poor sampling techniques, but contains mostly a review and discussion of diffusion concepts and practices.

\author{
SEQ\# 121 \\ AUTH Roth, C.E. \\ TITL The Power of the Pen \\ PUBL Nature study \\ DATE $30,3: 1-3,1976$ \\ KEY roth76a \\ SRCH environmental education, communication systems \\ ABST This paper (1) details characteristics of human communica- \\ tions systems, (2) assesses the fundemental concerns of envi- \\ ronmental education, (3) examines how different cultures \\ evolve different perceptions and attitudes towards the envi- \\ ronment, and (4) examines the role the written word will play \\ on shaping Man's response to the environment in the future. \\ SEQ\# 122 \\ AUTH Sachsman, D.B. \\ TITL Public Relations Influence on Coverage of Environment in. the \\ San Francisco Area \\ PUBL Journalism Quarterly \\ DATE 53. 1:54-60 spr 1976 \\ KEY Sach76a \\ $\mathrm{SRCH}$ mass media, public relations \\ ABST none supplied by ERIC \\ NOTE Data produced, content analysis.
}

SEQ\# 125

AUTH Schoenfeld, C.; Murry, A.; Ross, J.; Stamm, K.; witt, W.

TITL Interpreting Environmental Issues: Research and Development in Conservation Communications

PUBL Dembar Educational Research Sevices

DATE 1972

KEY Scho72a

SRCH review-conservation communications

ABST A review of the field of interpreting evironmental issues. Articles from the 1969-72 issues of the Journal of Environmental Education are reprinted with added editorial remarks. The book is divided into 5 sections: 1) the environmental communications ecosystem: an overview of the field, 2) outlines of the ecological message: clarifying content and clientele, 3) environmental media and methods in perspective: roots and trends, 4) the role of interpretation in policy formation: essays and investigations, and 5) conservation 
communications frontiers: reports of behavioral research.

\begin{abstract}
SEQ\# 127
AUTH Seidman, D.

TITL Simulation of Public Opinion: A Caveat

PUBL Public Opinion Quarterly

DATE 39. 3:331-42 fall 1975

KEY seid75a

SRCH public policy, methodology, review-public opinion methodology, public opinion polls

ABST Recent research on the determinants of policy outcomes in American states and related matters has employed simulated state-level public opinion data. This article critically examines the simulation methodology; its assumptions are evaluated, its computation procedures shown to be unnecessarily complicated and innaccurate, and its estimates demonstrated to be logically confounded with the socio-demographic factors that define them, Thus, they cannot be used, as intended, to investigate the role of public opinion in the policy-making process.
\end{abstract}

NOTE 1 iterature review.

SEQ\# 128

AUTH Semple, R. \& Richetto, J.

TITL Locational Trends of an Experimental public Facility: The Case of Nuclear Power Plants

PUBL The Professional Geographer

DATE 28 pp. 248-253 August 1976

KEY Semp76a

SRCH power plants, nuclear, land use, site selection

ABST The study discusses the locational trends of nuclear power plants within the united statco and examinco the premige that regulated experimental public facilities perceived as noxious undergo four distinct phases in the locational process. These phases are identified as experimental, rapid expansion, retrenchment and controlled expansion, and provide, it is hoped, a locational framework within which to examine trends in the location of newer and more experimental public facilities such as coal gasification and solar units that are beginning to make their appearances on the landscape.

\title{
SEQ\# 129
}

AUTH Sharon, A.T.

TITL What Do People Read?

PUBL Reading Research Quarterly

DATE 9. 2:148-69 1974

KEY shar74a 
ABST A survey of the reading habits of a national sample of 5,067 adults was conducted in order to determine what is being read --by whom, for how long, and for what reason and to determine how reading fits into people's daily activities. The results indicate that reading is a ubiquitous activity of American adults. A substantial portion of the waking hours of many persons is spent in reading, frequently during daily activities--such as working, shopping, attending school, church, or theater, and traveling or commuting--and during recreational or free-time activities. Most reading time is spent on newspapers, magazines, books, and job-related matter. Many types of reading on which a relatively short time is spent, however, are an integral part of other activites of the individual, such as reading street or traffic signs while traveling. Although the average person reads for almost 2 hours on a typical day, people differ greatly in the amount that they read. Persons with high socioeconomic status tend to read more of all kinds of printed matter than those with low status. The 58 of all adults who are unable to read have an extremely low socioeconomic status and frequently depend on others to read to them.

NOTE Data produced, national survey of reading activity. Sample = 5,067 adults.

SEQ\# 130

AUTH Sherman, J.L.

TITL Contextual Information and Prose Comprehension

PUBL Journal of Reading Behavior

DATE 8. 4:369-79 1976

KEY sher $76 a$

SRCH information processing, textual variables, readability

ABST One hundred forty-four high school students read four 70 word passages describing fictitious scenes. A partial or complete, verbal. or graphic context was presented before or after each passage. The retention measures were total words recalled, idea units correctly recalled, and number of high-thematic intrusions produced. In all cases, subjects receiving graphic contexts recalled more than those receiving verbal contexts. Recall was greater for concrete passages than for abstract passages. Thus, contextual information was shown to have facilitative effects on comprehension and retention of prose material. Also, the degree to which recall was facilitated varied as a function of the type of contextual information provided.

NOTE Data produced, experiment, recall differences between message formats. Sample $=144 \mathrm{high}$ school students.

SEQ\# 131

AUTH Shingi, P.M.; Mody, B. 
TITL The Communications Effects Gap: A Field Experiment on Television and Agricultural Ignorance in India

PUBL Communication Research

DATE 3. 2:171-90 apr 1976

KEY shin76a

SRCH diffusion, mass media, television

ABST The medium of television in the context of organized teleclubs with carefully designed content may actually be effective in leveling previous inequities and thus reduce the gap between larger and smaller farmers. The present research is unique in several respects: 1) it examines television for one of the first times in relation to the communication effects gap; 2) its results run contrary to many previous studies; 3 ) the study was conducted under field conditions in India on an extremely low budget, demonstrating a necessary resourcefulness;. 4) survey research methods are combined with content analysis; and 5) the results are crucially relevant to the Indian government's policy and to the recently initiated satellite Instructional Television Experiment (SITE), in which the ATS-6 satellite broadcasts television programs to schoolchildren and adults in almost 2,400 villages in six different Indian states.

NOTE Data produced, field experiment (before/after). Sample = Indian villages, teleclub members.

SEQ\# 132

AUTH Shoenfeld, C.

TITL Environmental Mass Communications: Problems and Promises

PUBL Journal of Environmental Education

DATE 6. 3:20-26 spr 1975

KEY shoe75a

SRCH review-environmental communications

ABST Environmental communication processes are discussed in terms of the process components outlined in the Hiebert-UngureitBohn model of mass communications. The major elements of this model are: communicators, codes, gatekeepers, media, regulators, filters, audiences, feedback, noise, and ampl if ication. Each of these terms are discusssed both in terms of their advantages and disadvantages regarding environmental communications. The autor concludes that the goal of environmental communication should be to increase and reinforce individual freedom of choice through discovering and outlining viable options in a unemotional and objective manner.

NOTE A sometimes insightful but generally $r$ ambling discussion of several communication concepts within the context of environmental communications.

SEQ\# 133

AUTH Simnad, M.

TITL Public Education and the Acceptance of Nuclear Power 
PUBL American Nuclear Society Transactions

DATE 25 Apr il 1977 pp. 91-92

KEY $\operatorname{simn} 77 . a$

$\mathrm{SRCH}$

ABST

dissemination, nuclear energy, public, attitude change

simnad holds that "the most useful source of information for teaching the public about nuclear power has been a pamphlet which provides the answers of often-asked questions about nuclear power." He outlines the content of the pamphlet, which includes facts and figures of such concerns as the status of nuclear power, the economics of nuclear power, the availability of nuclear fuel and the disposal of nuclear wastes. Simnad ends with, "the public will accept nuclear power only when they are convinced it can satisfy the continuous need for increased energy production and provide the world with the energy capacity to help solve many pressing human problems in the shortest time, at the, lowest cost and with a minimum impact on the environment."

NOTE No data produced. A series of brief arguments taken from a pamphlet for the use of nuclear energy.

SEQ\#

AUTH

TITL

PUBL

DATE

KEY

$\mathrm{SRCH}$

ABST

NOTE

SEQ\#

AUTH

TITL

PUBL

DATE

KEY

SRCH

ABST

\section{4}

So franko, A.J.; Bridgel and, w. Illinois Mayors and the Environment Journal of Environmental Education 5. 2:43-8 win 1973 sofr $73 a$

attitudes-environment, community, public policy, interest groups

Reported is a summary of interviews with Illinois mayors in 130 middle-sized towns concerning their attitudes toward environmental issues. Most mayors did not consider environmental quality to be a serious issue for their towns.

\section{5}

Staff of Project GM-34938 NSF

Science Symposium Series for Editiors... Report 1973

University of Missour i

$19731-177 \mathrm{pp}$.

staflig73a

mass media, newspapers, science writing, science coverage

This report is a discussion and evaluation of a series of symposia which took place in 1972 and 1973. The symposia involved editors of newspapers, scientists, and leaders of business and government from a seven state region. Although the symposia. were loosely structured, the central topic for discussion was "how best to further the public's understanding of science by way of the mass media - newspapers in particular." The conclusions that were drawn from the symposia by the project staff were as follows - 1) editors do not 
think of 'science news' as a specific type of news in their general readership newspapers 2) scientists have quite a different conception of science news - for them it remains in an academic framework, as science for science sake 3) professional science writers write within the scientists framework, not that of the editors of daily newspapers 4) the widely held belief is that science news begins with science and scientists...editors maintain, instead, that what goes into newspapers is determined more by public than by science interests 5) the editors' position has the profound implication that science is already in the public domain, integral to its culture 6) it is helpful to distinguish between 'science news' written with the science and public frameworks respectively 7) there will be more science-related news in the daily newspapers of the editors attending the symposia. Elaborating on these last points, the staff writes, "the current approach in science writing (whether for print, $r$ adio or film) is basically to inform, to educate and interest the public about science, its outstanding achievements, discoveries, and progress... (Another approach to science writing), the concourse paradigm, seeks out the great mass audiences of the commercial television networks, but also the daily newspapers and everyday radio programs. It provides pscience writing - news, features, radio, film, editorials, commentaries - as concerned primarily with what people are interested in and know something about already, which is read, 1 istened to, or viewed for entertainment and 'play' $r$ ather than for any information it may provide. The stories are written from the public's standpoint, not necessarily the scientist's."

NOTE Data produced, edited proceedings of symposia.

SEQ\#

AUTH

TITL

PUBL

DATE

KEY

SRCH

ABST

\section{6}

St.amm, $K$.

Two Orientations to the Concept of Scarcity Journal of Environmental Education 1. $4: 134-39$ sum 1970

stampa

attitudes-enviornmental, conservation, understanding

Described is a concept and scale for measuring environmental attitudes and relationships between environmental attitudes, conservation media exposure, and participation in outdoor recreation. The concepl of conservation. is explicated and it is concluded that conservation problems are not perceived in the absence of extant or impending scarcity. An individuals view as to how to remedy or avert a scarcity is termed his/her "scarcity orientation". The author distinguishes and verifies two dimensions of "scarcity orientation"; 1) functional substitution --an attitude favoring replacement of scarce resources: with substitutes, and 2) reversal of trends 
--an attitude favoring the reversal of any trend toward scarcity. The studies findings indicate that outdoor recreation $-a$ form of involvement with natural resources- is a likely antecedent to forming opinions and solutions to scarcity problems. Participation in outdoor activities was associated with both dimensions of scarcity orientation. Instead, the significant factor appears to be whether the individual regards scarcity a problem, and whether $s /$ he perceives a need to find a solution. Futher, participation in outdoor activities was found to be associated with exposure to potential "means" of communicating environmental understanding, e.g. outdoor and conservation publications and interpersonal communications about the environment.

NOTE Data produced, survey.

SEQ\#

AUTH

TITL

PUBL

DATE

KEY

$\mathrm{SRCH}$

ABST

\section{7}

Stamm, K.; Bowes, J.E.

Communication During an Environmental Decision

Journal of Environmental Education

3. 3:49-55 spr 1972

$\operatorname{stam} 72 a$

decision-making, dissemination, information sources, communication effectiveness, public relations

This paper presents an empirical analysis of a collective decision-making procedure involving flood control technology. The study is part of a "social impact survey" of the individuals and communities affected by two proposed alternative flood control projects. Emphasis was focused on the question of whether their was adequate commmunication between local citizens and the government authority undertaking the project. The following definitions of communication were used: 1) awareness of the proposed project, 2) exposure to sources of information about the project, and 3) relevance of the proposed project (awareness of the ways in which the project will personally affect the individual), and 4) understanding amoung the parties concerned (the extent to which citizens feel they view attributes of the project in the same way as its government sponsor. The particular failings of current communication channels and procedures (or the lack of them) are documented, and suggestions are made for increasing the contribution of communication to improved environmental decision-making. Prior to formal hearings about the projects, mass media coverage was minimized and consisted largely of echoing "handout" information from the government sponsor. Independent probes of the project advantages or disadvantages were not evidenced in the mass media. Only when vocal opposition from residents affected began did the media give extensive play to opposition of arguments. The findings clearly indicate that the negative arguments come a long time after 
the favorable arguments were publicized. The authors suggest that preliminary environmental and social "impact" studies be made public (in terms which are readily understood) on a timely basis, rather than long after the government agencies have advocated their position. This would provide a knowledgeable basis for public action, rather than having the public merely react to fixed solutions offered by the project's sponsor.

NOTE Data produced, survey.

\section{SEQ\# 138}

AUTH Stamm, K.; Bowes, J.E.

TITL Environmental Attitudes and Reaction

PUBL Journal of Environmental Education

DATE 3. 3:5ћ-6ด spr 1972

KEY stam72b

SRCIl community, publics, attitudes-environmental, conservation problem solving

ABST A concept of environmental attitudes based on a meaning analysis of conservation which concludes that conservation problems are not perceived in the absence of extant or impending scarcity. Two dimensions of "scacity orientation" were distinguished in terms of how a situation involving scarcity may be averted or remedied: 1) functional substitution-an attitude favoring the replacement of scarce resources with substitutes, and 2) reversal of trends-an attitude favoring the reversal of any trend toward scarcity. As nart of a social and environmental impact survey of a proposed flood control project, environmental attitudes were measured along with support for the Army Corps of Engineers (the project sponsnr), knowledgc of the issue, and percelved agreement with the corpe rcgarding the likely effects of the project. It was hypothesized that persons scoring high on the reversal of trends attitude scale would; 1) show less support for the Corps, 2) know more about about the project's disadvantages, and 3) perceive less agreement with the corps than would those with lower scores. Further, that persons scoring high on the functional substitutes attitude scale would; 4) show greater support for the Corps, 5) know more of the projects disadvantages, and 6) percieve greater agreement with the corps than would those with lower scores. Hypotheses 4,5 , and 6 were supported by the data. 'The authors note that the construct validity of the functional substitute scale was strongly supported. However, serious questions are raised about the unidimensionality of the reversal of trends scale, and it is suggested this scale be further developed and tested if it is to be used in subsequent research.

NOTE Data produced, survey. 
SEQ\# 139

AUTH Stamm, K.R.; Grunig, J.E.

TITL Communication Situations and Cognitive strategies for the Resolution of Environmental Issues

PUBL Journalism Quarterly

DATE 54. 4:713-20 1977

KEY $\quad s \operatorname{tam} 77 a$

SRCH decision-making, attitudes-environmental, problem solving, communication systems

ABST This study is concerned with the cognitive strategies people use in arriving at judgements on environmental issues. To examine these strategies, the authors employ two theories Grunig's multi-systems theory of communication behavior and Stamm's theory of cognitive strategies. Grunig's model consists of four variables, all of which pertain to the individual's perception of a particular issue or problematic situation. The four variables are - problem recognition, perception of constraints, level of involvement and the presence or absence of a referent criterion. Stamm's model consists of two strategies - hedging and wedging. Hedging occurs when the individual cognitively' 'squeezes' together alternative solutions to a problem. Wedging occurs when the individual forces alternative solutions apart. The data for this study were gathered from 231 people randomly drawn from four metropolitan areas. From the data, several conclusions are made: the resolution of environmental issues involves the use of cognitive strategies that are strongly controlled by the nature of the issue and an individual's perceptions of the situation in which it occurs; individuals do not respond consistently across issues (as $\mathrm{might}$ be suggested by notions of attitude); and involvement in a situation seems to make a person more likely to hedge (than wedge) in that situation.

NOTE Data Produced, survey. Sample $=231$ metropolitan residents (including college students and environmental scientists). Sample design follows the logic of Stephenson's Q-methodology in which respondents are chosen to represent theoretical conditions.

SEQ\#

AUTH

TITL

PUBL

DATE

KEY

SRCH

ABST

\section{1}

Ste in, A. A.

Conflict and Cohesion: A Review of the Literature Journal of Conflict Resolution

20. 1:143-72 mar 1976

stei76a

review-conflict, conflict

The paper reviews the theoretical formulations and the empirical tests of the proposition tha external conflict increases internal cohesion. Literature from sociology, anthropology, psychology, and political science is discussed. Though it is 
often assumed to be true and is easily illustrated, the empirical studies suggest that there are a number of intervening. variables and that the hypothesis is not uniformly true. while hardly adequate, these empirical studies provide a subtler specification of the hypothesis, knowledge of which can lead researchers to structure their studies differently. Examples of this are provided and other areas of application are also discussed.

\section{SEQ\# 142}

AUTH Stewart, Earl E. \& Stewart, Robert E.

TITL

PUBL

DATE

KEY

SRCH

ABST

Little Missour $i$ Grasslands study Southwestern North Dakota North Dakota State University

January 1973 1-27 pp.

stew $7,3 a$

site selection, community, land use

This paper consists of two parts - 1) an introduction to the Little Missouri Grassland study and 2) related studies. The introduction to the Little Missouri Grassland Study is an outline for a proposed study of nine counties in southwestern North Dakota: The purpose of this study will be to develop a multiple land use plan to guide future development and conservation in the area. To arrive at this plan, the study will go through a number of phases - 1) an inventory phase in which basic data is collected concerning human and natural resources (ie. agriculture, recreation, public housing,soils, climatology; paleontology) 2) a resource mapping phase in which selected human and natural resources are plotted on area maps 3) an analysis phase in which alternative goals and objectives are weighed 4) a planning and program development phase in which various multiple land use plans are developed from selerter gnals and objectives, and policies for implcmentation for the recommended plan are developed. The second part of the paper provides a brief synopsis of studies currently underway of particular significance to the Little Missour $i$ Grasslands study. Several are: Coal study to determine the feasibility of leasing 12, $0 \emptyset$ acres of National Grasslands lands for coal extraction; North- South Area study to determine the ecological impact of proposed resource development within the North-South unit of Theodore Roosevelt National Memorial Park; and Northern Great Plains Resource program to assess the potential social, economic and environmental impacts that would result from future development of the coal resources in the five Northern Great plains States.

NOTE Although this paper provides only an outline of the Little Missouri Grasslands study and related studies, more complete documents may now be available from the authors. 
SEQ 143

AUTH Tanaka, T.

TITL Japanese Attitudes Toward Nuclear Arms.

PUBL Public Opinion Quarterly

DATE 34. 1:26-42 Spring 1970

KEY tana7ga

SRCH public opinion, attitudes-nuclear, public, iand use

ABST Antiwar and anti-nuclear weapons sentiments have been very strong in Japan since world war Two. The author asks; will these attitudes persist, or are they subject to change as the generations having direct experience with the war and its aftermath are replaced by "postwar" youth? This study describes two approaches to this problem: a survey of students expectations concerning Japanese nuclear development and a study of students' changing evaluations of this development. The results of national Japanese polls have indicated that the Japanese experience "nuclear allergy" an "irrational," "unrealistic" fear of the manufacture, testing and stockpiling of nuclear weapons. The author describes consistent trends in anti-nuclear weapons sentiment and investigates the possibility of the continuation of this trend. First in a survey of students' attitudes toward Japanese nuclear development, 116, 125, and 173 college and techical students in $12 / 1965-10 / 1966$ were asked to name the nations that they expected would be the sixth, seventh and eighth nuclear nations. They were also asked within how many years would Japan beg in to manufacture its own nuclear weapons. Results showed that students expected that Japan would not be the first nuclear nation after China, about 208 felt that Japan would be the eighth. Thirteen percent believed Japan would begin to manufacture nuclear weapons within five years while less than 25\& believed manufacture would begin within the forseeabel future. Twenty five percent believed that such a thing would never occur. The authors believe these results to be inconsistent with previous trends and the idea of "nuclear allergy." In a second study $4 \ddot{0}$ college students born in 1943 and 47 college students born in 1948 filled out 26 bipolar adjective pairs with stimulus words (four nation-names, five nouns denoting political phenomena and 20 compound words.) Results showed a shift in attitudes toward the us in an unfavorable direction and a shift in attitudes towrds the USSR in a favorable direction. The author concludes that "nuclear allergy" is not salient for three out of four subjects, while nuclear testing and mulitary power are still seen to be undesirable but less so than previous studies have indicated.

NOTE Data produced,survey. Sample $=414$ Japanese students. Opinion survey produced bipolar adjective pairs concerning changing trends in Japanese youth's attitudes about nuclear arms. 
SEQ\# 144

TITL A Behavioral Approach to Public Acceptance of Nuclear Energy in Japan

PUBL The American Political Science Association

DATE 1977

KEY tana77a

SRCH attitudes-nuclear, psychological distance, nuclear waste, land use, site selection, power plants, utilities, nuclear

ABST First, Japan's contradictory position as being both a victim of atomic bombs as well as being one of the leading industrialized nations in the world was presented. Nuclear allergy - was taken as symptomatic of the nations traumatic experience with nuclear weapons and the strong anti-nuclear weapon feelings which still persist in a great majority of the Japanese. on the other hand, there is a growing awareness amoung the contemporary Japanese that both peaceful and military uses of atomic power are no lonqer separable as, for example, reprocessing spent nuclear fuel easily produces high level nuclear materials which can be used in nuclear explosives. Secondly, the notion of "subjective culture" was introduced as most relevant to an understanding of the ongoing nuclear power controversy. It was proposed in this connection that the interface of nuclear technology and society is specially important to promote societal and individual well-being. Contemporary Japanese literature on socio-behavioral-scientific investigations of nuclear matters was also breifly reviewed. Finally, the major results of an interdisciplinary investigation were reported and discussed. The research was carried out in 1975-77 in both Tokyo and a small town where an atomic power plant is in operation, in order to examine the organization of attitudes toward atomic power, to identify those who are in favor of or in opposition to atomic power, and to discover what psychological and non-psychological variables are most influential in determining attitudes toward atomic power. A unique communication variable termed "information space" was also taken into account. With respect to attitude orgainization, the results of a multivariate analysis clearly showed both "cognition" and affect-laden "acceptance" as being the two most salient dimensions of attitudes regarding nuclear matters. Non-psychological factors, such as age, sex, and education, were found to interact with "cognition" but not with "arceptance". When distance from the atomice power plant is taken into consideration, this "distance" variable was found to be one of the best predictors which discriminate between "acceptance" and "rejection". of atomic power. Amoung the psychological variables, perceptions of the "safety" of atomic power facilities were the best predictors of "acceptance". An analysis make with respect to "information space" also showed that persuasive communications intended to promote atomic power acceptance are not so effective to those 
committed to opposition as might be expected. On the whole, it is concluded that the results obtained have produced evidence that public acceptance of atomic power is a complex psycho-ecological-communication process which involves all major aspect of subjective culture in Japan.

NOTE Data produced, survey. Sample $=2$ cities/towns. Very pertinent source. Appears to be well done.

SEQ\# 145

AUTH Tankard, J.W.; Ryan, M.

TITL News Source Perceptions of Accuracy of Science Coverage

PUBL Journalism Quarterly

DATE 51. 2:219-25,334 sum 1974

KEY tank74a

SRCH science writing, newspapers

ABST This study was designed to gather evidence with regard to the following questions; 1) what kinds of errors (from a list of 42) are perceived to occur by the source of a given news story, 2) what are the general attitudes of these sources toward science news coverage, 3) what variables appear to be influential in determining the accuracy of newspaper science coverage. A random sample of 20 out of 167 newspapers with circulations exceeding 50,000 was selected. Each issue was searched for science articles (newspaper reports of empirical results obtained through controlled observation) over a 3 month period in 1972. These stories needed to be judged unanimously as "science articles" by the authors of this study before they were clipped and sent along with a 4 pg. questionnnaire to the scientist-source of the article. The scientist-sources were asked to indicate the number and $k$ ind of errors they perceived to occur in the news-story. The mean number of kinds of errors reported by the scientist's was 6.2 per story. Only 8.88 of the stories were "error-free". While a majority of the scientists agreed that newspaper coverage of science is important, they indicated strong criticism of the handing of this informaltion by newspapers. Of the 9 possible "predictor" variables that were analyzed, only one, whether or not the scientist had read the story before its publication, was found to be significant.

NOTE Data produced, error analysis of science articles by scientist sources. Sample = daily newspapers over 50,000 .

SEQ\# 146

AUTH Tannenbaum, P.H.

TITL Communication of Science Information

PUBL Science

DATE 140. 3567:579-583, MaY 10, 1963

KEY tann63a. 
SRCH review-science communication, communication effectiveness science writing, audiences, dissemination, mass media

ABST The author begins with a variety of premises about the communication of science information supported by survey data. 1) that knowledge of science is widely but shallowly distributed and is closely related to the amount of formal education the individual has had. 2) the mass media play a prominent role, but the likelihood that an individual will be exposed to the media that carry science news is largely a function of his education. 3) that "sensational and personalized" news stories generally attract a larger audience than more personal accounts. 4) generally the mass media apply the same criteria in selecting and featuring a science story that they apply in selecting and handing a general news story. The author reports additional research on the communication of science information. One major study stemmed from a program of research that dealt with the public's opinions and conceptions about llintal illness, and the role of the mass media in shaping and nour ishing such beliefs. A questionnaire was designed to determine knowledge about and attitudes toward mental illness. It was administered to a sample of the public and a sample of psychiatrists. High agreement was found between these two groups about attitudes and knowledge. In addition, a content analysis of television and magazine portrayals of mental illness was performed. Then the views of the public, experts and mass media were compared. Results showed high agreement between public and experts while the mass media described a different picture. The regulation of mental health content was discovered by interviewing key news media personnel, examining records and documents and making detailed studies of individual programs. Results showed that the dominant considerations regarding the inclusion and exclusion of certain subject matter was largely market-oriented. When key personnel in the media industry were asked to specify what they thought the typical audience member's attitudes and knowledge were, they described a picture which conformed more closely to what the media presented than what the public knew and felt. The author concludes that the public does not believe what the media people think it believes, and it may not want what the media people think it wants. The author then focuses on the chain of communication events associated with the communication of science information. He notes that in this chain, the editor, the crucial mediatur. bctwcen the sclentlst and the reader, may not be the best mediator. He cites a study which investigated the degrees of semantic compatibility between the various units invovlved in the science communication chain. On the semantic dimensions compared, the scientists, science writers and sclence readers revealed the most agreement, while the editors deviated most from the other groups. The judgments of the editors on valuable and exciting science news were highly correlated. 
The author concludes that the crucial mediator between the scientist and reader - the editor-may fail at times because he differs from both in fundamental outlook. Scientists react most to what is being said, editors to how it is said. The author also discusses problems with the language of science. He found that science writers tend to rely heavily on cliches and stock phrases, the meanings of which are not well understood or agreed upon. The author al so investigated the translation of scientific terms into laymans language. Results showed that the regular science reader found most of the original scientific terms at least as meaningful as the lay terms. Moreover, his judgments for the scientific terms were more similar to those of the scientist and science writer than were his judgments for lay terms. For the nonreader of science news, the lay terms were, somewhat more meaningful, but the differences were not large. The author conludes over all that the science writer is well-suited to the role of mediator between the scientist and the science reader. A good deal of the science communication problems may stem from ignorance about the science-reading public, who it is, what it knows, what it wants, how it should be addressed. A reorganization of the system is necessary to better disseminate science news to the public.

NOTE Data produced, interpretation of previous experimental studies, in a review article form. The article identified the problems in communicationg science information and suggested ways of improving this communication. Meanings of science terms, identification of differences in attitudes.

SEQ\#\#

AUTH

TITL

PUBL

DATE

KEY

SRCH

ABST

NOTE

\section{7}

Thomas, G.; Hartley, R.D.; Kincaid, J.P.

Test-Retest and Inter-Analyst Reliabiltiy of the Automated Readability Index, Flesch Reading Ease Score, and the Fog Count

Journal of Reading Behavior

7. 2:149-54 1975

thom $75 a$

methodology, readability

Using six analysts, test-retest and inter-analyst reliabilities were determined or the Automated Readability Index (ARI), the Flesch Reading Ease Score, and the Fog Count. All coeffieients, with the exception of one. Flesch measure, were above .94 . Analysis of variance applied to measured working times indicated that the Flesch takes significantly longer to use than the ARI and Fog

Data produced, reliability data on several readability instruments. 
AUTH Tichenor., P.J.; Olien, C.N.; Harrison, A.; Donohue, G. TITL Mass Communication systems and Communication Accuracy in Science News Reporting

PUBL Journal ism Quarterly

DATE 47. 4:673-83 win 1970

KEY tich7ga

SRCH newspapers, information sources, science writing, science coverage, communication systems

ABST A systems perspective is taken with regard to communication accuracy; which is defined as the extent to which a message produces agreements between source and receiver. Behavior in a mass communication system should be related to a) energic factors, such as incentive and motivation b) control factors, such as organizational constraints and feedback. Messages delivered to an audience are conceptualized as outcomes of processes ocurring within specified subsystems. These include source, channel or gatekeeper, and audience subsystems. It was hypothesized that factors increasing the motivation level of persons in these subsystems should be less accurate than editor-assigned or reporter-intitiated articles, and that scientists which place a high value on reporting to the public should be more accurately understood. Further, scientists that are involved with teaching or administrative functions should be more understood than those that are not. 73 science news articles (not including wire service sources) appearing in midwestern newspapers in 1967 and early 1968 were selected to be shown to survey respondents. Each respondent was asked to read 2 articles and state what it said. The proportion of audience statements generally acceptable to the scientist quoted in the article was used as a measure of communication accuracy. Articles originating from other written reports, such as press releases and journal articles, and those assigned by editors, were found to be above average in communication accuracy compared to articles originated by reporters or routine kinds of coverage. The strongest correlate of communication variables was the scientist's being involved in administrative roles, perception of strict organizational policy for research reporting, and perception of communication accuracy in newspaper reports. The discussion concludes that factors that point to specific, purposive control of communication to the public by the science organization contribute to communication accuracy.

NOTE Data produced,survey.

SEQ\# 150

AUTH Tichenor, P.J.; Rodenkirchen, J.M.; Olien, C.N.; Donohue, G.A.

TITL Community Issues, Conflict, and Public Affairs Knowledge

PUBL New Models for Mass Communication Research

DATE Sage Publications: 1973 
KEY tich73a

SRCH dissemination, mass media, community, conflict

ABST Tested 9 hypotheses about the effect of information distribution by the mass media on perceptions of conflict surrounding community issues (e.g., water quality) by residents of 15 communities in Minnesota. Data suggest the existence of a dynamic community process in which mass media input, community structure, and the development of social tension may be directly related and interacting factors. Conflict as a variable system condition and social conflict and the knowledge gap are discussed.

SEQ\#

AUTH

TITL

PUBL

DATE

KEY

$\mathrm{SRCH}$

ABST

NOTE

SEQ\#

AUTH

TITL

PUBL

DATE

KEY

SRCH

ABST

\section{1}

Tichenor, P.J.; Olien, C.N.; Donohue, G.A. Community Control and Care of Scientific Information Communication Research

\section{4:403-24 oct 1976}

$\operatorname{tich} 76 a$

community, interest groups, values, dissemination

Two midwestern cities were studied to evaluate how support for the basic values of widespread information and the use of specialized knowledge by the public and leaders is related to community structure as measured by homogeneity and heterogeneity. The public in the more hetergeneous community was more likely to support wide distribution and use of information. There were fewer differences between leaders in the two communities. The authors suggest that as social differention increases, information is evaluated in terms of perceived relevance for specific social ends.

Data produced, survey of values regarding use of specialized information. Sample $=2$ communities.

\section{2}

Tuinman, J.J.

Determining the Passage Dependency of Comprehension Questions in 5 Major Tests

Reading Research Quarterly

9. 2:206-23 win 1974

tuin $74 a$

information processing, methodology, readablility

Tests of reading comprehension presently used do not provide one important item of technical data: the extent to which questions used in the test could be answered without reading passages upon which these questions are based (passage dependency). This leaves the test user guessing as to whether students taking the the test and performing well, did or did not understand the written material contained in the test. Indices for paragraph dependency for 5 widely used standardized tests of reading comprehension were obtained. Five tests were administered to 1,200 students each, who were allowed to read 
the passages. In addition, control data were obtained by administering the tests in their normal formats to 600 students each. Students were selected from 10 locations covering Indiana and equally divided over the grades 4,5 , and 6. The results indicate that none of these major tests provided sufficient guarantee against answering items on the basis of information other than that presented in the passage. Average probabilities of responses with no passage present ranged well above the expected chance score of .25. Some statistics for calculating passage dependency are proposed.

NOTE Data produced, experiment on passage dependency of answers to a reading test. Sample $=4 \mathrm{th}, 5 \mathrm{th}, 6 \mathrm{th}$ grade students. Article may be useful when attempting to determine the effects of different communication modes, styles, formats etc., insomuch as it suggests a means for observing the influence of "outside". sources of information on a dependent variable such as ". comprehension.

SEQ\#

AUTH

TITL

PUBL

DATE

KEY

SRCH

ABST

153

von Glaserfeld, E.

The Problem of Syntactic Complexity in Reading and Readability

Journal of Reading Behavior

3. $2: 1-14$ spr 1970-71

vong 7071 a

content analysis, readability, methodology

The paper examines the concept of syntactic complexity from the point of view of readability and shows that the factors that make for reading difficulty are several and that some of them remain inaccessible to studies that are based on traditional or generative grammars. The measurement of "Syntactic Depth" is adapted to the interpretive processing direction of the reader and the relevance of relational semantics as well as of the "prospective" ambiguity of phrase structures is demonstrated. Some of the features of an interpretive grammar deemed to be useful in readability studies are illustrated by reference to the correlational grammar developed for the automatic interpretation of English sentences by computer.

\section{SEQ\# 154}

AUTH Wade, S.; Schramm, w.

TITL The Mass Media as Sources of Public Affairs, science, and Health Knowledge

PUBL Public Opinion Quarterly

DATE 33. 2:197-209 sum 1969

KEY wade69a

SRCH national surveys, newspapers, radio, television, magazines, mass media, information sources

ABST The focus of this paper is the relationship of different pat- 
terns of information seeking to different levels of public knowledge in three areas: public affairs, science, and health. The data come from secondary analysis of national sample surveys, and were obtained as by-products of a broad study of public knowledge in the United States. Results showed that newspapers and magazines were used more often than television as sources of public knowledge of science. Better educated persons and persons with high income are more likely than others to seek science information from more than one source. Also when public knowledge derives directly from events that are readily available for people to view, then television is more important as a source. When they must be reported or interpreted, then the advantage is with the print media. An interaction between education and mass media use is evident; education is a powerful predictor of media use. The more education a person has, the.more likely he is to use print as his major source of news and information.

NOTE

Data produced, secondary analysis of survey data. Demonstrated relationship between education and print media use and education and multiple media use.

\section{SEQ\# 155}

AUTH Walker., R.; Bayley, S.

TITL Quantitative Assessment of Natural Values in Benefit-Cost Analysis

PUBL Journal of Environmental Systems

DATE $7.2: 131-47 \quad 1977-78$

KEY

$\mathrm{SRCH}$ walk7778a

ABST Two methods of quantifying the contribution of natural ecosystems to man's economy in benefit-cost analysis are presented. The economic approach uses dollar costs to approximate the more tangible natural system contributions. The energetic approach use energy flows of the natural ecosystems to quantify the contributions. Sample calculations of each approach are made of the impact of a highway on a floodplain.

\section{SEQ\# 156}

AUTH Warner, K.E.

TITL The Need for Some Innovative Concepts of Innovation: An Examination of Research on the Diffusion of Innovations

PUBL Policy Sciences

DATE 5. 4:433-51 dec 1974

KEY Warn74a

SRCH review-diffusion,

ABST The final stage of technological change, the diffusion of innovation through society, is reexamined. Such research draws on 2 traditions: economics and sociology. Economists have emphasized the rational decision-making processes which cause a 
gradual satuaration of the interested population; sociologists have paid more attention to noneconomic, irrational factors. However, these contributions have not yet been integrated into any unified theory, due largely to the parochialism of scholars in each discipline, which leads them to concentrate on those factors and methods which are most compatible with their specific fields, rather than on understanding diffusion as a general phenomenon. Many problems remain unsolved, or even unexamined.

SEQ\#

AUTH

TITL

PUBL

DATE

KEY

SRCH

ABST

NOTE

SEQ\#

AUTH

TITL

PUBL

DATE

KEY

SRCH

ABST

157

White, W.J.

An Index for Determining the Relative Importance of Information Sources

Public Opinion Quarterly

33. 4:607-610 winter 1969-1979

white69-70a

methodology, information sources

The researcher interested in the diffusion of information often has to determine the relative importance of a number of sources. An instrument, the Most Important source Instrument, was developed to solve this problem. It is a modification of the paired comparisons method of psychological scaling. The index consists of a mumber of potential sources listed in a particular sequence. Sources are arrnaged so that those most similar are listed closest to each other. Sources were divided on the basis of interpersonal vs. mass media. Within each group further divisions were made until those which were most slinliar were closest together. After potential sources from which the subject has not received any information have been screened out, he is asked to compare the remaining sources two at a time. The most important sources from each pair are again rompared two at a time until the must important source is reached. The instrument was tested on a group of farmers concerning information they received about hybrid corn. The Most Important Source Index is applicable in all situations where potential sources can be identified.

Data produced.survey. Sample = farmers. Pretcst of instrument in field study. Methodological study to determine usefulness of Most Important Source Index.

\section{8}

Wiebe, G.D.

Mass Media and Man's Relationship to His Environment Journalism Quarterly

50. 3:426-32,446 aut 1973

wieb73a

dissemination

Offers an antidote for the widespread feeling among people of 
well-informed futility toward practical problems in society, including those relating to the environment.

SEQ\#

AUTH

TITL

PUBL

DATE

KEY

SRCH

ABST

159

Wilkening, E.

Roles of Communicating Agents in Technological Change in Agriculture

Social Forces

34 May 1956 pp. 361-367

wilk56a

diffusion, information sources

wilkening draws on the research of Merton (Merton, "Patterns of Influence: A Study of Interpersonal Influence and of Communication Behavior in a Local Community," Communications Research (New York: Harper and Bros., 1949)) and Ryan (Ryan and Gross, "The Diffusion of Hybrid Seed Corn in Two Iowa Communities," Rural Sociology, May, 1943, pp. 115-124) to formulate his research problem. The problem is to determine the role of different types of communicating agents in the process of accepting technological changes in farming. To explore this problem wilkening selects four types of communicating agents - mass media, other farmers agricultural agencies and commercial sources. Further, he creates three types of information - that which permits hearing about the change, that which helps in deciding whether to try out the change and that which instructs how to put the change into effect. From the findings of previous research, wilkening hypothesizes that 1) the mass media will primarily allow farmers to hear of the change, 2) other farmers will primarily help the farmer in deciding whether to try out the change, 3) agricultural agencies and commercial sources will primarily help farmers put the change into effect. To test these hypotheses wilkening questioned 636 young farm operators in six wisconsin counties. The findings from this survey largely supported the hypotheses. The mass media proved to be the most frequent source of information of new farm practices, cited by 708 of the farmers. Forty-seven percent of the respondents gave neighbors, relatives or other farmers as the main source of help in deciding whether to try out a new idea on their own farms. Forty-four percent of the farmers turned to agricultural agencies for advice on how to go about changing farming practices. Twenty-one percent of the respondents gave commercial. sources as sources for actually changing farming practices. The findings of the study support the general assumption that the type of information transmitted about farm technology is related to the characteristics and functions of the transmitting agents.

NOTE Data produced, field survey. Sample $=636$ Wisconsin farmers. 


\begin{abstract}
SEQ⿻肀 160
AUTH Witt, W.

TITL Communication Concepts for Science and Environmental Communications

PUBL Journal of Environmental Education

DATE 5. 1:58-62 aut 1973

KEY witt73a

SRCH dissemination, mass media, information services, review- dissemination

ABST Communication models describing the flow of information are reviewed and those pertaining to science and environmental inforamtion are given special attention.
\end{abstract}

SEQH 162

AUTH Witt, $w$.

TITL Effects of Quantification in Science Writing

PUBL Journal of Communication

DATE 26. 1:67-69 win 1976

KEY

$\mathrm{SRCH}$

ABST

witt $76 a$

textual variables, problem sovlving, readability, science writing

Numerical data are conceptualized as a textual variable influencing readability: It is proposed that numbers are more precise than descriptive modifiers, and thus while reducing more uncertainty, quantified material should require greater decoding effort. The hypothesis was tested that quantification would adversly affect predispositions toward problem solving; insomuch as quantifacation increases text difficulty--the issues to be solved may also appear more difficult to the reader. Two versions of a scientific article on air pollution were prepared. Both were identical except that in one version numerical data was replaced by descriptive modifiers (e.g. atmosphere contains 8h\% nitrngen vs. ... high proportion of nitrogen). All other sources of difficulty were controlled. A sample of 100 university students were randomly assigned to read one of the articles and then asked to indicate their opinion regarding the likelihood of solving the problems posed in the article. The results showed that predisposition significantly decreased in favorability toward problem solving after exposure to quantifaction compared to descriptive modifiers. The authors suggest that quantified information communicated to the public may inhibit the resolution of scientific problems through public action

NOTE Data produced, post-test only experiment on readability. Sample = university students. The authors attach no qualifactions to the interpretation of their results; salience, previous history with the subject matter, audience type etc., which indeed might be expected to affect this finding. 
AUTH Yeracaris, C.A.

TITL Political Conflict and the Diffusion of Innovations

PUBL Rural Sociology

DATE $35.4: 488-99$ dec 1970

KEY Yera70a

SRCH diffusion, innovation, conflict

ABST An interaction model for the diffusion of innovatons is developed. It is postualted that when social boundaries are cystallized between two groups in conflict a system of relationships and communication within each group is established which may speed the acceptance-diffusion of innovations. An hypothesis derived from this model is empirically tested though data collected in a town in Greece. The rapid diffusion of strawberry cultivation (innovation) is found to be a function of political polarization between $r$ ight and left.

NOTE Data produced, observations on speed of diffusion of innovations. Sample = a Grecian town. 